Aus der Abteilung Gastroenteropathologie

(Komm. Leiter: Prof. Dr. med. J. Rüschoff)

im Zentrum Pathologie

der Medizinischen Fakultät der Universität Göttingen

\title{
Mikrosatelliteninstabilität (MSI) in Rektumkarzinomen vor und nach Chemoradiotherapie
}

\author{
INAUGURAL - DISSERTATION \\ zur Erlangung des Doktorgrades \\ der Medizinischen Fakultät \\ der Georg-August-Universität zu Göttingen \\ vorgelegt von \\ Leonie Türk \\ aus \\ Göttingen
}


Dekan: Prof. Dr. med. C. Frömmel

I. Berichterstatter: Prof. Dr. med. J. Rüschoff

II. Berichterstatter/in:

III. Berichterstatter/in:

Tag der mündlichen Prüfung: 


\section{INHALTSVERZEICHNIS}

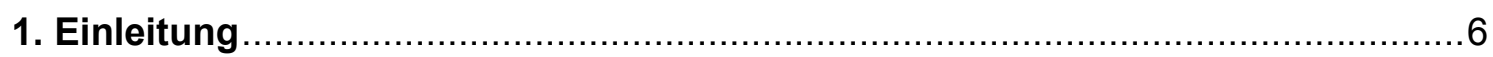

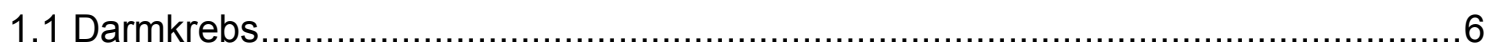

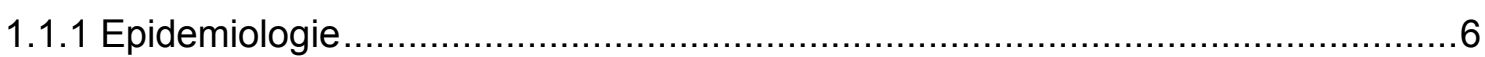

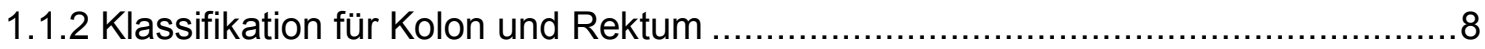

1.1.3 Entwicklungen in der Therapie des Rektumkarzinoms.....................................

1.2 Molekulare Tumorgenese und erblicher Einfluss in der

Karzinomentstehung …….............................................................................

1.2.1 Klinische Kriterien zur Einteilung in sporadische vs. hereditäre Genese

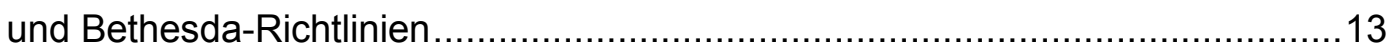

1.2.2 Mechanismen des Mismatch-Repair-Gen-Ausfalls ........................................15

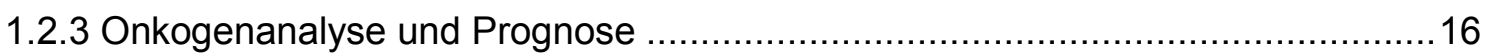

1.2.4 Häufigkeitsverteilung sporadische vs. hereditäre Genese und

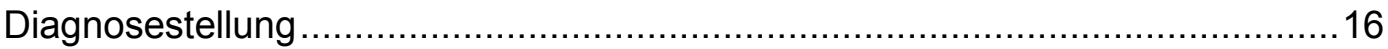

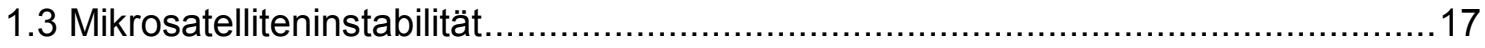

1.4 Prognostische Bedeutung der Mikrosatelliteninstabilität ...................................19

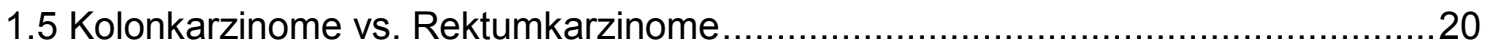

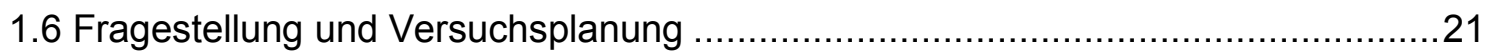

2. Material

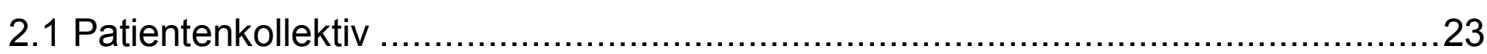

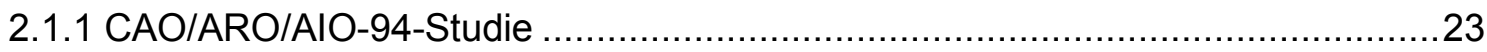

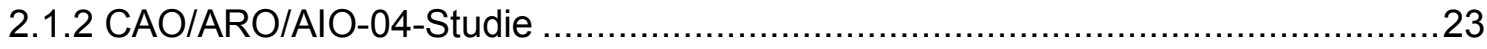

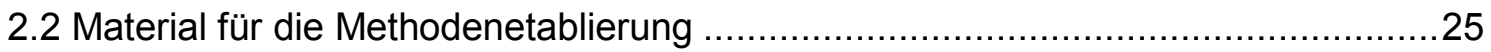

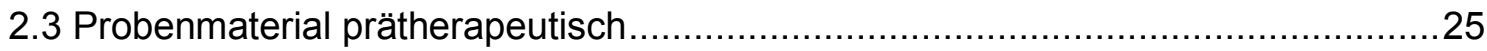

2.3.1 Patientenkollektiv der prätherapeutischen Proben .........................................25

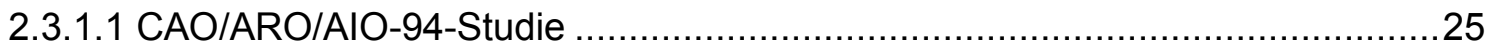

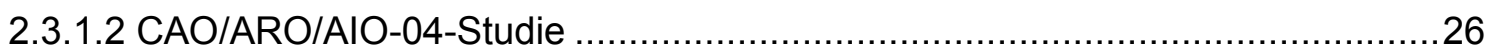

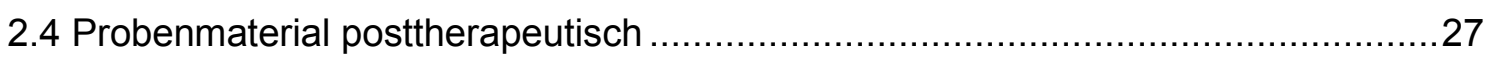

2.5 Grundlagen der Analyse auf Mikrosatelliteninstabilität.......................................28 


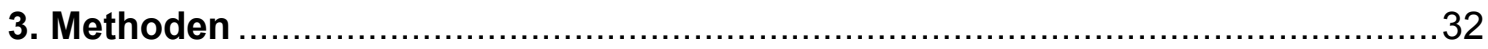

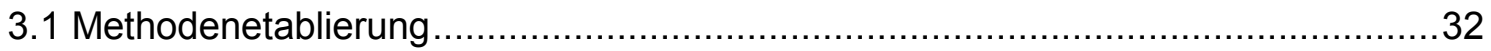

3.2 Durchführung der Polymerase-Ketten-Reaktion ............................................. 33

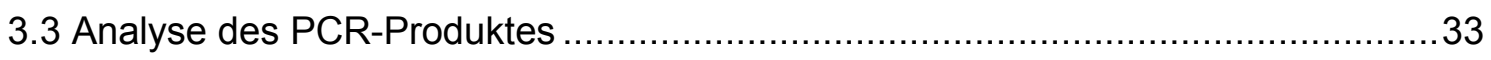

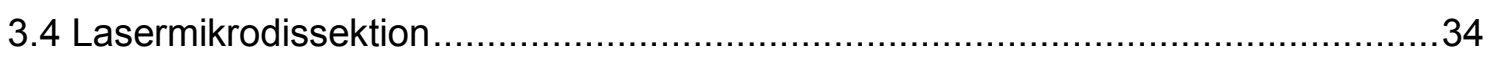

3.5 Ergebnissicherung und Interpretation der Ergebnisse ................................... 34

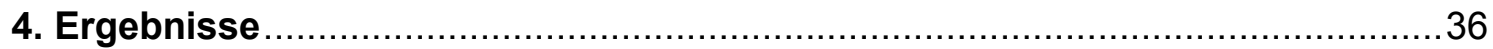

4.1 Eigene Erfahrungen mit der Untersuchung der Mikrosatelliten ............................36

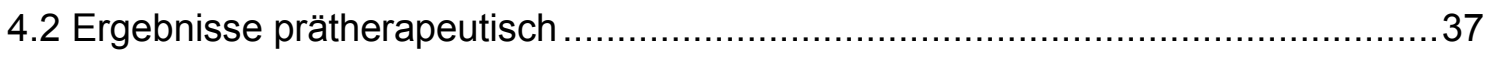

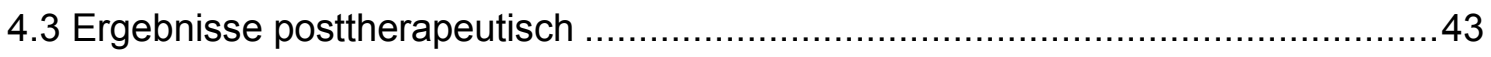

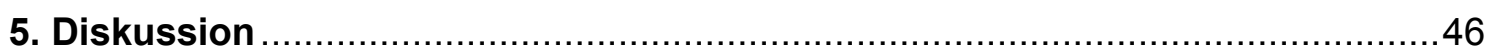

5.1 Bezugnahme zur Eingangsfragestellung, Ergebnisse und ableitbare

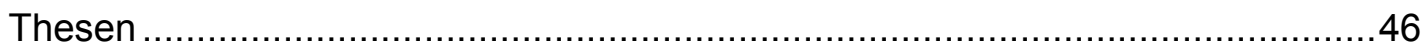

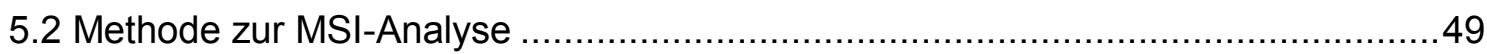

5.3 Häufigkeit von MSI-H in Rektumkarzinomen .....................................................51

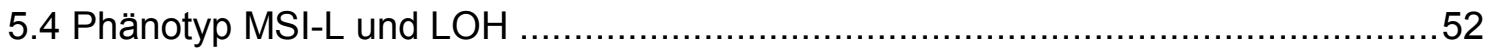

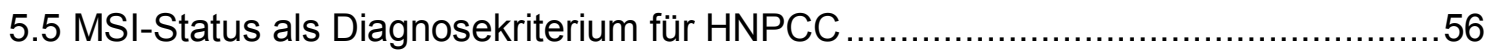

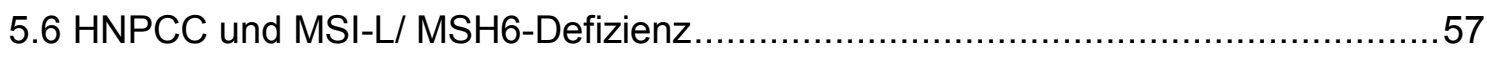

5.7 Ursachen eines variierenden Grades an MSI im Tumorgewebe ...........................58

5.8 Chemoresistenz durch neoadjuvante Behandlung.......................................6 60

5.9 Einschränkungen und Gewinn dieser Arbeit ..................................................62

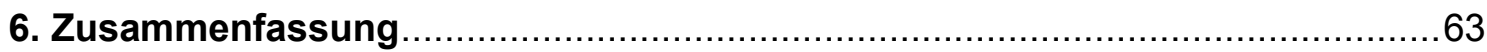

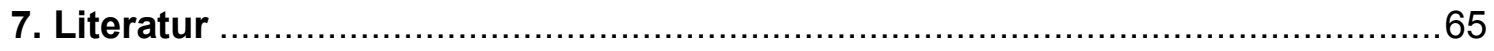




\section{Verzeichnis der AbBiLdungen Und TABellen}

Abb.Il-1 Behandlungsplan für Patienten der CAO/ARO/AIO-04-Studie .......................24

Abb.II-2 Patientenkollektiv prätherapeutisch CAO/ARO/AIO-94-Studie........................26

Abb.II-3 Patientenkollektiv prätherapeutisch CAO/ARO/AIO-04-Studie........................27

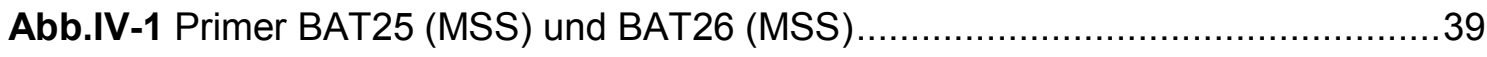

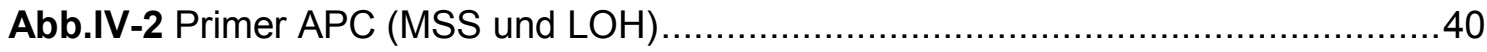

Abb.IV-3 Primer AFM093xh3 (MSS und LOH) .................................................. 41

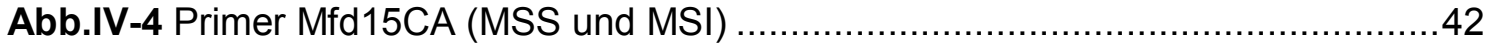

Abb.IV-5 MSI und mRNA-Expression nach neoadjuvanter Chemo-

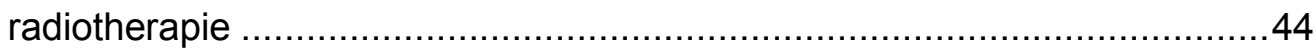

Tab.I-1 Kolon- und Rektumkarzinome klassifiziert nach TNM-Kriterien .......................8

Tab.I-2 Stadiengruppierung für Kolon- und Rektumkarzinome nach UICC ....................9

Tab.II-1 Patientenkollektiv prätherapeutisch CAO/ARO/AIO-94-Studie ......................26

Tab.II-2 Patientenkollektiv prätherapeutisch CAO/ARO/AIO-04-Studie ......................27

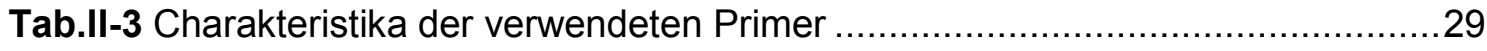

Tab.II-4 Sequenzen der verwendeten Primer .................................................. 30

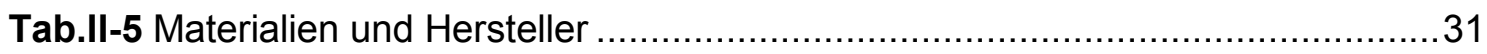

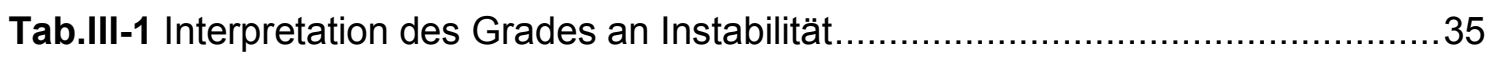

Tab.IV-1 Ergebnisse prätherapeutisch CAO/ARO/AIO-94-Studie und CAO/ARO/AO-04-Studie 38 


\section{EINLEITUNG}

\subsection{Darmkrebs}

\subsubsection{Epidemiologie}

Maligne Darmtumore stellen sowohl bei Männern als auch bei Frauen die zweithäufigste Krebserkrankung sowie die zweithäufigste Krebstodesursache dar. In Deutschland liegt die Neuerkrankungsrate pro Jahr für Männer bei 37.000 und für Frauen bei ca. 36.000. Das mittlere Erkrankungsalter beträgt bei Männern 69 Jahre, bei Frauen 75 Jahre. Vergleicht man die altersstandardisierte Inzidenz bei Männern und Frauen getrennt voneinander im Zeitraum zwischen 1980 und 2004, so ist die Inzidenz bei Männern in diesem Zeitraum um 45\% gestiegen, bei Frauen um 25\%. Dies entspricht einer Verdopplung der Erkrankungsfälle bei Männern zwischen 1980 und 2004 auf 37.000 und einem Anstieg der Erkrankungsfälle um 60\% für Frauen auf 36.000 Erkrankungsfälle im selben Zeitraum. Am stärksten stiegen die Erkrankungsraten bei Männern zwischen dem 55. und dem 74. Lebensjahr und bei Frauen ab dem 75. Lebensjahr an. (Daten entnommen: Bertz et al. 2010)

Waldmann et al. (2010) beschreiben für den Zeitraum 2004-2006 weiterhin ein signifikantes Ansteigen der Inzidenz kolorektaler Karzinome in Deutschland.

Die Darmkrebsprävalenz hat sich in den Jahren zwischen 1990 bis 2004 deutlich erhöht. Die Gründe dafür sind in einer Zunahme der Inzidenz und veränderten demographischen Bedingungen zu suchen, wie zum Beispiel dem Anstieg der durchschnittlichen Lebenserwartung. Im Gegensatz zum Anstieg der Inzidenz ließ sich in den letzten Jahren ein deutliches Absinken der Mortalität bei Darmkrebs verzeichnen. Die Mortalität sank bei Männern seit Mitte der 1980er Jahre um 24\%, bei Frauen um 38\%. (Daten entnommen: Krebs in Deutschland, Häufigkeiten und Trends 2008).

Eine Verbesserung der 5-Jahres-Überlebensrate wurde ebenfalls mit einem Anstieg von $45 \%$ Mitte der 80 er Jahre auf 60\% im Zeitraum zwischen den Jahren 2000 und 2004 beobachtet (Brenner et al. 2005). Die Verbesserung der 5-Jahres-Überlebensrate betrifft jedoch nach wie vor mehr die jüngeren Patientengruppen, für ältere Patienten 
konnte bisher nur eine deutlich weniger ausgeprägte Verbesserung erzielt werden (Gondos et al. 2007).

Als allgemeine Risikofaktoren für das Auftreten von Darmkarzinomen werden Ernährungs- und Lebensgewohnheiten, wie fettreiche, ballaststoffarme Ernährung mit hohem rotem Fleischanteil, Bewegungsmangel, Übergewicht und erhöhter Alkoholkonsum angenommen. Auch stark Gesalzenes, Gepökeltes oder Geräuchertes sowie Nikotinkonsum werden als Auslöser diskutiert. Weitere wichtige Risikofaktoren sind genetischer Ursache. Bei Personen, welche an einer familiären adenomatösen Polyposis (FAP) oder an einem hereditären, nicht-polypösen kolorektalen Krebssyndrom (HNPCC) leiden, ist das Risiko, bereits in jüngerem Lebensalter an Darmkrebs zu erkranken, stark erhöht, ebenso bei Personen, die an chronischentzündlichen Darmerkrankungen wie Colitis ulcerosa und Morbus Crohn leiden. Eine Risikoerhöhung besteht auch für Verwandte ersten Grades von betroffenen Patienten. (Daten entnommen: Krebs in Deutschland, Häufigkeiten und Trends 2008). 


\subsubsection{Klassifikation für Kolon und Rektum}

Tab.I-1 Kolon- und Rektumkarzinome klassifiziert nach TNM-Kriterien

\begin{tabular}{|c|l|}
\hline Tumorbezeichnung & Tumorausdehnung \\
\hline T1 & Submukosa \\
\hline T2 & Muscularis propria \\
\hline T3 & $\begin{array}{l}\text { Subserosa, nicht peritonealisiertes perikolisches/ } \\
\text { perirektales Gewebe }\end{array}$ \\
\hline T4 a & Viszerales Peritoneum \\
\hline T4 b & Andere Organe oder Strukturen \\
\hline
\end{tabular}

\begin{tabular}{|c|l|}
\hline Lymphknoten & Status, Tumorbefall \\
\hline N1 a & 1 regionärer \\
\hline N1 b & 2 - 3 regionäre \\
\hline N1 c & Satellit(en) ohne regionäre Lymphknotenmetastasen \\
\hline N2 a & $4-6$ regionäre \\
\hline N2 b & $\geq 7$ regionäre \\
\hline
\end{tabular}

\begin{tabular}{|c|l|}
\hline Metastasen & Befall \\
\hline M1 a & ein Organ \\
\hline M1 b & mehr als ein Organ oder Peritoneum \\
\hline
\end{tabular}

(Daten entnommen: Wittekind \& Meyer 2010, S.99) 
Tab.I-2 Stadiengruppierung für Kolon- und Rektumkarzinome nach UICC

\begin{tabular}{|c|c|c|c|}
\hline Stadium 0 & $\mathrm{~T}$ in situ & NO & M0 \\
\hline Stadium I & T1, T2 & NO & M0 \\
\hline Stadium IIA & T3 & No & $\mathrm{M0}$ \\
\hline Stadium IIB & T4 a & No & M0 \\
\hline Stadium IIC & T4 b & NO & M0 \\
\hline Stadium III & Jedes T & $\mathrm{N} 1, \mathrm{~N} 2$ & M0 \\
\hline \multirow{2}{*}{ Stadium IIIA } & $\mathrm{T} 1, \mathrm{~T} 2$ & N1 a & $\mathrm{MO}$ \\
\hline & $\mathrm{T} 1$ & $\mathrm{~N} 2 \mathrm{a}$ & MO \\
\hline \multirow{3}{*}{ Stadium IIIB } & T3, T4 a & N1 & M0 \\
\hline & T2, T3 & $\mathrm{N} 2 \mathrm{a}$ & MO \\
\hline & $\mathrm{T} 1, \mathrm{~T} 2$ & $\mathrm{~N} 2 \mathrm{~b}$ & MO \\
\hline \multirow{3}{*}{ Stadium IIIC } & $\mathrm{T} 4 \mathrm{a}$ & $\mathrm{N} 2 \mathrm{a}$ & MO \\
\hline & T3, T4 b & $\mathrm{N} 2 \mathrm{~b}$ & MO \\
\hline & $\mathrm{T} 4 \mathrm{~b}$ & N1, N2 & MO \\
\hline Stadium IVA & Jedes $\mathrm{T}$ & Jedes $\mathrm{N}$ & M1 a \\
\hline Stadium IVB & Jedes T & Jedes $\mathrm{N}$ & M1 b \\
\hline
\end{tabular}

(Daten entnommen: Wittekind \& Meyer 2010, S.98)

\subsubsection{Entwicklungen in der Therapie des Rektumkarzinoms}

Für die Entwicklungen in der Therapie des Rektumkarzinoms der letzten Jahrzehnte lassen sich drei große Ziele definieren:

1. Verbesserung der lokalen Kontrolle

2. Verbesserung der Verträglichkeit der Therapie

3. Erhöhung der Überlebenschance.

Intensive Forschung und die Entwicklung verschiedener neuer Therapiestrategien haben vor allem Fortschritte in den beiden zuerst genannten Punkten erbracht. Eine Erhöhung der Überlebenschance durch Verminderung von Lokalrezidiven und Fernmetastasierung ist Zielsetzung der CAO/ARO/AIO-04-Studie (Rödel \& Sauer 2007), aus welcher sich die von mir untersuchten Patienten hauptsächlich rekrutieren. Es stellt sich die Frage, welche neuen Erkenntnisse zu Fortschritten in der Therapie des Rektumkarzinoms geführt haben. Des Weiteren ist zu überprüfen, ob sich aus einem veränderten Therapiestandard Auswirkungen auf meine Resultate ergeben. 
Bis vor wenigen Jahren galt für das Rektumkarzinom die primäre Operation und anschließende Chemoradiotherapie als Therapie der Wahl, eine Entwicklung, die sich seit den 90er Jahren etabliert hatte (Steele et al. 1991; O'Connell et al. 1994). Das Ende der 80er Jahre entwickelte OP-Verfahren der totalen mesorektalen Exzision (Heald \& Ryall 1986) kam in den Folgejahren bald weit verbreitet zum Einsatz. Daraufhin durchgeführte Studien belegten, dass sich das verlängerte Überleben und die lokale Kontrolle des Tumors auch mit der alleinigen totalen mesorektalen Exzision (TME) erzielen ließen (Heald et al. 1998; Martling et al. 2000; Kapiteijn et al. 2002). TME plus adjuvanter Chemoradiotherapie verloren somit an Bedeutung.

Untersuchungen zu neoadjuvant angewandter Radiotherapie (Frykholm et al. 1993; Kapiteijn et al. 2001; Marijnen et al. 2002) erweiterten das Behandlungsspektrum in Richtung einer präoperativen Chemotherapieform. Weitere Studien über eine Kombination aus neoadjuvanter Chemo- und Radiotherapie zeigten, dass das neue Therapieregime genauso sicher und gut verträglich war, wie die ausschließliche adjuvante Chemoradiotherapie (Hyams et al. 1997). Zusätzlich konnte aber durch neoadjuvant angewandte Chemoradiotherapie ein neuer Vorteil in der Verbesserung der lokalen Kontrolle erwirkt werden (Gérard et al. 2006). Durch diese Therapieform wird ein Downstaging der Tumore erzielt (Velenik et al. 2010), wodurch die Rate der kurativen R0-Resektionen beim fortgeschrittenen Rektumkarzinom erhöht werden konnte (Rödel et al. 2000). Dadurch wurden ebenfalls mehr Sphinkter-erhaltende Operationen bei tief liegenden Karzinomen möglich (Silberfein et al. 2010).

Allerdings zeigte sich auch, dass die akute Toxizität der neoadjuvanten Behandlung mit Radiotherapie durch die Addition von präoperativer Chemotherapie stieg (z.B. Neurotoxizität und Schmerzintensität unter Therapie) (Bosset et al. 2004; Gérard et al. 2006). Eine Erhöhung der postoperativen Komplikationen wie Wundheilungsstörungen, Anastomoseninsuffizienzen, Blutungen, lleus- oder Fistelbildungen, kardiovaskuläre Komplikationen etc. konnte hingegen nicht beobachtet werden (Sauer et al. 2001).

Auch für ultra-low Rektumkarzinome, die präoperativ chemoradiotherapiert wurden, zeigten Studien unlängst, dass im Vergleich nicht mehr perioperative Komplikationen auftraten und ebenso die Wahrscheinlichkeit eines erneuten lokalen Tumorwachstums vermindert wurde (Lim et al. 2010).

Heute gilt die Kombination aus beidem, präoperative Chemotherapie mit 5-FU und Radiotherapie, als Therapie der Wahl in der Behandlung der lokal fortgeschrittenen Rektumkarzinome, wodurch vor allem eine Verbesserung der lokalen Kontrolle durch 
erhöhte Ansprechraten des Tumors auf die Therapie, weniger des Überlebens, erzielt werden konnte (Sauer et al. 2004; Gérard et al. 2006; Bosset et al. 2006; Liska \& Weiser 2010).

Offenbar kann zwar die lokale Kontrolle positiv beeinflusst werden, weniger aber die Fernmetastasierung, die wesentlich das Überleben bestimmt (Peeters et al. 2007).

Erwähnt sei auch die Wirkung der neoadjuvanten Chemoradiotherapie auf die den Tumor umgebenden Lymphknoten. Im Rahmen der verbesserten lokalen Kontrolle wird neben dem Downstaging der Tumore auch eine Reduktion der Anzahl positiver Lymphknoten im den Tumor umgebenden Gewebe erreicht (Wichmann et al. 2002). Aus der Anzahl der metastatisch befallenen Lymphknoten kann wiederum eine Prognose für das Überleben des Einzelnen abgeleitet werden (Beresford et al. 2005). Für eine Subgruppe von Patienten, bei welchen man nach neoadjuvanter Behandlung keine Lymphknoten - weder metastatsich befallene noch tumorzellfreie - im Resektat des distalen Rektumkarzinoms finden kann, wurde beschrieben, dass diese Tatsache mit geringer Invasionstiefe des Tumors und gutem Überleben einhergeht (Habr-Gama et al. 2008).

Eine Verbesserung der Verträglichkeit der neoadjuvanten Chemotherapie erreichte man durch Substitution von 5-FU, welches i.v. gegeben werden muss, durch das Prodrug Capecitabine, welches oral verabreicht werden kann.

Mehrere Studien zeigten, dass 5-FU und Capecitabine ähnlich verträglich und effektiv sind (Kim et al. 2002; Corvò et al. 2003; Lay et al. 2007; de Marsh et al. 2010). Die orale Gabe des Chemotherapeutikums bedeutet eine Vereinfachung für die Patienten und somit eine erhöhte Compliance (Ballonoff et al. 2008).

Des Weiteren soll an dieser Stelle noch auf die Therapieentwicklungen mit monoklonalen Antikörpern, den sogenannten „Biologicals“, hingewiesen werden. Auch hier zeigen Studien sehr unterschiedliche Ergebnisse bezüglich Effektivität und Verträglichkeit. Da sich die Angiogenese von Lymph- und Blutgefäßen als prognostischer Faktor in Rektumkarzinomen auswerten lässt (Holmqvist et al. 2010), verspricht man sich von der Therapie mit Angiogenesehemmern wie Bevacizumab einen erheblichen Nutzen für das krankheitsfreie und das gesamte Überleben, vor allem bei bereits metastasierten Karzinomen (Lièvre et al. 2009). Auch über eine verbesserte Downstaging-Rate bei lokal fortgeschrittenen Rektumkarzinomen unter 
neoadjuvanter Antikörpertherapie plus Chemoradiotherapie wurde berichtet (Velenik et al. 2010). Andere Studien zeigen eine mäßige Erhöhung der Ansprechrate der Karzinome von $5 \%$ auf $12 \%$ bei zusätzlicher Gabe von Cetuximab zu neoadjuvanter Chemoradiotherapie (Wadlow \& Ryan 2010). Allerdings wird der zusätzliche Benefit der Gabe von Bevacizumab in Kombination mit adjuvanter Chemoradiotherapie von weiteren Studien in Frage gestellt (Javle \& Hsueh 2010). Die Datenlage zeigt in diesem Gebiet noch neuen Raum für Forschung, da es sich bei der Therapie mit monoklonalen Antikörpern um den Einsatz von noch sehr jungen Medikamenten handelt.

André et al. (2009) zeigten eine Verbesserung des krankheitsfreien Überlebens durch zusätzliche Gabe des Platinderivates Oxaliplatin zu 5-FU, was bisher fast ausschließlich im adjuvanten Therapiezweig getestet wurde. Die Wahrscheinlichkeit für ein krankheitsfreies Überleben von 5 Jahren konnte durch adjuvant additiv gegebenes Oxaliplatin um 4-7\% erhöht werden, wobei schwerer betroffene Patienten von der Therapie mehr profitierten als weniger schwer betroffene.

Als „FOLFOX“-Schema bekannt, wird heute die Gabe von Folsäure plus Oxaliplatin in der postoperativen Phase als Standard in der Behandlung kolorektaler Karzinome weitverbreitet angewandt. Präklinische Studien zeigten, dass Oxaliplatin das Absterben kolorektaler Karzinomzellen induziert, indem es den programmierten Zelltod auslöst (Tesniere et al. 2010).

In Studien, in denen präoperativ zu 5-FU bzw. Capecitabine das Platinderivat Oxaliplatin als Wirkverstärker verabreicht wurde, zeigte sich: die akute Toxizität steigt und das Tumoransprechen auf die Therapie wird nicht zusätzlich beeinflusst, dafür ist aber die Rate der Metastasierungen geringer (Wolmark et al. 2008; Aschele et al. 2009; Gerard et al. 2009). Die Metastasierungsrate ist wiederum der Haupteinflussfaktor auf die Überlebenschance des Patienten. Die Datenlage zeigt, dass ein zusätzliches Ansprechen des Tumors im Sinne eines verbesserten Downstagings unterschiedlich beurteilt wird, in anderen Studien wurde ein besseres Ansprechen beobachtet (Rödel et al. 2007).

An einem kleinen Patientenkollektiv wurde von Musio et al. (2010) das Therapieregime bereits so getestet, wie es auch in der derzeit durchgeführten Studie CAO/ARO/AIO-04 angewandt wird, die Grundlage dieser Arbeit ist. In diesen Studien werden Patienten mit Rektumkarzinomen zu zwei Therapieschemata randomisiert: einem neoadjuvanten Behandlungsschema mit 5-FU plus Oxaliplatin und Radiotherapie und dem 
neoadjuvanten Standardbehandlungsschema mit 5-FU und Radiotherapie. Die ersten Ergebnisse zeigten hierbei, ohne bereits Aussagen über das Überleben treffen zu können, dass eine Hinzunahme von Oxaliplatin zu einem verbesserten Downstaging führt, wodurch mehr Sphinkter-erhaltende Operationen möglich sind. Dass die Toxizität gesteigert ist (Diarrhoe, Schmerzen im Beckenbereich, Neurotoxizität) und die Patienten einer gründlichen Überwachung bedürfen, wurde ebenso deutlich.

In der CAO/ARO/AIO-04-Studie soll geprüft werden, ob eine Ergänzung der neoadjuvanten und adjuvanten Therapie mit Oxaliplatin zu einer geringeren Metastasierungsrate führen und somit eine Verlängerung des Überlebens für die Patienten erzielt werden kann.

\subsection{Molekulare Tumorgenese und erblicher Einfluss in der Karzinomentstehung}

Kolorektale Karzinome gehören zu den häufigsten Malignomen in der BRD. In den vergangenen Jahren stellte sich heraus, dass der Genotyp des Tumors sein Verhalten bestimmt. Kolorektale Karzinome können durch verschiedenste molekulare Mechanismen entstehen, bei denen genetische Veränderungen in Protoonkogenen, Tumorsuppressorgenen und Mismatch-Repair-Genen akkumulieren und zur Entstehung kolorektaler Karzinome führen (Jass 2006; Duffy et al. 2007). Vogelstein et al. (1988) zeigten im Tumorprogressionsmodell, dass die erforderlichen Schritte für die Entwicklung eines Karzinoms häufig in der Aktivierung von Onkogenen durch Mutationen liegen. Ebenfalls förderlich für die Karzinomentstehung ist der Verlust unterschiedlicher Gene, die normalerweise das Tumorwachstum unterdrücken (Vogelstein et al. 1988).

\subsubsection{Klinische Kriterien zur Einteilung in sporadische vs. hereditäre Genese und Bethesda-Richtlinien}

Das Hereditary Nonpolyposis Colorectal Cancer-Syndrom (HNPCC) zeichnet sich durch ein für den Betroffenen erhöhtes Risiko aus, in frühem Lebensalter an kolorektalen (HNPCC Typ I) und/ oder anderen (Endometrium, Ovar, Magen, Leber, Gehirn, Haut etc.) Karzinomen zu erkranken (HNPCC Typ II). Das Lebenszeitrisiko für 
HNPCC-Patienten, an Dickdarmkrebs zu erkranken, beträgt annähernd $80 \% \mathrm{im}$ Vergleich zu 5,5\% in der europäischen Bevölkerung (Aarnio et al. 1995).

Das mittlere Erkrankungsalter beträgt bei HNPCC-Patienten 41 Jahre. Sporadisch aufgetretene kolorektale Karzinome manifestieren sich hingegen am häufigsten zwischen dem 60. und dem 70. Lebensjahre. 68\% der Kolonkarzinome treten bei HNPCC-Patienten im rechten Kolon auf, sporadische Kolonkarzinome finden sich nur zu 39\% im rechten Kolon. (Review Müller \& Fishel 2002)

Objektive Kriterien für die klinische Diagnose eines HNPCC-Syndroms wurden erstmalig 1991 durch die Amsterdam-Kriterien (Vasen et al. 1991) und 1997 durch die Bethesda-Richtlinien (Rodriguez-Bigas et al. 1997) festgelegt. In den 2004 herausgegebenen, überarbeiteten Bethesda-Richtlinien fließen klinische und molekulare Diagnosekriterien mit ein (Umar et al. 2004). Nachfolgende Aufzählung zeigt, in welchen Situationen ein Patient gemäß den Bethesda-Richtlinien auf MSI getestet werden sollte, da der Verdacht gegeben ist, dass ein HNPCC-Syndrom vorliegen könnte:

1. Diagnosestellung eines kolorektalen Karzinoms, wenn der Patient jünger als 50 Jahre ist

2. Bei Vorhandensein von synchronen oder metachronen kolorektalen, oder anderen HNPCC-assoziierten Tumoren, ungeachtet des Patientenalters

3. Kolorektales Karzinom mit MSI-H-Status (hoher Anteil instabiler Mikrosatelliten, vgl. S.20) bei einem Patienten jünger als 60 Jahre

4. Diagnosestellung eines kolorektalen Karzinoms bei einem oder mehreren Verwandten ersten Grades mit HNPCC-assoziierten Tumoren, wenn eines der Karzinome vor dem 50 Lebensjahre aufgetreten ist

5. Diagnosestellung eines kolorektalen Karzinoms bei zwei oder mehr erst- oder zweitgradig Verwandten mit HNPCC-assoziierten Tumoren, ungeachtet des Patientenalters

Aufzählung modifiziert entnommen aus: Umar et al. (2004) 


\subsubsection{Mechanismen des Mismatch-Repair-Gen-Ausfalls}

Die Ursache der Erkrankung HNPCC findet sich in einer Keimbahnmutation eines Mismatch-Repair-Gens (MMR). Betroffen sind in der Vielzahl der Fälle die MMR-Gene MSH2 und MLH1 (ca. 95\%) (Leach et al. 1993; Bronner et al. 1994; Peltomäki \& Vasen 1997). Seltener liegen Defekte in MSH6 (7-10\%) und PMS2 vor (<5\%), sehr selten in PMS1 (Kolodner et al. 1999; Nicolaides et al. 1994). Diese Defekte manifestieren sich in Mikrosatelliteninstabilität (MSI). Liegt ein MSI-positiver Status vor, sollte sich nach den Bethesda-Richtlinien eine Keimbahnanalyse des MMR-Gens anschließen, welches immunhistochemisch einen Ausfall gezeigt hat.

Verschiedene andere Ursachen, neben der Keimbahnmutation bei HNPCC-Patienten, können zu einem Ausfall bzw. einer Herunterregulation der Proteinexpression eines MMR-Gens führen:

Eine Ursache kann die epigenetische Inaktivierung durch Methylierung der CpG-Insel in der Promotor-Region des MLH1-Gens sein (Herman et al. 1998). Diese Untergruppe kolorektaler Karzinome wird als CpG-Island-Methylator-Phänotype (CIMP) charakterisiert (Ogino et al. 2009). Methylierung von Promotor-Regionen innerhalb des Genoms führt zu einem Gen-Silencing in dem Abschnitt, welcher der Promotor-Region folgt. Hypermethylierung innerhalb der CpG-Inseln findet sich häufig im Entstehungsweg sporadischer kolorektaler Karzinome, welche als mikrosatelliteninstabil auffallen (Toyota et al. 1999). Von Mikrosatelliteninstabilität darf daher nicht zwingend auf HNPCC geschlossen werden, die Diagnose ist im Zusammenhang mit den klinischen Daten zu stellen.

Auch ein multifaktorielles Geschehen kann einen Ausfall von MMR-Genen bedingen. Beispielsweise ein Ausfall von $\mathrm{MSH} 2$ ist häufig mit einem Ausfall von MSH6 verbunden. Eine Ursache kann ein mutierter Mikrosatellit im MSH6-Gen sein, der durch den Ausfall von $\mathrm{MSH} 2$ entstanden ist. Eine andere Ursache kann sein, dass das Heterodimer $\mathrm{MSH} 2-\mathrm{MSH} 6$ durch den Schaden an $\mathrm{MSH} 2$ nicht mehr gebildet werden kann. Wenn MSH6 nicht mehr von MSH2 gebunden wird, entwickelt sich ein negativer Feed-Back-Mechanismus, bei dem MSH6 vermehrt frei vorliegt und als Folge davon herunterreguliert wird (Rigau et al. 2003). Eine ebensolche Verknüpfung liegt bei den MMR-Genen MLH1 und PMS2 vor (Wu X et al. 2003). Da eine HeterodimerVerknüpfung zu erhöhter Repair-Effizienz führt, bedingt ein Vorliegen von Homodimeren eine herabgesetzte Repairtätigkeit und erhöhte Fehlerquoten (Leong et al. 2009). 


\subsubsection{Onkogenanalyse und Prognose}

Ist ein MMR-Gen mutiert und die Frage nach einer hereditären Ursache nicht eindeutig geklärt, kann zur Unterscheidung die Analyse von Onkogenen herangezogen werden. HNPCC-Patienten können neben MMR-Mutationen auch KRAS-Mutationen haben. BRAF-Mutationen in Kombination mit MMR-Mutationen finden sich nur in sporadisch aufgetretenen kolorektalen Karzinomen und sind mit einer reduzierten Mortalität verbunden. (Gryfe et al. 1997; Ogino et al. 2009). Sporadische Tumore mit MSI-HStatus und BRAF-Mutation zeigen in nahezu allen Fällen auch einen CIMP (Weisenberger et al. 2006).

\subsubsection{Häufigkeitsverteilung sporadische vs. hereditäre Genese und Diagnosestellung}

In ca. $65 \%$ der kolorektalen Karzinome mit MSI kann von einem sporadischen Auftreten ausgegangen werden. Bei denjenigen Karzinomen, welche nicht dieser Gruppe zuzuordnen sind, muss ein Einfluss von erblichen Faktoren angenommen werden, wie es Zwillingsstudien nahe legen (Lichtenstein et al. 2000). Von diesen 35\% MSI-positiven, erblich bedingten Karzinomen sind ca. $5 \%$ durch einen monogenetischen Defekt entstanden, der in den meisten Fällen autosomal dominant vererbt wird. Die HNPCC-Erkrankung fällt unter diese Kategorie und stellt einen Gesamtanteil von ca. 2-4\% aller kolorektalen Karzinome dar (Aaltonen et al. 1998; Salovaara et al. 2000; Lynch \& de La Chapelle 2003).

Für die Diagnose eines HNPCC-Syndroms spielen der beurteilende Pathologe, der die typische Histopathologie erkennen und beurteilen muss (Rüschoff et al. 2004), die Amsterdam-Kriterien als klinischer Hinweis (Vasen et al. 1991) und die BethesdaRichtlinien als genetischer Hinweis (Umar et al. 2004) eine Rolle.

Für die Kontrolle des Erkrankungsverlaufes sind regelmäßige Vorsorgeuntersuchungen inklusive Koloskopie alle 1-2 Jahre wichtig, da damit die Krebshäufigkeit um $80 \%$ gesenkt werden kann (Järvinen 2003). 


\subsection{Mikrosatelliteninstabilität}

Bei Mikrosatelliten handelt es sich um kurze, repetitive DNA-Sequenzen, welche individuelle Längenpolymorphismen aufweisen (Weber \& May 1989). Sie kommen als Tandem-Repeats mit einer Länge von 1-6 Basenpaaren ubiquitär im Genom vor. Die Rate an Keimbahnmutationen der Mikrosatelliten ist hoch, die Polymorphismen sind umfangreich, aber sie sind in jedem Individuum einzigartig und einheitlich in allen Geweben (Ellegren 2000). Während einige Mikrosatelliten für das Genom bedeutungslos erscheinen, können andere Mikrosatelliten Veränderungen in der Genexpression, in der Proteinsequenz und/ oder im Splicing bewirken ( $\mathrm{Li}$ et al. 2004; Iglesias et al. 2004). Ca. 40 Mikrosatelliten sind als Risikofaktoren für neurologische, neurodegenerative und neuromuskuläre Erkrankungen bekannt, bzw. können funktionelle Relevanz für die Erkrankung haben (Pearson et al. 2005). Bezogen auf Erkrankungen des Darmes haben Mikrosatelliten beispielsweise Relevanz für das HNPCC-Syndrom, bei dem sie Instabilitäten aufweisen, und bei der Familiären Adenomatösen Polyposis. Bei dieser autosomal-dominant vererbten Erkrankung kommt es durch eine Mutation innerhalb des APC-Gens zu einer Prädisposition, kolorektale Karzinome zu entwickeln (Church 2009).

Mikrosatelliteninstabilität (MSI) ist definiert als eine Längenänderung jedweder Form, entweder aufgrund einer genomischen Deletion oder Insertion in Mikrosatellitenregionen innerhalb eines Tumors im Vergleich zu Normalgewebe (Boland et al. 1998).

Mikrosatelliteninstabilität entsteht durch Fehler im DNA-Mismatch-Repair-System (MMR) einer Zelle, wodurch diese nicht mehr in der Lage ist, Fehler, die während der DNA-Replikation auftreten, zu korrigieren. Dies zeigt sich in einer beschleunigten Akkumulation von Einzelnukleotid-Mutationen sowie in Längenänderungen der repetitiven Mikrosatellitensequenzen, die ubiquitär im gesamten Genom vorkommen. (Boland et al. 1998)

Die Benennungen einzelner MMR-Gene leiten sich ursprünglich von den eukaryontischen MMR-Genen MutS und MutL ab. Das MMR-System von Hefen und Säugetieren ist in seiner Funktion aber komplexer. Aus Hefen geklonte homologe Gene erhielten die Bezeichnungen MutS-Homolog (MSH) und MutL-Homolog (MLH). Wiederum homologe Klone von MSH und MLH wurden unterteilt in MSH1, MSH6 und MLH1, sowie MLH3. Andere in Hefen gefundene Homologe von MutL wurden PostMeiotic-Segregation-1 (PMS1) und PMS2 benannt. Jedem dieser MMR-Gene kann 
mittlerweile eine spezifische Reparaturfunktion in der Zellkern-DNA, während der Meiose oder in der Mitochondrien-DNA, zugeschrieben werden (Grilley et al. 1990).

Während in Prokaryonten MutS und MutL als Homodimere vorliegen, findet man in eukaryontischen Zellen MSH2 als Heterodimer mit MSH6 oder MSH3 (Acharya et al. 1996). Ebenso können MLH1 und PMS2 ein Heterodimer eingehen, welches effizienter arbeiten kann als MLH1 und PMS2 als Monomere (Leong et al. 2009). Auch MSH4MSH5 liegen als MMR-Heterodimer vor (Fishel \& Wilson 1997). Dem MSH2-MSH6Heterodimer wird die Funktion zugeschrieben Einzelnukleotid-Mismatches und kleine Insertion/Deletion-Schleifen erkennen und reparieren zu können. MSH2-MSH3 erkennt kleine und große Insertion/Deletion-Schleifen (Bocker et al. 1999).

Die Untersuchung der Mikrosatelliten einer Zelle lässt Rückschlüsse auf ein ausgefallenes oder eingeschränkt funktionierendes Mismatch-Repair-System zu. Damit kann ein Ausfall der MMR-Gene objektiviert und gemessen werden.

Zunächst wurde Mikrosatelliteninstabilität vor allem mit kolorektalen Karzinomen von HNPCC-Patienten assoziiert, aber auch in sporadisch aufgetretenen Karzinomen des Kolorektums wurde MSI beobachtet (Aaltonen et al. 1993), sowie in anderen Tumortypen, die im Rahmen des HNPCC-Syndroms auftreten können (Peltomäki et al. 1993), zum Beispiel in Endometriumkarzinomen (Risinger et al. 1993) und Magenkarzinomen (Rhyu et al. 1994). Die Testung auf MSI gilt als Screening-Methode für an HNPCC erkrankte Patienten, die eine hohe Sensitivität und Reliabilität aufweist (Müller et al. 2004a). Ca. 90\% der HNPCC-assoziierten Tumore weisen MSI auf (Mueller et al. 2009).

Die fluoreszenzmarkierte Polymerase-Ketten-Reaktion (polymerase chain reaction PCR) in Kombination mit einer Genescan-Analyse erwies sich als ein schnelles und unkompliziertes Verfahren für die Detektion von MSI (Cawkwell et al. 1995).

Die Definition für Mikrosatelliteninstabilität wurde 1997 bei einem internationalen consensus meeting festgelegt, wobei drei Subtypen klassifiziert wurden: highfrequency MSI (MSI-H), low-frequency MSI (MSI-L) und stabile Mikrosatelliten als MSS (Boland et al. 1998). MSI-H-Tumore können auf unterschiedlichen Wegen entstehen, zum Beispiel durch Keimbahndefekte in Mismatch-Repair-Genen, wie es bei dem HNPCC der Fall ist (Thibodeau et al. 1996). Eine andere Möglichkeit ergibt sich durch epigenetische Hemmung des Mismatch-Repair-Systems, verursacht durch PromotorHypermethylierung (Cunningham et al. 1998). Speziell die PromotorHypermethylierung des MLH1-Gens ist etwa zehnmal häufiger für das Auftreten von MSI-H-Tumoren im Kolorektum verantwortlich als die Keimbahnmutation (Auclair et al. 
2011). Der Anteil von MSI-positiven, sporadisch entstandenen Tumoren ist somit wesentlich größer (12-17\%) (Popat et al. 2005; Ward et al. 2001) als der Anteil von HNPCC-assoziierten Tumoren (3\%) (Hampel et al. 2005; Hampel et al. 2008), wenn man die Gesamtheit aller Tumore des Kolorektums betrachtet.

MSI findet sich vor allem in Tumoren im proximalen Colon. Es wurde des Weiteren beobachtet, dass Patienten mit mikrosatelliteninstabilen Tumoren eine bessere Prognose haben, als Patienten mit mikrosatellitenstabilen Tumoren. Der Verlust von Heterozygosität (loss of heterozygosity, LOH) ist in mikrosatelliteninstabilen Tumoren vermindert beobachtet worden (Thibodeau et al. 1993).

Außerdem wurde für MSI-H-Tumore ein verändertes Ansprechen auf Chemotherapien und damit eine möglicherweise veränderte Überlebenschance des Patienten gefunden (Warusavitarne \& Schnitzler 2007; Sargent et al. 2010).

\subsection{Prognostische Bedeutung der Mikrosatelliteninstabilität}

Derzeit gilt das UICC-Stadium eines Patienten mit kolorektalem Karzinom als ein sicheres Kriterium, um eine Prognose bezüglich der 5-Jahres-Überlebensrate ableiten zu können. Das UICC-Stadium bildet dabei in erster Linie ab, wie weit die Erkrankung zum Diagnosezeitpunkt bereits fortgeschritten ist. Molekulare Unterschiede von Karzinomen und damit Karzinomsubgruppen finden dabei keine Berücksichtigung. So ist der Frage, ob man individuelle molekulare Unterschiede, so wie die MSI, als Biomarker und Prädiktoren für Prognostik und individuelle Therapieempfehlung nutzen kann, in den letzten Jahren verschärft nachgegangen worden.

Lediglich in einer Studie über Patienten mit Rektumkarzinomen, welche neoadjuvant chemoradiotherapiert wurden, wurde bisher der prätherapeutische MSI-Status als prädiktiver Marker für den Therapieerfolg analysiert. Die Schlussfolgerung, die in dieser Studie trotz eines kleinen Patientenkollektivs von 57 Patienten und davon $5 \mathrm{MSI}-$ Positiven getroffen wurde, war, dass MSI und der Verlust von MMR-Expression in Rektumkarzinomen eine Verbesserung des Tumoransprechens unter neoadjuvanter Chemoradiotherapie (CPT-11, 5-FU, Bestrahlung) bewirken können (Charara et al. 2004).

Die Datenlage zur prognostischen Bedeutung des MSI-Status für Rektumkarzinome ist umstritten. Da Rektumkarzinome die kleinste Fraktion der MSI-positiven 
kolorektalen Karzinome darstellen, befassen sich nur wenige Studien gesondert mit innen. Colombino et al. (2002) fanden in der ausschließlichen Betrachtung von Rektumkarzinomen eine deutliche Prognoseverbesserung für Patienten mit mikrosatelliteninstabilen Tumoren, unabhängig davon, ob die Patienten adjuvant eine Chemotherapie, eine Radiotherapie oder beides erhielten. Für die Gesamtheit der kolorektalen Karzinome sind die Forschungsergebnisse weiterhin uneindeutig, obwohl die Frage nach der prognostischen Bedeutung des MSI-Status schon lange in der Forschung thematisiert wird. Einige Arbeitsgruppen fanden eine verbesserte Prognose (Aebi et al. 1997; Elsaleh et al. 2000; Hemminki et al. 2000; Sinicrope et al. 2006), einige sehen die Prognose unbeeinflusst (Deschoolmeester et al. 2008; Meng et al. 2007; Emterling et al. 2004). Wieder andere verzeichnen anhand ihrer Ergebnisse sogar eine Tendenz zu einer verschlechterten Prognose bei Patienten mit mikrosatelliteninstabilen Tumoren (Hawn et al. 1995; Carethers et al. 1999; Samowitz et al. 2009), v.a. durch verändertes Ansprechen auf Chemotherapie. Vor allem eine Chemoresistenz von MSI-positiven kolorektalen Karzinomen gegenüber 5-FU wird diskutiert und für ein möglicherweise verschlechtertes Überleben des Patienten verantwortlich gemacht (Jover et al. 2009; Sargent et al. 2010).

Trotz widersprüchlicher Daten ist heute MSI als prognostischer Marker für ein verbessertes Überleben bei kolorektalen Karzinomen anerkannt. Weitere Studienauswertungen mit großen Patientenkollektiven haben MSI als signifikanten prognostischen Marker bestätigt (Roth et al. 2009).

\subsection{Kolonkarzinome vs. Rektumkarzinome}

In der Literatur werden Kolon- und Rektumkarzinome häufig als gemeinsame Entität diskutiert, es ergeben sich jedoch bei näherer Betrachtung einige Unterschiede, die Relevanz für die Untersuchung auf Mikrosatelliteninstabilität in Rektumkarzinomen haben.

Viel seltener als in Kolonkarzinomen findet man in Rektumkarzinomen hohe Instabilitäten in Mikrosatelliten $(27,2 \%$ in Kolonkarzinomen vs. $6,7 \%$ in Rektumkarzinomen). Auch der Anteil an CpG-Island-Methylator-Phänotyp (CIMP+) ist in Rektumkarzinomen geringer $(28 \%$ in Kolonkarzinomen vs. $3,4 \%$ in Rektumkarzinomen). Während KRAS-Mutationen in Kolon- und Rektumkarzinomen nahezu gleich häufig vorkommen, sind BRAF-Mutationen im Rektum sehr selten im 
Gegensatz zum Vorkommen in Kolonkarzinomen (17\% in Kolonkarzinomen vs. $0 \%$ in Rektumkarzinomen). (Kalady et al. 2009)

Die Daten legen nahe, dass Methylierung in der Genese des Rektumkarzinoms eine geringe Rolle spielt, da die Methylierung von MLH1 mit CIMP+ und BRAF-Mutationen in Verbindung zu bringen ist (O'Brien et al. 2006).

Ein positiver MSI-Status ist dementsprechend im Rektumkarzinom für die Untersuchungen selten zu erwarten (1-7\%) (Kalady et al. 2009). Liegt ein MSI-positiver Status vor, ist eine sporadische Genese dafür unwahrscheinlicher, da MLH1Methylierungen, CIMP+ und BRAF-Mutationen seltener sind.

\subsection{Fragestellung und Versuchsplanung}

Kolonkarzinome und Rektumkarzinome werden häufig als gemeinsame Entität behandelt, da Diagnostik, Klassifikation und Therapie gleich sind. Eine Arbeitsgruppe hat im Direktvergleich von Kolonkarzinomen vs. Rektumkarzinomen Unterschiede herausgearbeitet (Kalady et al. 2009), die für die Fragestellung und Planung dieser Arbeit Bedeutung haben, da in den zugrunde liegenden Studien ausschließlich Rektumkarzinome untersucht wurden.

MSI findet sich nur in 1-7\% aller Rektumkarzinome (Kalady et al. 2009). Sein Vorkommen kann verschiedene Ursachen haben und ist in sporadischen wie auch in erblichen Tumoren möglich. Tritt MSI auf, ist dies möglicherweise ein Hinweis auf ein HNPCC-Syndrom.

In der vorliegenden Arbeit soll der Fragestellung nachgegangen werden, ob vor dem Hintergrund der Entwicklungen der Therapie des Rektumkarzinoms in den letzten Jahrzehnten MSI ein geeigneter Prädiktor und Biomarker für das Ansprechen auf Chemoradiotherapie, für den Verlauf der Erkrankung und für das Überleben ist.

Als Grundlage für die Untersuchungen steht DNA-Material aus zwei groß angelegten Studien, der CAO/ARO/AIO-94-Studie, sowie der CAO/ARO/AIO-04-Studie zur Verfügung (Abkürzungen stehen für: Chirurgische Arbeitsgemeinschaft für Onkologie/ Arbeitsgemeinschaft Radiologische Onkologie/ Arbeitsgemeinschaft Internistische Onkologie). Die CAO/ARO/AIO-04-Studie fasst jeweils im Prüf- und im Kontrollarm 600 Patienten. Mehrere Zentren sind in die Studie eingebunden. Angebunden an diese klinische Studie ist eine, von der DFG geförderte, klinische Forschergruppe (KFO 179) 
mit 10 Teilprojekten, welche Daten zu den Studienpatienten sammeln und über verschiedenste Fragestellungen forschen.

Um den neuen therapeutischen Bedingungen der zugrunde liegenden Studien Rechnung $\mathrm{zu}$ tragen, wurden die Untersuchungen vergleichend sowohl an Tumorgewebe aus prätherapeutisch entnommenen Biopsien, als auch an Tumorgewebe aus Resektatmaterial nach neoadjuvanter Behandlung durchgeführt. Möglichst gute Vergleichbarkeit mit in der Vergangenheit durchgeführten Studien über MSI wurde durch eine Auswahl von fünf Primern erzielt, welche in einer internationalen Konferenz 1998 als Referenz-Primer festgelegt wurden (Boland et al. 1998). Durch Referenz-Primer ist die Analyse auf MSI standardisiert worden.

In der Forschung finden sich bisher keine Publikationen zu der Fragestellung, ob eine Untersuchung auf MSI vor oder nach neoadjuvanter Chemoradiotherapie stattfindet. Ob das untersuchte DNA-Material aus Biopsie oder Resektat stammt, findet in Studien zum Thema MSI-Analyse keine Erwähnung. Ein möglicher Grund ist, dass lange Zeit eine adjuvante Behandlung des kolorektalen Karzinoms Standard war. Umso wichtiger ist es vor dem neuen Hintergrund der neoadjuvanten Therapieform zu untersuchen, ob alte Regeln noch ihre Gültigkeit besitzen. Folgende Fragestellungen sollen als Ziel dieser Arbeit beantwortet werden können:

1. Hat die neoadjuvante Chemoradiotherapie einen Effekt auf den MSIStatus?

2. Ist der MSI-Status als Biomarker und Prädiktor für das Überleben und das Ansprechen auf die Therapie geeignet? 


\section{MATERIAL}

\subsection{Patientenkollektiv}

Das auf Mikrosatelliteninstabilität untersuchte Patientenkollektiv rekrutiert sich aus zwei prospektiven Studien zum Rektumkarzinom, in denen Patienten präoperativ mit Chemoradiotherapie behandelt wurden. Eingeschlossen sind Patienten mit lokal fortgeschrittenem Karzinom des unteren und mittleren Rektumdrittels.

\subsubsection{CAO/ARO/AIO-94-Studie}

Das erste Kollektiv von Patienten, welches auf Mikrosatelliteninstabilität untersucht wurde, wurde im Rahmen der CAO/ARO/AIO-94-Studie behandelt. Bei der CAO/ARO/AIO-94-Studie handelt es sich um die Vorläuferstudie für die CAO/ARO/AIO-04-Studie, die im Zeitraum zwischen 1995 und 2002 durchgeführt wurde. Die Patienten erhielten eine präoperative Chemoradiotherapie mit 5Fluorouracil (5-FU), auf die die Operation folgte. Anschließend wurde postoperativ eine weitere Chemotherapie mit 5-Fluorouracil angeschlossen. (Sauer et al. 2001)

Der therapeutisch erfolgreichste Arm der CAO/ARO/AIO-94-Studie wurde als Kontrollarm für die CAO/ARO/AIO-04-Studie gewählt.

\subsubsection{CAOIARO/AIO-04-Studie}

Die interdisziplinäre Studie CAO/ARO/AIO-04 wird derzeit im Rahmen der Klinischen Forschergruppe 179 an der Universitätsmedizin Göttingen (UMG) durchgeführt. Es handelt sich um eine prospektiv randomisierte, multizentrische Phase-III-Studie, die Patienten einschließt, welche am lokal fortgeschrittenen Rektumkarzinom (UICCStadium II und III, entspricht T3/4 und/oder N+) erkrankt sind (Tab.I-2 Stadiengruppierung für Kolon- und Rektumkarzinome nach UICC, S.9 unter 1.1.2). Studienziele sind die Verlängerung des krankheitsfreien Überlebens und 
Gesamtüberlebens, Senkung der Fernmetastasierungsrate, Erhöhung der Lebensqualität und Erhöhung der Rate an Sphinkter-erhaltenden Operationen.

Alle Studienpatienten wurden gemäß dem derzeitigen Kenntnisstand neoadjuvant bestrahlt und erhielten eine Chemotherapie.

Anschließend erfolgte die Operation. Postoperativ erhielten alle Patienten wiederum eine Chemotherapie.

Patienten, die dem experimentellen Arm der Studie zugewiesen wurden, erhielten eine neoadjuvante und adjuvante Chemotherapie, bestehend aus 5-Fluorouracil plus Oxaliplatin. Als Wirkverstärker wurde im experimentellen Arm außerdem Folinsäure dazu gegeben. Diejenigen Patienten, die dem Kontroll-Arm zugewiesen wurden, erhielten eine neoadjuvante und adjuvante Chemotherapie, welche lediglich 5Fluorouracil beinhaltet.

Beide Arme wurden mit der gleichen Strahlendosis (50,4 Gray) neoadjuvant behandelt (vgl. nachfolgende Abb.ll-1).

Abb.Il-1 Behandlungsplan für Patienten der CAO/ARO/AIO-04-Studie

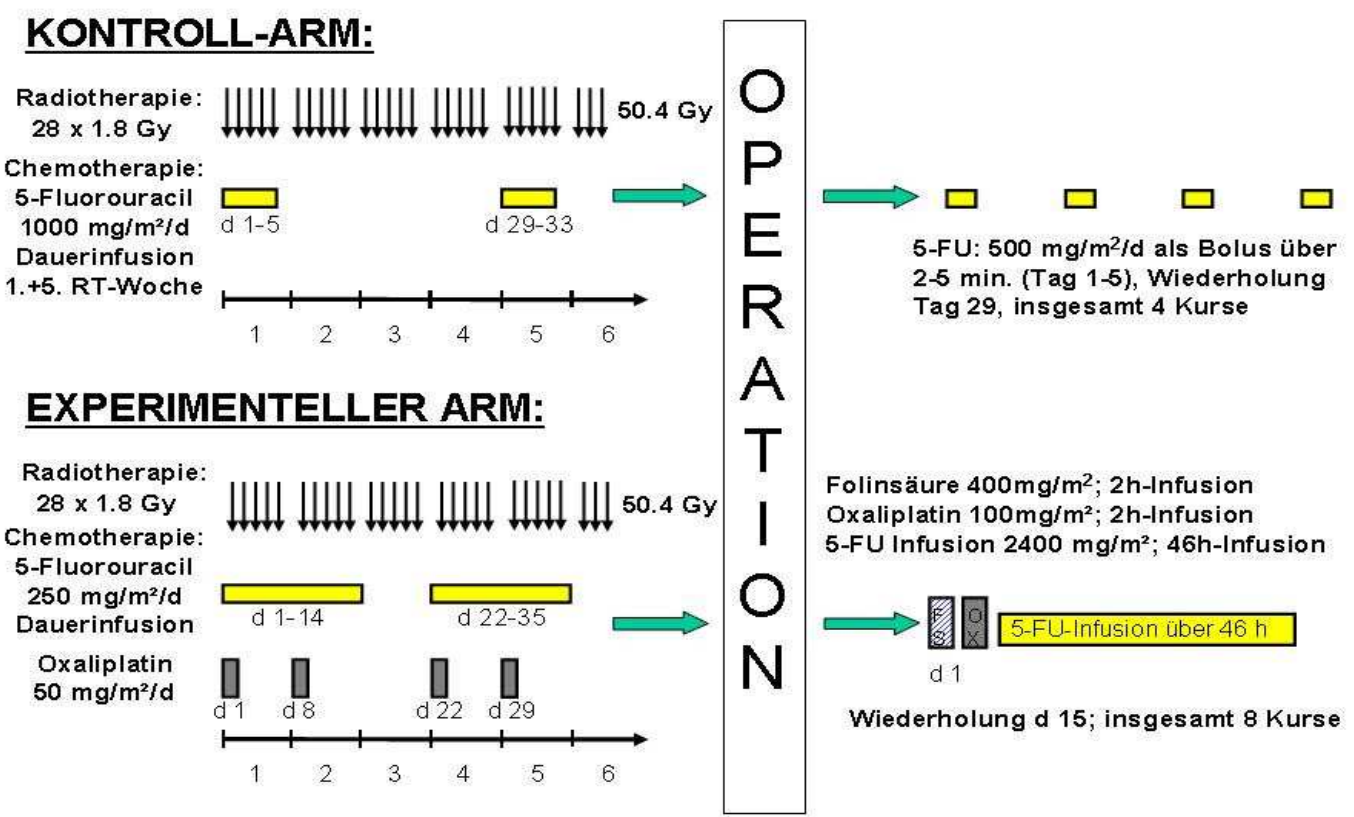

(Institut für Medizininformatik, Biometrie und Epidemiologie Uni Erlangen, 2010) 


\subsection{Material für die Methodenetablierung}

Für die Methodenetablierung wurde DNA von sieben Patienten verwendet, welche weder der CAO/ARO/AIO-94-Studie noch der CAO/ARO/AIO-04-Studie zuzuordnen sind, darunter ein MSI-H-Fall mit LOH.

\subsection{Probenmaterial prätherapeutisch}

Zur prätherapeutischen Untersuchung auf Mikrosatelliteninstabilität wurde DNA aus Paraffin-fixierten Biopsien von 9 Patienten untersucht, die der CAO/ARO/AIO-94Studie (Sauer et al. 2001) zuzuordnen sind und Biopsiematerial von 56 Patienten, welche in die CAO/ARO/AIO-04-Studie eingeschlossen sind.

\subsubsection{Patientenkollektiv der prätherapeutischen Proben}

\subsubsection{CAO/ARO/AIO-94-Studie}

Aus der CAO/ARO/AIO-94-Studie wurden insgesamt 9 Patienten prätherapeutisch auf Mikrosatelliteninstabilität untersucht. 
Abb.II-2 Patientenkollektiv prätherapeutisch CAO/ARO/AIO-94-Studie

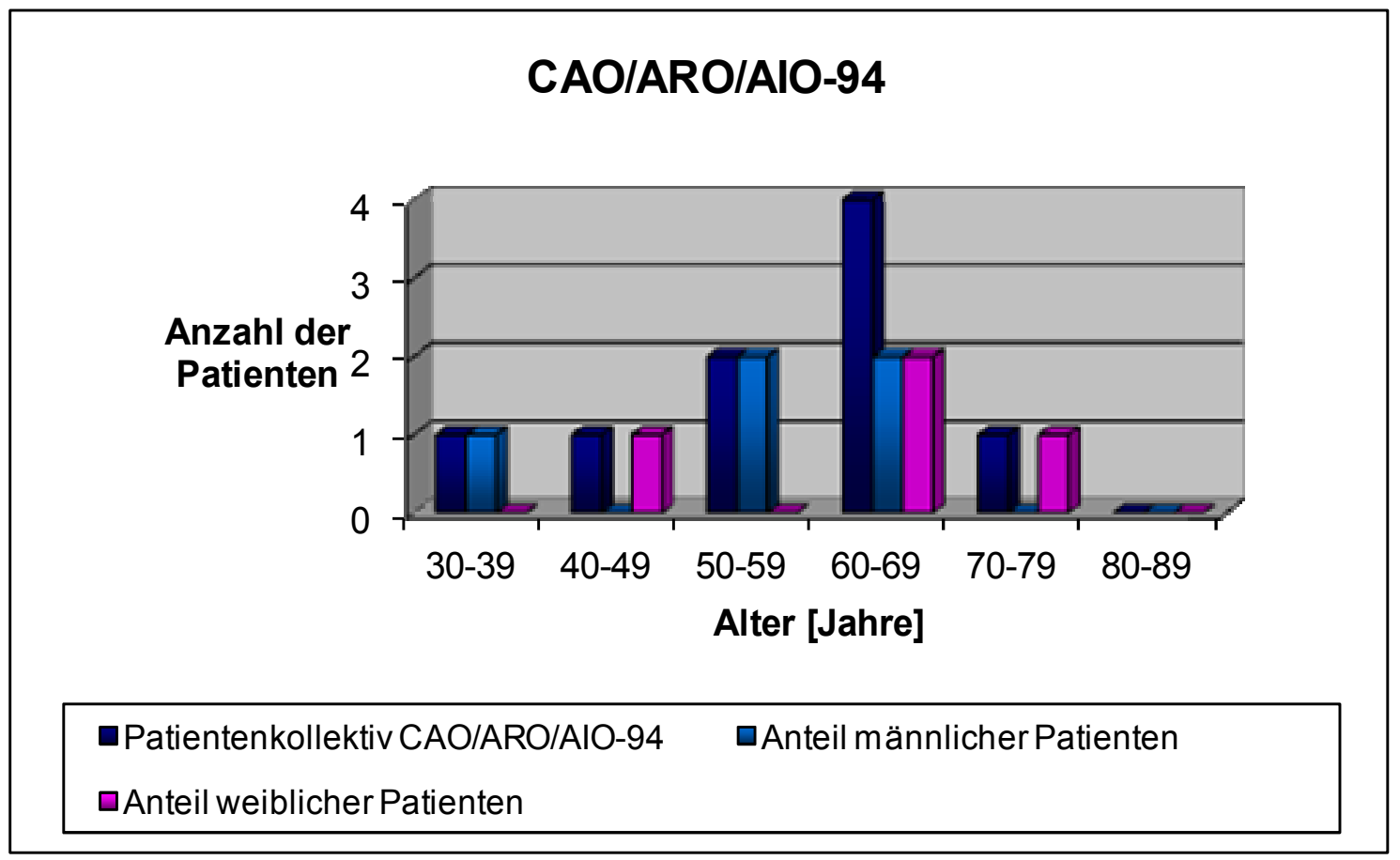

Tab.II-1 Patientenkollektiv prätherapeutisch CAO/ARO/AIO-94-Studie

\begin{tabular}{|c|c|c|c|}
\hline Alter & Anzahl Patienten & männlich & weiblich \\
\hline $30-39$ & 1 & 1 & 0 \\
\hline $40-49$ & 1 & 0 & 1 \\
\hline $50-59$ & 2 & 2 & 0 \\
\hline $60-69$ & 4 & 2 & 2 \\
\hline $70-79$ & 1 & 0 & 1 \\
\hline $80-89$ & 0 & 0 & 0 \\
\hline
\end{tabular}

\subsubsection{CAOIAROIAIO-04-Studie}

Aus der CAO/ARO/AIO-04-Studie wurden insgesamt 56 Patienten prätherapeutisch auf Mikrosatelliteninstabilität untersucht. 
Abb.II-3 Patientenkollektiv prätherapeutisch CAO/ARO/AIO-04-Studie

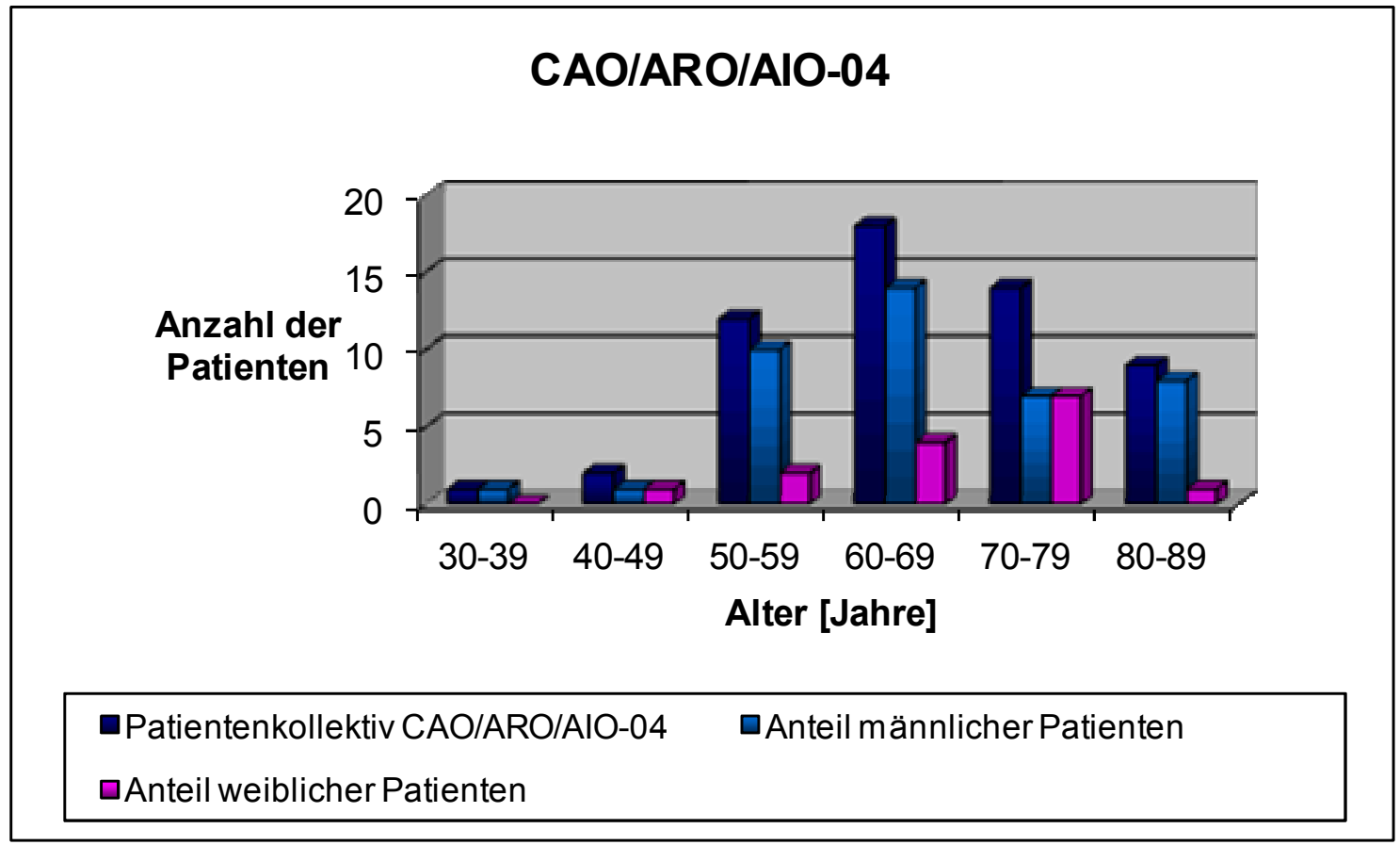

Tab.II-2 Patientenkollektiv prätherapeutisch CAO/ARO/AIO-04-Studie

\begin{tabular}{|c|c|c|c|}
\hline Alter & Anzahl Patienten & männlich & weiblich \\
\hline $30-39$ & 1 & 1 & 0 \\
\hline $40-49$ & 2 & 1 & 1 \\
\hline $50-59$ & 12 & 10 & 2 \\
\hline $60-69$ & 18 & 14 & 4 \\
\hline $70-79$ & 14 & 7 & 7 \\
\hline $80-89$ & 9 & 8 & 1 \\
\hline
\end{tabular}

\subsection{Probenmaterial posttherapeutisch}

Von 37, dem prätherapeutisch untersuchten Kollektiv entsprechenden, Rektumkarzinomresektat-Gewebeblöcken nach neoadjuvanter Chemoradiotherapie wurde aus der parallel stattfindenden immunhistochemischen Untersuchung (durch Mitarbeiter des Teilprojektes 5 der KFO 179) eine Subgruppe von 7 Patienten auf MSI untersucht. Diese 7 Patienten hatten sich immunhistochemisch auffällig gezeigt. 


\subsection{Grundlagen der Analyse auf Mikrosatelliteninstabilität}

Für die Analyse der Mikrosatelliten wurden die vom National Cancer Institute Workshop on Microsatellite Instability ausgesuchten Referenz-Primer gewählt (Boland et al. 1998), basierend auf der Arbeit von Dietmaier et al. (1997).

Die fünf Mikrosatellitenmarker beziehen sich auf nicht-kodierende DNA-Sequenzen und setzen sich aus zwei Markern für mononukleotide Wiederholungseinheiten (BAT25, BAT26) und drei Markern für dinukleotide Wiederholungseinheiten zusammen (D5S346, D2S123, D17S250). Sie besitzen die in der folgenden Tabelle aufgeführten Charakteristika: 


\begin{tabular}{|c|c|c|c|c|c|}
\hline Name (Lokus) & $\begin{array}{l}\text { Chromosom } \\
\text { und Lokus }\end{array}$ & Repetitives Motiv ${ }^{1}$ & $\begin{array}{l}\text { Basenpaar- } \\
\text { größe }\end{array}$ & verbunden mit $^{2}$ & Referenz \\
\hline BAT25 & $4 q 12$ & TTTT.T.TTTT.(T) $)_{7} \cdot \mathrm{A}(\mathrm{T})_{25}$ & $\sim 90$ & c-kit & $\begin{array}{l}\text { Papadopoulos et } \\
\text { al. (1995) }\end{array}$ \\
\hline BAT26 & $2 p$ & $(\mathrm{~T})_{5} \ldots .(\mathrm{A})_{26}$ & 80-100 & MSH2 & $\begin{array}{l}\text { Papadopoulos et } \\
\text { al. (1995) }\end{array}$ \\
\hline APC (D5S346) & $5 q 21 / 22$ & $(\mathrm{CA})_{26}$ & 96-122 & APC & $\begin{array}{l}\text { Spirio et al. } \\
\text { (1991) }\end{array}$ \\
\hline $\begin{array}{l}\text { AFM093xh3 } \\
\text { (D2S123) }\end{array}$ & $2 \mathrm{p} 16$ & $(\mathrm{CA})_{13} \mathrm{TA}(\mathrm{CA})_{15}(\mathrm{~T} / \mathrm{G} \mathrm{A})_{7}$ & $\sim 197-227$ & MSH2 & $\begin{array}{l}\text { Weissenbach et } \\
\text { al. (1992) }\end{array}$ \\
\hline $\begin{array}{l}\text { Mfd15CA } \\
\text { (D17S250) }\end{array}$ & $17 q 11.2-q 12$ & $(\mathrm{TA})_{7} \ldots \ldots \ldots \ldots \ldots \ldots(\mathrm{CA})_{24}$ & $\sim 150$ & TP53 & $\begin{array}{l}\text { Weber et al. } \\
(1990)\end{array}$ \\
\hline
\end{tabular}

${ }^{1}$ Punkte zeigen nichtrepetitive Nukleotide an

${ }^{2}$ Gene, welche mit der Darmkrebsentstehung assoziiert sind

(Tabelle modifiziert entnommen aus: Dietmaier et al. 1997, S.4751)

Tab.II-3 Charakteristika der verwendeten Primer 
Nachfolgende Tabelle führt alle Primersequenzen für Bestellung und Herstellung der Primer auf:

Tab.Il-4 Sequenzen der verwendeten Primer

\begin{tabular}{|l|l|l|}
\hline Name & Richtung & Sequenz \\
\hline BAT25 & forward & 5' - TCG CCT CCA AGA ATG TAA GT - 3' \\
\hline BAT25 & reverse & 5' - TCT GCA TTT TAA CTA TGG CTC - 3' \\
\hline BAT26 & forward & 5' - TGA CTA CTT TTG ACT TCA GCC - 3' \\
\hline BAT26 & reverse & 5' - AAC CAT TCA ACA TTT TTA ACC C - 3' \\
\hline D5S346 & forward & 5'- ACT CAA TCT AGT GAT AAA TCG GG - 3' \\
\hline D5S346 & reverse & 5' - AGC AGA TAA GAC AGT ATT ACT AGT T - 3' \\
\hline D2S123 & forward & 5' - GCT GGA AGT TCT GGC CAG - 3' \\
\hline D2S123 & reverse & 5' - GAC TTG GAT ACC ATC TAT C - 3' \\
\hline D17S250 & forward & 5' - CAT ACA TAA ACT TTC AAA TGG - 3' \\
\hline D17S250 & reverse & 5' - TTA CAG GCA TGA GCC ACT C - 3' \\
\hline
\end{tabular}

Alle Primer waren mit Fluoreszenz-Farbstoffen (5') 5FAM-up (BAT25, D2S123), Joe-up (BAT26, D17S250) und NED (D5S346) für die anschließende Analyse im Genescan® ABI PRISM 310 Genetic Analyzer markiert.

Die mononukleotiden Marker BAT25 und BAT26 weisen Längenänderungen im Sinne von Instabilität in der Mehrheit der Tumoren auf, welche breitgefächert instabil sind (MSI-H), jedoch seltener in Tumoren, die als MSI-L zu klassifizieren sind (Dietmaier et al. 1997; Hoang et al. 1997). Die Marker BAT26 und D17S250 zeigen die höchste Spezifität für MSI-H-Tumore (Dietmaier et al. 1997).

D5S346 und D2S123 zeigen eine hohe Sensitivität sowohl für MSI-H-Tumore, als auch für MSI-L-Tumore, weniger für MSS-Tumore (Dietmaier et al. 1997).

Die Kombination der Referenzprimer ist in der Lage, vor allem Tumore zu identifizieren, die Ausfälle in den beiden Mismatch-Repair-Genen MSH2 und MLH1 aufweisen, und hat eine 100\%-Sensitivität und -Spezifität für MSI-H-Tumore (Dietmaier et al. 1997). Nachfolgende Tabelle führt auf, welche Materialien von welchem Hersteller bezogen wurden: 
Tab.II-5 Materialien und Hersteller

\begin{tabular}{|l|l|}
\hline Polymerase Taq Platinum & Invitrogen, Darmstadt \\
\hline $10 X$ PCR Puffer ohne $\mathrm{MgCl}_{2}$ & Invitrogen, Darmstadt \\
\hline $50 \mathrm{mM} \mathrm{MgCl}$ & 2 \\
\hline Alle Primer & Invitrogen, Darmstadt \\
\hline Nukleotide & Biometra, Göttingen \\
\hline Gereinigtes Wasser & PeqLab, Erlangen \\
\hline Formamid & Merck, Darmstadt \\
\hline Längenstandard ROX 500 & Applied Biosystems, Darmstadt \\
\hline
\end{tabular}

Für die Amplifizierung wurde ein Thermocycler der Firma Analytik Jena („Flexcycler“) verwendet. Die DNA-Denaturierung wurde in einem DNA Thermal Cycler 480 der Firma Perking Elmer vorgenommen. Die Analyse der Fluoreszenz-markierten PCRProdukte erfolgte in einem Genescan® ABI PRISM 310 Genetic Analyzer. Die Mikrodissektion der posttherapeutischen Proben wurde mit einem PALM Microbeam Laser Microdissecting Microscope von Carl Zeiss, Deutschland, durchgeführt. 


\section{Methoden}

\subsection{Methodenetablierung}

Die eingesetzte DNA-Menge wurde in der Phase der Methodenetablierung von 1 bis $20 \mu \mathrm{g}$ variiert. $\mathrm{Ab} 10 \mu \mathrm{g}$ eingesetzter DNA-Menge war ein Verdünnen des PCRProduktes auf ca. 1:10 Anteilen mit gereinigtem Wasser nötig, bevor die Analyse am Genescan® ABI PRISM 310 Genetic Analyzer durchgeführt werden konnte. Alle Peaks hätten sonst außerhalb der messbaren Peakhöhe gelegen.

Das Temperaturprogramm für die PCR wurde ebenfalls variiert. Die initiale Denaturierung der DNA wurde für $94^{\circ}$ und $95^{\circ}$ getestet bei 2 Minuten und 10 Minuten. Die zyklische Denaturierung wurde für $93-95^{\circ}$ bei 30 Sekunden und einer Minute untersucht. Als Annealing-Temperatur wurden die vom Hersteller genannten $55^{\circ}$ gewählt und der Zeitraum zwischen 30 Sekunden und einer Minute variiert. Als zyklische Extensionszeit wurden eine Minute und 2 Minuten getestet.

30, 35 und 40 Zyklen wurden auf bestmögliche Peakhöhen und Artefaktrate untersucht. Nach anfänglichen Versuchen mit einer Polymerase TaqGold wurde die Polymerase TaqPlatinum als für die Analyse geeigneter befunden. Zur Vereinfachung der Analyse und zur Verkürzung des Zeitaufwandes wurden die drei Primer BAT25, BAT26 und D5S346 in einem gemeinsamen Mastermix für die PCR angesetzt. Die Primer D2S123 und D17S250 wurden einzeln amplifiziert.

Um neu aufgetretene Veränderungen im Tumorgewebe abgrenzen zu können, wurde bei jedem Patienten DNA aus gesundem Mukosagewebe mit DNA aus Tumorgewebe vergleichend untersucht. Prä- und posttherapeutisches Probenmaterial wurde, in Paraffinblöcken eingelassen, konserviert. 


\subsection{Durchführung der Polymerase-Ketten-Reaktion}

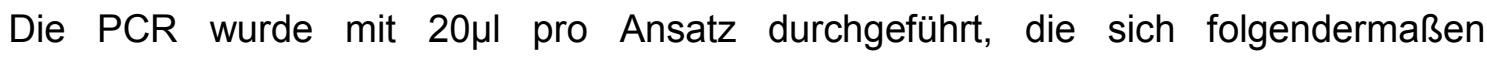
zusammensetzten:

10X PCR Puffer ohne $\mathrm{MgCl}_{2} \quad 2 \mu \mathrm{l}$

$50 \mathrm{mM} \mathrm{MgCl}_{2} \quad 0,6 \mu \mathrm{l}$

$10 \mathrm{mM}$ dNTP $\quad 0,4 \mu \mathrm{l}$

Forward-Primer $(0,1 \mathrm{nmol} / \mu \mathrm{l}) \quad 0,2 \mu \mathrm{l}$

Reverse-Primer $(0,1 \mathrm{nmol} / \mu \mathrm{l}) \quad 0,2 \mu \mathrm{l}$

Taq Platinum $\quad 0,3 \mu l$

Zum Mastermix wurden 5ng/ $\mu$ l Patienten-DNA zugesetzt und das verbleibende Volumen bis $20 \mu \mathrm{l}$ mit gereinigtem Wasser aufgefüllt.

Es wurden folgende Werte für die Amplifizierung im Thermal Cycler gewählt: Erhitzen auf $94^{\circ} \mathrm{C}$ für 2 Minuten für die Aktivierung der Polymerase; anschließend 40 Zyklen mit $94^{\circ} \mathrm{C}$ für 30 Sekunden, $55^{\circ} \mathrm{C}$ für 30 Sekunden und $72^{\circ} \mathrm{C}$ für 1 Minute. Anschließend wurden die Proben für 10 Minuten auf $72^{\circ} \mathrm{C}$ erhitzt und zuletzt für die Erhaltung der DNA auf $4^{\circ} \mathrm{C}$ heruntergekühlt.

\subsection{Analyse des PCR-Produktes}

Für die Analyse Genescan® ABI PRISM 310 Genetic Analyzer wurde ein Ansatz aus

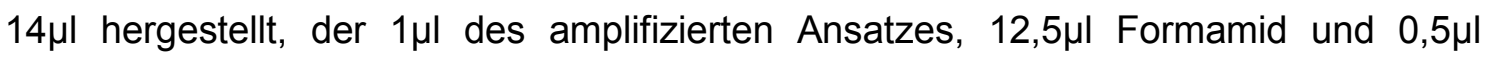
Längenstandard ROX 500 enthielt. Der Ansatz wurde bei $94^{\circ} \mathrm{C}$ für 3 Minuten in einem DNA Thermal Cycler 480 erhitzt, um die DNA zu denaturieren. Im Anschluss wurde der Ansatz für weitere 3 Minuten auf Eis gestellt, um die Einzelstränge zu erhalten und erneutes Aneinanderlagern zu verhindern. Die auf diese Weise vorbereiteten Fluoreszenz-makierten PCR-Produkte wurden hernach in einem Genescan ${ }^{\circledR} A B I$ PRISM 310 Genetic Analyzer analysiert. 


\subsection{Lasermikrodissektion}

In Kooperation mit der Rheinischen Friedrich-Wilhelms-Universität Bonn, Universitätsklinikum, Abteilung Pathologie, wurde für die Analyse von posttherapeutischem Probenmaterial die Methode der Laser Mikrodissektion angewendet, da die Tumorzellen durch die Therapie teilweise stark dezimiert waren. Hierzu wurden Hämatoxylin-Eosin (HE) gefärbte Schnitte von luminalem Tumor, von Tumor der Invasionsfront und von normalem Gewebe HE-gefärbt. Mit einem PALM Microbeam Laser Microdissecting Microscope (Carl Zeiss, Germany) wurden einzelne Zellen mikrodisseziert. Die Laser-Mikrodissektion ermöglicht ein Herauslösen einzelner Tumorzellen aus Geweben, die durch Chemoradiotherapie und dadurch bedingtem Downstaging nur noch wenige Tumorzellen enthalten. Auf diese Weise konnte speziell DNA aus Tumorzellen gewonnen werden, was die Sensitivität der Methode erhöht (Giuffrè et al. 2005). Heterogenität des Gewebes konnte somit ebenfalls berücksichtigt und falsch-negative Fälle nahezu ausgeschlossen werden (Müller et al. 2004b).

Parallel zur Untersuchung auf MSI wurde im Rahmen des Teilprojektes 5 der Klinischen Forschergruppe 179 die bereits erwähnte immunhistochemische Analyse durchgeführt, welche die Mismatch-Repair-Proteinexpression in prä- und posttherapeutischen Proben von MSH2, MSH6, MLH1 und PMS2 ermittelte. Die genauen Ergebnisse dieser Untersuchung sind Gegenstand der Dissertationsarbeit von Herrn Lennard Loweg.

\subsection{Ergebnissicherung und Interpretation der Ergebnisse}

Bei nicht erfolgreichen Amplifizierungen, oder wenn die vom Genescan ${ }^{\circledR}$ Analyzer gemessene Peakhöhe weniger als 400 Fluoreszenzeinheiten betrug, wurde die PCR für die betroffenen Proben wiederholt. Jeder wahre Mikrosatelliten-Peak sollte von Stutterpeaks mit geringerer Intensität umgeben sein, welche im Verlauf der Amplifizierung entstehen. Bei zu kleinen Peaks wurde im weiteren Durchlauf mehr DNA eingesetzt (bis zu 20 $\mu$ g), um ein besseres Ergebnis zu erzielen.

Auffällige oder uneindeutige Befunde wurden ebenfalls wiederholt, um Verunreinigungen, Pipettierfehler oder Ähnliches als Ursache für die Veränderung auszuschließen. Eine Positivkontrolle mit DNA eines Rektumkarzinoms, welches keiner 
Studie zugeordnet war, und eine Negativkontrolle ohne DNA wurden bei jedem Lauf mit eingesetzt.

Zeigte das Tumorgewebe verglichen mit Keimbahngewebe im Amplifikat neue „wahre“ Peaks, so wurde dieser Genort als mikrosatelliteninstabil definiert. Einzelne Peaks ohne Stutterpeaks wurden als nicht-spezifisch betrachtet und unbeachtet gelassen. Stutterpeaks wurden folglich als Ausdruck einer Amplifizierung eines repetitiven Elements innerhalb des Primersets angesehen. Trotz Mikrodissektion ist ein geringer Grad der Verunreinigung der Tumor-DNA mit DNA aus normalem Gewebe nicht zu vermeiden, so dass im Tumorgewebe neben der Mutation auch die KeimbahnBasenpaarlänge abgebildet sein sollte. Für alle Primer mussten für eine jeweilige Probe alle oben genannten Kriterien erfüllt sein, um den Grad der Instabilität (MSI-H, MSI-L oder MSS) sicher feststellen zu können.

Die Interpretation der Ergebnisse erfolgte gemäß den International guidelines for evaluation on MSI in colorectal cancer (Boland et al. 1998) für die fünf ReferenzMarker:

Tab.III-1 Interpretation des Grades an Instabilität

\begin{tabular}{|c|l|}
\hline $\begin{array}{l}\text { Anzahl der Marker, die Instabilität, } \\
\text { bzw. Längenänderungen anzeigen }\end{array}$ & Interpretation \\
\hline$\geq 2$ & MSI-H \\
\hline 1 & MSI-L \\
\hline 0 & MSS oder MSI-L ${ }^{1}$ \\
\hline
\end{tabular}

${ }^{1}$ Die genaue Unterscheidung zwischen MSS oder MSI-L ist nur möglich, wenn mehr als fünf Marker untersucht wurden. 


\section{ERGEBNISSE}

\subsection{Eigene Erfahrungen mit der Untersuchung der Mikrosatelliten}

In der Methodenetablierung der MSI-Analyse stellte sich heraus, dass oftmals DNAMengen von $5 \mu \mathrm{g}$ oder weniger ausreichend waren, um mit einer relativ hohen Zykluszahl von 40 Zyklen gute Ergebnisse zu erzielen. Das Ergebnis war sogar besser, als mit größeren DNA-Mengen und kleineren Zykluszahlen. Es zeigten sich weniger Artefakte und die Peakhöhe überschritt seltener den möglichen abzubildenden Bereich in der graphischen Darstellung. Durch die hohe Zykluszahl produzierte falsch-positive Ergebnisse wurden durch Vergleich mit der Positivkontrolle ausgeschlossen.

Die Tatsache, dass nur wenige $\mu$ g DNA benötigt wurde war sehr von Vorteil in der Analyse der posttherapeutischen Proben. Durch das "Downstaging" des Tumors mittels Chemoradiotherapie waren nur sehr kleine DNA-Mengen zu gewinnen, da nur noch wenige Tumorzellen im Resektat-Gewebe übrig geblieben waren.

Der Primer D2S123 erwies sich in der Etablierungsphase als der Schwierigste. Häufig waren keinerlei Peaks in der graphischen Darstellung sichtbar, wenn die übrigen Primer Peaks zeigten. Gute Ergebnisse konnten erst erzielt werden, als die Polymerase von Taq Gold zu Taq Platinum gewechselt wurde. Nach der Umstellung von Taq Gold auf Taq Platinum verlief die Analyse komplikationslos. Einige Proben mussten wiederholt amplifiziert und analysiert werden, weil keine Peaks vorhanden waren, oder die Peaks zu klein waren. Die Analysen mit den Primern BAT25, BAT26 und D5S346 mussten selten wiederholt werden, mit dem Primer D2S123 in ca. 10\% der Fälle, mit dem Primer D17S250 in ca. 4\% der Fälle.

Die Primer D2S123 und D17S250 wurden einzeln amplifiziert, da sie sich in Mischungen als sehr Artefakt-anfällig zeigten. Die Primer BAT25, BAT26 und D5S346 konnten in einem Mastermix amplifiziert werden. 
Bestmögliche Ergebnisse wurden erzielt mit folgender Zusammensetzung des Mastermixes:

$\begin{array}{ll}\text { 10X PCR Puffer ohne } \mathrm{MgCl}_{2} & 2 \mu \mathrm{l} \\ 50 \mathrm{mM} \mathrm{MgCl}_{2} & 0,6 \mu \mathrm{l} \\ 10 \mathrm{mM} \text { dNTP } & 0,4 \mu \mathrm{l} \\ \text { Forward-Primer }(0,1 \mathrm{nmol} / \mu \mathrm{l}) & 0,2 \mu \mathrm{l} \\ \text { Reverse-Primer }(0,1 \mathrm{nmol} / \mu \mathrm{l}) & 0,2 \mu \mathrm{l} \\ \text { Taq Platinum } & 0,3 \mu \mathrm{l}\end{array}$

Bestmögliche Ergebnisse wurden erzielt mit folgendem Temperaturprogramm:

Erhitzen auf $94^{\circ} \mathrm{C}$ für 2 Minuten,

40 Zyklen mit $94^{\circ} \mathrm{C}$ für 30 Sekunden,

$55^{\circ} \mathrm{C}$ für 30 Sekunden,

$72^{\circ} \mathrm{C}$ für 1 Minute,

Erhitzen auf $72^{\circ} \mathrm{C}$ für 10 Minuten,

Gekühlt halten bei $4^{\circ} \mathrm{C}$.

\subsection{Ergebnisse prätherapeutisch}

Von insgesamt 65 prätherapeutisch untersuchten Proben zeigten sich in 6 Fällen ein loss of heterozygosity (LOH). In einem Fall wurde MSI gefunden: MSI-L, da die Instabilität nur in einem Marker zu finden war, im Marker Mfd15CA (D17S250). MSI-H wurde bei keinem Patienten gefunden. Beim selben Patienten, der im Marker Mfd15CA (D17S250) instabil war, wurde LOH im Marker APC (D5S346) gefunden. 
Tab.IV-1 Ergebnisse prätherapeutisch CAO/ARO/AIO-94-Studie und CAO/ARO/AIO04-Studie

\begin{tabular}{|l|c|c|c|}
\hline Name (Lokus) & Fälle LOH & Fälle MSI-L & Fälle MSI-H \\
\hline BAT25 & 0 & 0 & 0 \\
\hline BAT26 & 0 & 0 & 0 \\
\hline APC (D5S346) & 3 & 0 & 0 \\
\hline AFM093xh3 (D2S123) & 3 & 0 & 0 \\
\hline Mfd15CA (D17S250) & 0 & 1 & 0 \\
\hline
\end{tabular}

Zu nachfolgenden Abb.IV 1-4

Nachfolgende Graphiken zeigen Beispiele für alle verwendeten Primer und Beispiele für LOH und MSI an. Die x-Achse einspricht der Basenpaargröße, die y-Achse den Fluoreszenzeinheiten. Graue Peaks zeigen Mikrosatelliten des Normalgewebes, rote Peaks zeigen Mikrosatelliten des Tumorgewebes. Die zwei höchsten Peaks stellen die Allele dar, die umgebenden Peaks sind Stutterpeaks. Graue Peaks ohne Überlagerung von roten Peaks bedeuten den Verlust eines Allels im Tumorgewebe (LOH). Zusätzliche rote Peaks ohne Überlagerung von grauen Peaks mit Höhendifferenzen zwischen grauen und roten Peaks zeigen Mikrosatelliteninstabilität. 

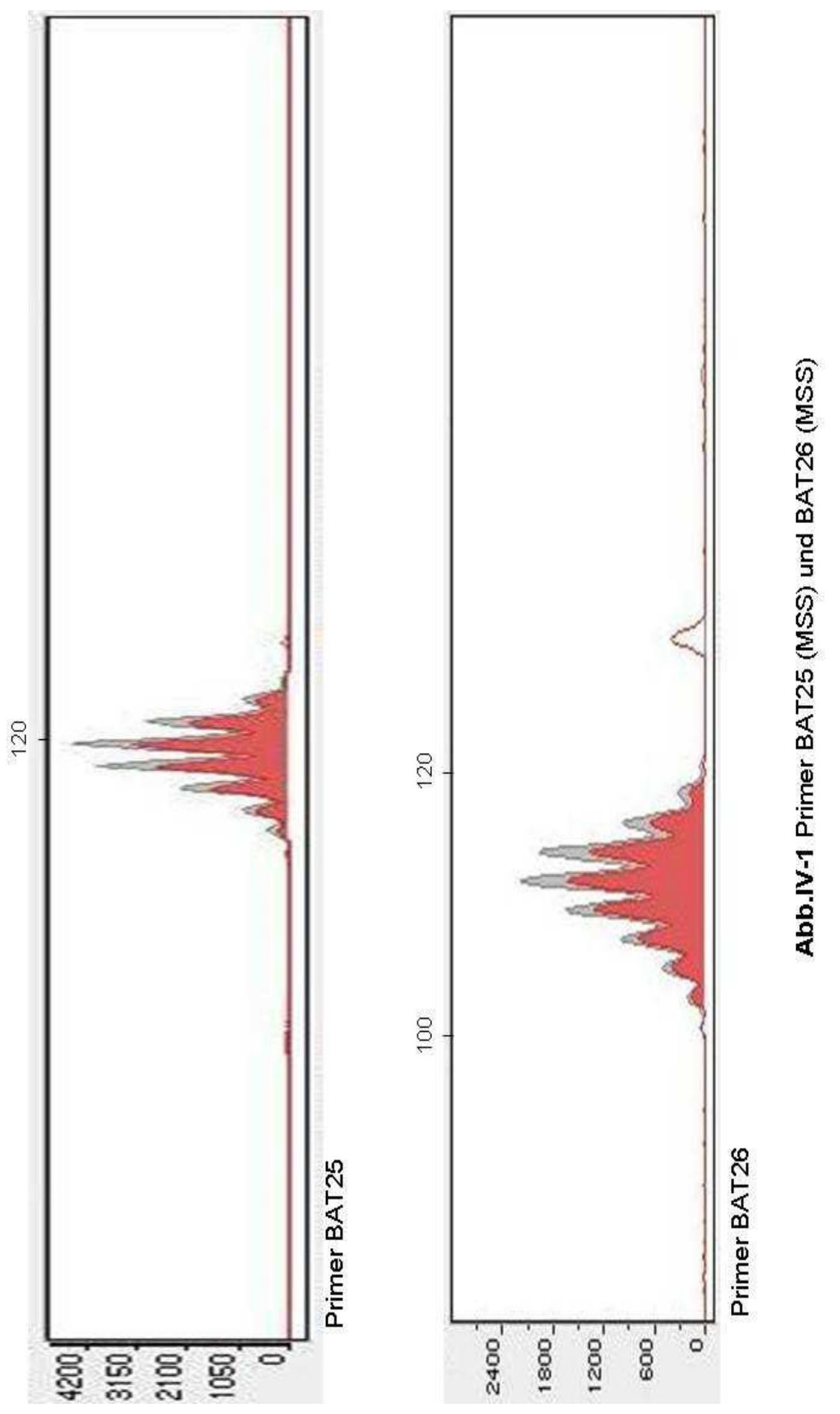

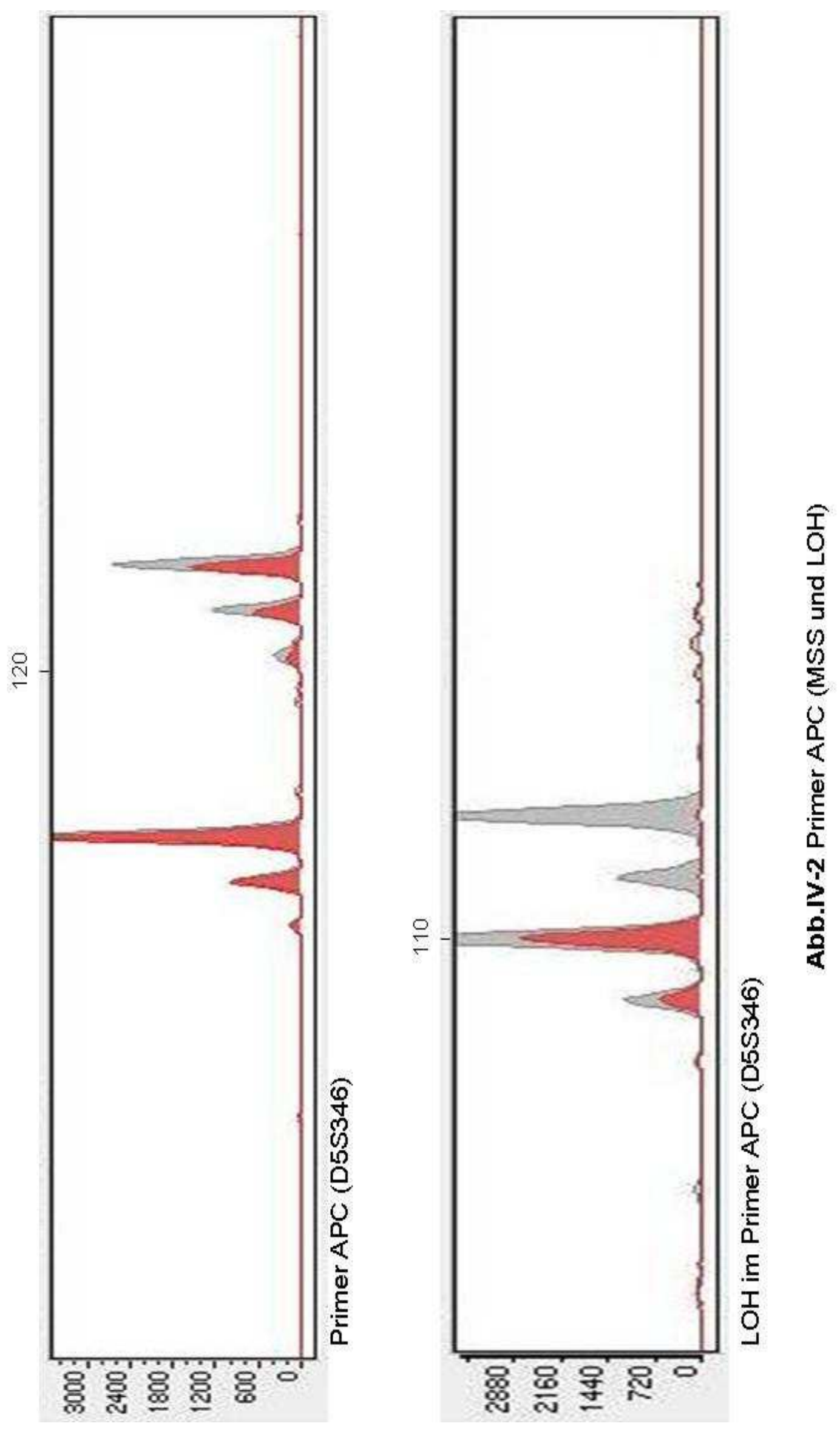

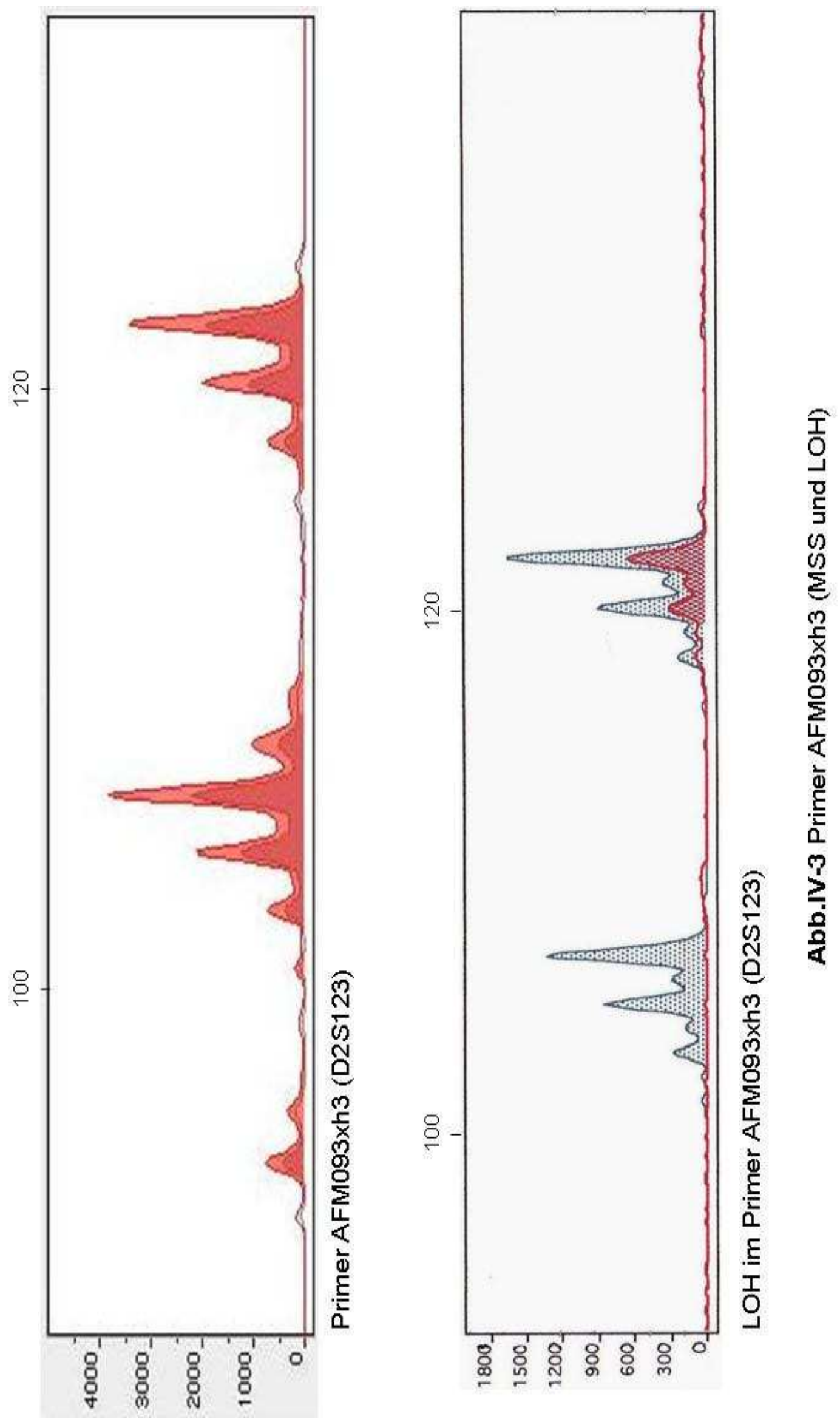

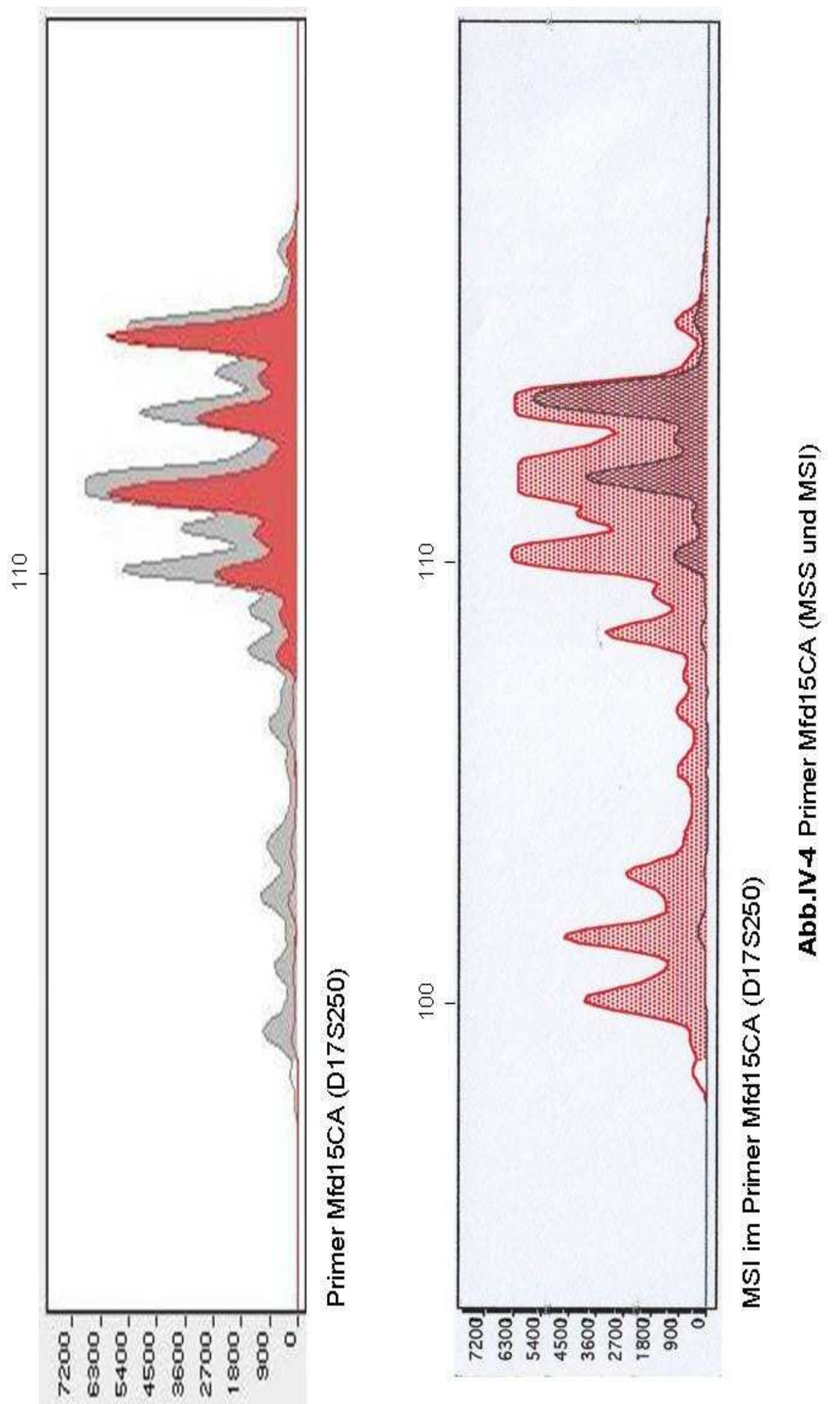


\subsection{Ergebnisse posttherapeutisch}

Aus den 37 immunhistochemisch durch ausgeprägte Reduktion von MSH6 auffälligen posttherapeutischen Fällen waren 7 für die MSI-Analyse ausgewählt worden (immunhistochemische Analyse durch Mitarbeiter des Teilprojektes 5 der KFO 179). Diese wiesen noch genügend residuelles Tumorgewebe nach erfolgter Chemoradiotherapie auf, um die Untersuchung durchführen zu können. Sowohl superfizial gelegenes Tumorgewebe, wie auch Gewebe des tiefen Tumorinvasionsrandes wurden mit Normalgewebe verglichen.

Von diesen 7 Fällen zeigten 2 einen MSI-L-Phänotyp mit DNA-Veränderungen in einem von den fünf getesteten Loci für MSI. Bei den betroffenen Markern handelte es sich um Mfd15CA (D17S250) und BAT25. In einem Fall stieg der Grad der Veränderung mit der Invasionstiefe des Tumors, was in der Immunhistochemie parallel als Reduktion von MSH6 auffiel.

MSI-L zeigte somit eine erhöhte Frequenz nach Chemoradiotherapie und war mit zunehmender Invasionstiefe des Tumors ausgeprägter. 

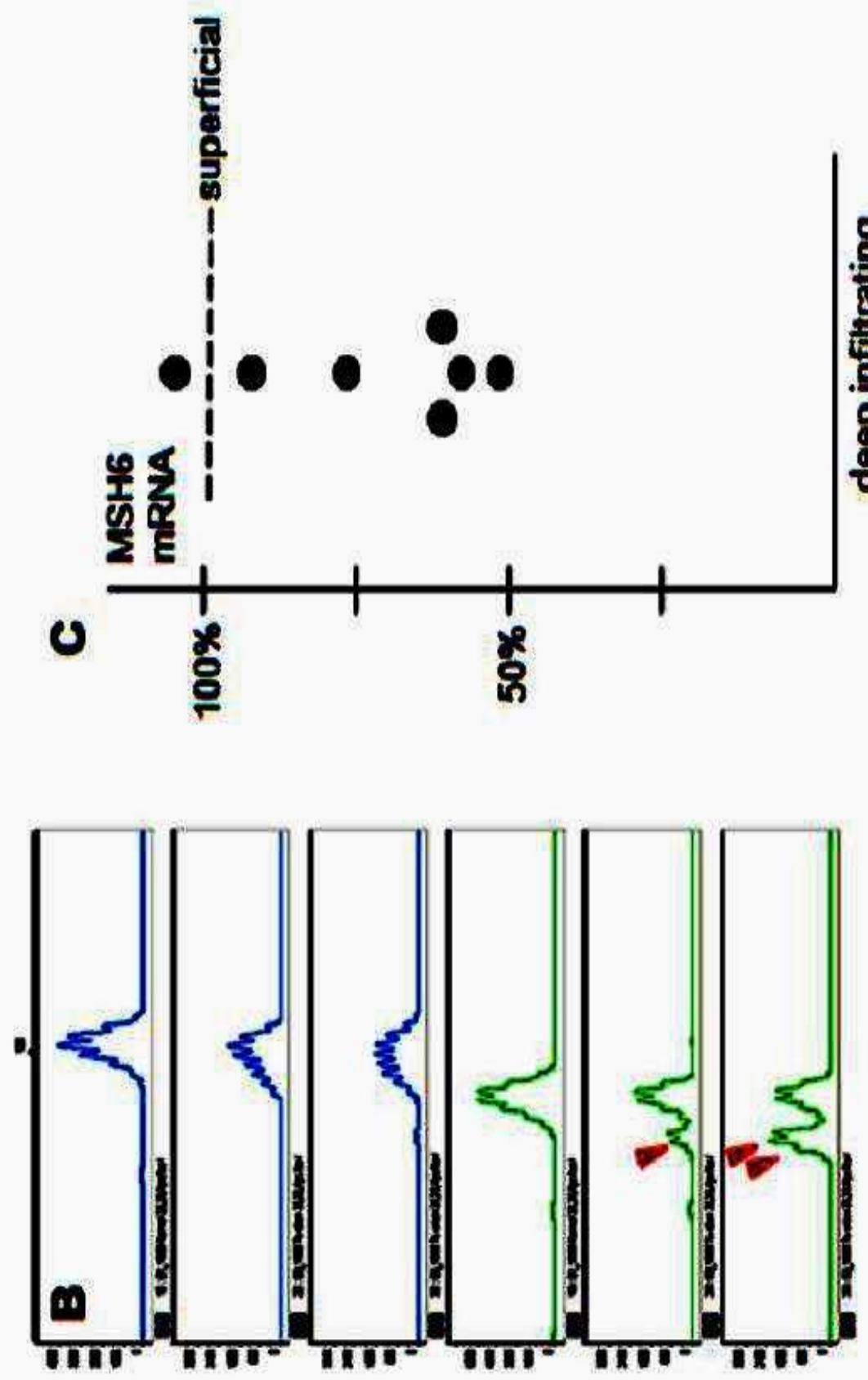

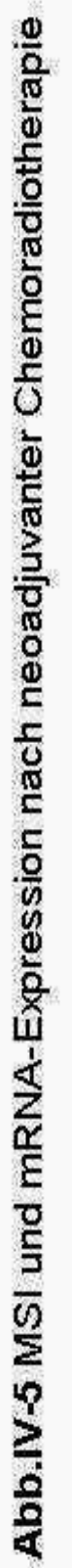

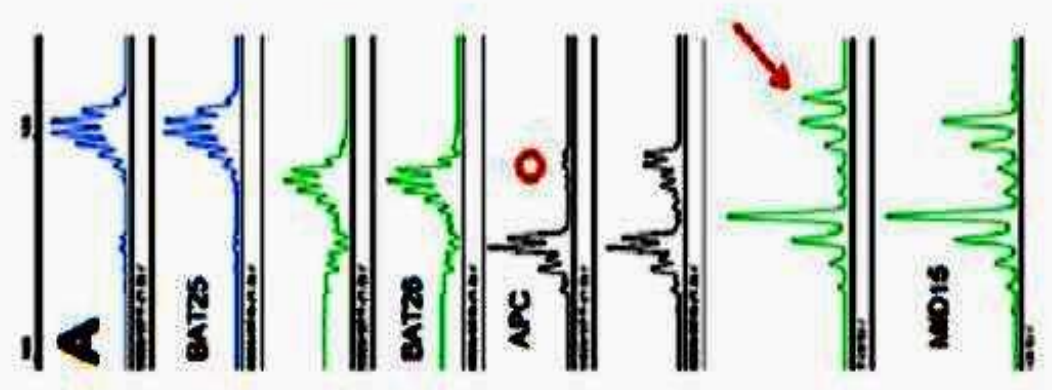




\section{Zu Abb.IV-5}

Mikrosatelliteninstabilität und mRNA-Expression an der tiefen Invasionsfront nach neoadjuvanter Chemoradiotherapie. (Die mRNA-Expressionsanalyse ist ebenfalls von Mitarbeitern des Teilprojektes 5 der KFO 179 durchgeführt worden.)

A \& B: In zwei Karzinomen werden DNA-Veränderungen mit neuen Peaks im Primer MfD15 und im Primer BAT25 sichtbar. Die Stärke der DNA-Veränderungen nimmt mit der Tiefe der Tumorinvasion zu.

A: Der Pfeil zeigt die DNA-Veränderungen des Tumors an, der Kreis zeigt loss of heterozygositiy (LOH) im APC-Primer.

B: Die obere grüne Kurve zeigt normale DNA, die mittlere grüne Kurve zeigt eine DNAAnalyse aus superfizial gelegenen Tumorzellen. Die untere grüne Kurve zeigt DNA von der tiefen Infiltration des Gewebes durch den Tumor.

C: Dargestellt ist der Vergleich der MSH6-mRNA-Expression an der tiefen Invasionsfront des Tumors im Gegensatz zur Expression in oberflächlich gelegenen Tumorzellen. Die Expression der MSH6-mRNA zeigte sich an der tiefen Invasionsfront um bis zu $45 \%$ reduziert. Die Datenerhebung erfolgte mittels RT-PCR.

(Anmerkung: Eine Veröffentlichung der Abb.IV-5 und der Ergebnisse des Teilprojektes 5 der KFO 179 befindet sich in Vorbereitung und wird voraussichtlich von Spitzner et al. unter dem Titel „Acquired mismatch repair deficiency after neoadjuvant treatment of rectal cancer." erscheinen.) 


\section{DISKUSSION}

\subsection{Bezugnahme zur Eingangsfragestellung, Ergebnisse und ableitbare Thesen}

In der vorliegenden Arbeit wurde der Fragestellung nachgegangen, ob die neoadjuvante Chemoradiotherapie einen Effekt auf den MSI-Status ausübt. Des Weiteren wurde hinterfragt, ob vor dem Hintergrund der Entwicklungen in der Therapie des Rektumkarzinoms MSI ein geeigneter Prädiktor und Biomarker für das Ansprechen auf Chemoradiotherapie, für den Verlauf der Erkrankung und für das Überleben sei.

Unter der Voraussetzung, dass die neoadjuvante Therapie von Rektumkarzinomen in den letzten Jahrzehnten immens an Bedeutung gewonnen und das ausschließlich adjuvante Therapiekonzept abgelöst hat, sollen die Zielfragen dieser Arbeit nun eine Antwort finden:

\section{Hat die neoadjuvante Chemoradiotherapie einen Effekt auf den MSI- Status?}

Interessanterweise konnte ein Effekt der Chemoradiotherapie auf die Mikrosatelliten der Tumor-DNA festgestellt werden: Rektumkarzinome zeigen eine erhöhte Frequenz an MSI-L nach neoadjuvanter Chemoradiotherapie.

Von 7 beispielhaft ausgewählten posttherapeutischen Proben zeigten 2 einen MSI-LPhänotyp (einer von 5 Markern positiv auf MSI getestet). Dieser MSI-L-Phänotyp war prätherapeutisch nicht nachweisbar gewesen. DNA-Veränderungen zeigten einmal der Marker MfD15 (D17S250) und einmal der Marker BAT25. In einem Fall war mit zunehmender Infiltrationstiefe des Tumors eine Zunahme der Veränderungen in den Mikrosatelliten zu beobachten.

In der parallel durch Mitarbeiter des Teilprojektes 5 der KFO 179 durchgeführten immunhistochemischen Untersuchung fiel eine Reduktion von MSH2 und MSH6 auf. MLH1 und PMS2 zeigten sich unverändert. Die stärkste Reduktion zeigte aber MSH6. Eine Korrelation von reduzierter Expression des MMR-Gens und der Tiefe der Invasionsfront konnte hergestellt werden. Dies fiel vor allem bei MSH6 auf. MSH6 
schien an der tiefen Invasionsfront gar nicht mehr exprimiert zu werden. Da die 2 Patienten, die posttherapeutisch MSI-L aufwiesen, prätherapeutisch keine Instabilitäten zeigten, lässt sich die Schlussfolgerung ziehen, dass der posttherapeutische MSI-LPhänotyp aufgrund einer ausgeprägten Reduktion der MSH6-Expression entstanden ist. Die Ergebnisse lassen vermuten, dass die reduzierte MSH6-Expression im Rektumkarzinom wiederum durch neoadjuvante Chemoradiotherapie induziert worden ist.

\section{Ist der MSI-Status als Biomarker und Prädiktor für das Überleben und das Ansprechen auf die Therapie geeignet?}

MSI ist für kolorektale Karzinome als prognostisch günstiger Marker anerkannt. Es wurde beobachtet, dass durch neoadjuvante Chemoradiotherapie ein MSI-L-Phänotyp induziert werden kann. Die Eignung als Biomarker für das Überleben muss unter neuen Gesichtspunkten betrachtet werden und kann an dieser Stelle keine eindeutige Beantwortung finden, da die Entdeckung eines Chemoradiotherapie-induzierten MSIL-Phänotyps wiederum zu viele neue Fragen aufwirft.

MSI entsteht in den meisten Fällen sporadisch und bedeutet einen Überlebensvorteil für den Patienten. Nun stellt sich die Frage, ob dies auch für Karzinome gilt, welche eine Instabilität in den Mikrosatelliten erst durch die Therapie erhalten. Könnte dies eine zusätzliche Prognoseverbesserung bedeuten? Dem entgegen spricht die Tatsache, dass es sich um MSI-L handelt und nicht um MSI-H. Denn die meisten Studien, die eine Prognoseverbesserung fanden, untersuchten Patienten mit MSI-H (Sinicrope et al. 2006; Roth et al. 2009). Das Ergebnis der hier vorliegenden Untersuchung war, dass MSI-L ohnehin in Rektumkarzinomen sehr selten auftritt $(1,5 \%)$. In jedem Fall wird also nur eine sehr kleine Subgruppe der Rektumkarzinompatienten betroffen sein, was die Forschung zum Thema MSI als Biomarker für das Überleben erschwert.

Auch bleibt die Frage unbeantwortet, zu welchem Zeitpunkt in der Karzinogenese eine Defizienz des MMR-Systems entstehen muss, um für den Patienten einen Überlebensvorteil auszumachen. Wirkt sich eine früh spontan in der Karzinogenese entstandene Mikrosatelliteninstabilität anders auf das Karzinom aus als eine Therapieinduzierte Instabilität? Sehr viele Fragen müssen offen bleiben und können als Grundlage für sich anschießende Forschung verstanden werden. Gezeigt hat sich, 
dass der MSI-Status durch äußere Faktoren beeinflussbar ist. Ein Rückschluss auf die Prognose sollte mit Vorsicht gezogen werden.

Eine Eignung von MSI als Prädiktor für eine mögliche Chemoresistenz gegen 5-FU zeichnet sich aus den vorliegenden Ergebnissen der CAO/ARO/AIO-04-Studie ab. Die Ursache der Instabilität der Mikrosatelliten ist die MMR-Defizienz, in diesem Fall wurde besonders MSH6 als defizient beobachtet. In 31 Fällen neoadjuvant behandelter Patienten der CAO/ARO/AIO-04-Studie konnte bereits ein Vergleich zwischen Überleben und veränderter Expression von MSH6 an der tiefen Infiltrationsfront des Tumors gezogen werden. Tumore mit reduzierter Expression von MSH6 (20 Fälle mit einer Expression unter 40\% des Normalen) verursachten ein verkürztes rezidivfreies Überleben. Patienten mit verminderter MSH6-Expression hatten in $46 \%$ ein rezidivfreies Überleben über einen Zeitraum von 54 Monaten. Patienten mit unveränderter MSH6-Expression hatten in $63 \%$ ein rezidivfreies Überleben über 54 Monate.

Der Tumorregressionsgrad zeigte ebenfalls Unterschiede. Patienten mit verminderter MSH6-Expression erreichten in 30\% der Fälle eine Tumorregression Grad III. Patienten mit unveränderter MSH6-Expression erreichten in 46\% der Fälle eine Tumorregression Grad III.

Diese Daten lassen keinen direkten Rückschluss zu, ob ein verkürztes rezidivfreies Überleben und eine weniger starke Tumorregression bei Patienten mit verminderter MMR-Expressivität tatsächlich auf eine Chemoresistenz gegen 5-FU zurückzuführen sind. Eine Verbindung erscheint aber möglich, da für MMR-defiziente Patienten ein schlechteres Ansprechen auf 5-FU vorbeschrieben ist (Jover et al. 2009; Sargent et al. 2010). Ebenfalls wurde bei Patienten mit Mammakarzinomen beobachtet, dass nach neoadjuvanter Chemotherapie mit Cyclophosphamid, Adriamycin und 5-FU die Anfärbbarkeit der Gewebeschnitte für MLH1, MSH2, MSH6 und PMS2 deutlich reduziert war gegenüber den prätherapeutischen Schnitten (Chintamani et al. 2007). Die vorliegenden Daten legen nahe, dass der neue Mechanismus einer Therapieinduzierten MMR-Defizienz in Zukunft als Marker für eine Prognose wesentlich an Bedeutung gewinnen kann. Auch sind Auswirkungen auf das Therapiekonzept für diese Patienten möglich, z.B. in Form einer verstärkten adjuvanten Behandlung oder einer Subgruppen-spezifischen Auswahl der verabreichten Chemotherapeutika. 
Aus den Ergebnissen der Untersuchung von Mikrosatelliten an DNA aus Rektumkarzinomen vor und nach neoadjuvanter Chemoradiotherapie lassen sich folgende Thesen ableiten:

1. MSI-H ist in Rektumkarzinomen selten zu beobachten.

2. Rektumkarzinome zeigen eine erhöhte MSI-L-Frequenz nach neoadjuvanter Chemoradiotherapie.

\subsection{Methode zur MSI-Analyse}

Die Grundlage aller Ergebnisse und ihrer Interpretation ist die Methode, mit der man die Ergebnisse gewonnen hat. Die vorliegenden Daten haben gezeigt, dass äußerste Sorgfalt nötig ist, um in der MSI-Analyse zu sicheren Ergebnissen zu kommen. Das durch neoadjuvante Therapie erzielte Downstaging der Tumore stellt neue Anforderungen an die Analyse der Mikrosatelliten.

Untersuchungen von Giuffrè et al. (2005) an Adenomen des Kolorektums zeigten, dass die Ergebnisse einer MSI-Analyse davon abhängig sind, ob Lasermikrodissektion zur DNA-Gewinnung verwendet wird oder die DNA unter makroskopischer Kontrolle aus dem Tumor heraus präpariert wird. Das immunhistochemische Expressionsmuster der MMR-Proteine zeigte größere Übereinstimmung mit dem MSI-Status, wenn als Methode zur DNA-Gewinnung die Lasermikrodissektion angewendet wurde. Außerdem ergab sich eine Umverteilung der MSI-H- und MSI-L-Fälle je nach Methode. Dieselben Gewebeproben ergaben bei makroskopisch gewonnener TumorDNA eine Verteilung von $50 \%$ MSI-H-Fällen (9 von 18 ) vs. $11,1 \% \mathrm{MSI}-\mathrm{L}$ (2 von 18). Nach Lasermikrodissektion ergab sich eine Verteilung von 83,3\% MSI-H (15 von 18) vs. $5,6 \% \mathrm{MSI}-\mathrm{L}$ (1 von 18). (Giuffrè et al. 2005)

Die Arbeit über Adenome zeigt, dass nicht nur die Frage, ob ein Tumor MSI- positiv ist oder nicht, davon abhängt, welche Methode zur DNA-Gewinnung verwendet wurde. Auch eine Ausdifferenzierung des MSI-Status in MSI-H oder MSI-L wird davon beeinflusst.

Für die Mikrosatellitenanalyse im Rektumkarzinom nach neoadjuvanter Chemoradiotherapie geht es bisher im Wesentlichen darum, überhaupt noch Tumorzellen zu finden, die einer Untersuchung unterzogen werden können. Das vorbehandelte Gewebe weist nur noch sehr wenige Tumorzellen auf, die durch eine 
HE-Färbung sichtbar gemacht werden müssen. Die Untersuchungen an Adenomen haben gezeigt, dass unter Lasermikrodissektion mehr MSI-H- und weniger MSI-LFälle gefunden wurden. Bezogen auf meine Ergebnisse heißt das, dass die MSI-LFälle, die sich, durch die Therapie induziert, manifestiert haben, mit großer Wahrscheinlichkeit tatsächlich MSI-L-Fälle sind. Allerdings ist unter diesen Voraussetzungen die Vergleichbarkeit der posttherapeutischen Proben mit prätherapeutischem Probenmaterial eingeschränkt zu bewerten. Alle prätherapeutischen Proben wurden durch makroskopische Kontrolle gewonnen. Nur eine Probe zeigte prätherapeutisch einen MSI-L-Phänotyp. Möglicherweise hätten sich unter Lasermikrodissektion noch weitere Proben gefunden, die einen MSI-L-Phänotyp aufgewiesen hätten. Durch Lasermikrodissektion besteht die gewonnene DNA zuverlässiger nur aus Tumor-DNA mit einer geringeren Wahrscheinlichkeit von Verunreinigungen mit DNA aus Normalgewebe.

Lasermikrodissektion als Methode um unterschiedliche Schichten eines Tumorgewebes getrennt voneinander untersuchen zu können, wurde bereits an unterschiedlichen Karzinomtypen getestet, z. B. an Mammakarzinomen und malignen Melanomen (Zhu et al. 2003; Roesch et al. 2003). Die Methode erwies sich als geeignet, um unterschiedliche Genexpressionen im Zentrum und in der Peripherie eines Tumors darzustellen. Oku et al. (2008) untersuchten im kolorektalen Karzinom unterschiedliche Genexpressionen, die zu einer Dedifferenzierung von Tumorzellen führten und verglichen superfizial gelegenes mit Tumorgewebe der Invasionsfront. Lasermikrodissektion der Tumorzellen wurde auch hier erfolgreich eingesetzt.

Lasermikrodissektion als Mittel zur Differenzierung zwischen Zellen unterschiedlicher Tumorschichten ist bereits mehrfach erfolgreich eingesetzt worden. Dies unterstützt die Sicherheit der vorliegenden Ergebnisse, da sich in der Immunhistochemie unterschiedliche Expressionsmuster der MMR-Gene zeigten, je nachdem, ob die Tumorzellen superfizial oder an der tiefen Invasionsfront gelegen waren.

Die Marker für die PCR wurden gemäß den Richtlinien für die HNPCC-Diagnostik ausgesucht (Boland et al. 1998). Diese Kombination aus Referenzprimern detektiert vor allem Tumore, welche Ausfälle in MLH1 und MSH2 aufweisen (Dietmaier et al. 1997). Da dies die häufigsten mutierten HNPCC-auslösenden MMR-Gene sind, ist das Panel sinnvoll ausgewählt. Die Sensitivität und Spezifität für MSI-H-Tumore beträgt bei den fünf Referezprimern 100\% (Dietmaier et al. 1997). 
Für zukünftige Untersuchungen zum MSI-Status an prä- und posttherapeutisch gewonnenen Proben, wäre es zweckdienlich ein Panel von Primern auszuwählen, das Ausfälle von MSH6 besser identifizieren kann und eine hohe Sensitivität und Spezifität für MSI-L-Tumore hat. In den posttherapeutischen Ergebnissen zeigte sich, dass die MSI-L-Phänotypen in den Markern D17S250 und BAT25 vorlagen. Da beide Marker eher hohe Sensitivität und Spezifität für MSI-H-Tumore haben, widerspricht dieses Ergebnis eher der Annahme, dass das Referenz-Panel weniger geeignet ist um MSIL-Tumore zu identifizieren. In diesem Punkt besteht weiterhin Forschungsbedarf.

\subsection{Häufigkeit von MSI-H in Rektumkarzinomen}

MSI-L wurde von 65 prätherapeutisch untersuchten Proben nur in einem Fall gefunden, was einem Gesamtanteil von 1,5\% entspricht. Der MSI-L Fall war im Marker D17S250 zu beobachten. MSI-H wurde bei keinem Patienten beobachtet.

Meine Untersuchungen an prätherapeutischen Proben haben Ergebnisse gezeigt, die mit bisherigen Beobachtungen in der Forschung übereinstimmen. MSI tritt in Rektumkarzinomen nur in $1-7 \%$ der Fälle auf, wie vorausgegangene Studien bestätigen (Kalady et al. 2009; Hoogerbrugge et al. 2003; Fernebro et al. 2002; Nilbert et al. 1999).

Kalady et al. (2009) untersuchten DNA von 357 Patienten, von denen 268 ein Kolonkarzinom und 89 ein Rektumkarzinom hatten. Insgesamt wiesen 22,1\% aller kolorektalen Karzinome MSI-H auf. Den weitaus größeren Anteil dabei stellten aber die Kolonkarzinome, von denen insgesamt 27,2\% (73 Patienten) MSI-H zeigten. Von den 73 MSI-H-Fällen entfielen 21 auf Patienten mit Verdacht auf HNPCC-Syndrom, was einen Anteil von 28,8\% ausmacht.

Von allen Rektumkarzinomen war in lediglich 6,7\% (6 Patienten) MSI-H zu finden. Zudem lag bei allen 6 Patienten der starke Verdacht auf ein HNPCC-Syndrom vor.

Man kann somit schlussfolgern, dass sporadisch entstandene MSI-H in Rektumkarzinomen vermutlich sehr selten $\mathrm{zu}$ beobachten ist. Findet sich in Rektumkarzinomen ein MSI-H-Fall, ist im Umkehrschluss die Wahrscheinlichkeit größer, dass es sich ursächlich um ein HNPCC-Syndrom handeln könnte, als in Kolonkarzinomen mit MSI-H-Status.

$\mathrm{MSI}-\mathrm{H}$ hat, wie dieses Ergebnis zeigt, eine sehr geringe Bedeutung in Rektumkarzinomen. 


\subsection{Phänotyp MSI-L und LOH}

Der prätherapeutische Fall, welcher MSI-L aufwies, zeigte sich im Marker D17S250. Dieser Marker ist in vorangegangenen Untersuchungen schon mehrfach bei sporadischen MMR-Veränderungen auffällig gewesen (Angaben mündlich nach Prof. Dr. J. Rüschoff).

MSI-L wurde bereits in unterschiedlichen Tumorentitäten beobachtet und zeigt bei kolorektalen Karzinomen dieselben molekularen Merkmale, wie Mikrosatelliten-stabile Tumore (Dietmaier et al. 1997; Laiho et al. 2002; Halford et al. 2003).

In einer Studie von Laiho et al. (2002) wurde geprüft, ob das Panel aus den fünf Referenz-Primern sensitiv für MSI-L Fälle ist. Laiho et al. (2002) untersuchten 90 Gewebeproben kolorektaler Karzinome. Diese 90 Fälle waren zuvor aus einer Gruppe von 1044 Fällen ausgewählt worden. Sie hatten sich dadurch ausgezeichnet, dass alle 90 Fälle im Marker BAT26 stabil gewesen waren. Der mononukleotide Marker BAT26 zeigt von den fünf Referenz-Primern die höchste Spezifität für MSI-H-Fälle (Dietmaier et al. 1997). Diese so ausgewählten Fälle wurden in 377 weiteren Markern untersucht mit der Zielsetzung, die Rate an MSI-L-Tumoren in einem großen Panel zu bestimmen und mit anderen Genveränderungen zu korrelieren. In $79 \%$ der Fälle wurde Mikrosatelliteninstabilität entdeckt, die Zahl der veränderten Genorte variierte zwischen 1-11. Die initiale Untersuchung mit den fünf Bethesda-Referenzprimern hatte in $7 \%$ Mikrosatelliteninstabilität gezeigt. Auch war auffällig, dass nur dinukleotide Marker instabil waren. Als signifikant wurde beobachtet, dass mit ansteigendem Patientenalter die Rate an MSI zunahm. Betreffend der Rate an KRAS-Mutationen, Promotor-Hypermethylierung und LOH konnte kein Unterschied zwischen MSI-L- und MSS-Fällen festgestellt werden.

Bezüglich der Häufigkeit von KRAS-Mutationen in MSI-L-Tumoren und MSS-Tumoren sind die Forschungsergebnisse sehr unterschiedlich. Eine Arbeitsgruppe beobachtete, dass MSI-L-Fälle häufiger KRAS-Mutationen aufweisen, als MSS-Fälle (50\% vs. $30 \%$ ) (Konishi et al. 1996). Auch eine identische Häufigkeit in MSI-L- und MSS-Tumoren wurde beobachtet (Ward et al. 2001), sowie eine niedrigere Frequenz in MSI-LTumoren, als in MSS Tumoren (29\% vs. 35\%) (Gebert et al. 2000).

Laiho et al. (2002) haben gezeigt, dass die Sensitivität des typischerweise benutzten Panels für MSI-L-Fälle sehr gering ist und das MSI-L viel häufiger in Karzinomen vorkommt, als es auf diese Weise detektiert werden kann. Der in meinen Untersuchungen prätherapeutisch aufgetretene MSI-L-Fall ist nicht als Sonderfall zu 
betrachten. Wäre ein größeres Primer-Panel verwendet worden, hätten wahrscheinlich weit mehr Fälle MSI-L gezeigt. Laiho et al. (2002) haben beschrieben, dass das hier verwendete Primer-Panel aus den 5 Referenzprimern nur in 7\% der Fälle MSI-L finden kann vs. $79 \%$ mit einem großen Panel von 377 Markern an den selben Proben. Die Vergleichbarkeit wird dadurch eingeschränkt, dass Laiho et al. (2002) kolorektale Karzinome als gemeinsame Entität betrachtet haben, die in dieser Arbeit untersuchten Proben aber ausschließlich Rektumkarzinome sind. MSI tritt in Rektumkarzinomen in 1-7\% der Fälle auf, in Kolonkarzinomen hingegen in 27\% der Fälle (Kalady et al. 2009; Hoogerbrugge et al. 2003; Fernebro et al. 2002; Nilbert et al. 1999). Würde man die Studie ausschließlich an Rektumkarzinomen wiederholen, käme sicherlich ein kleinerer Prozentsatz als 79\% an MSI-L-Tumoren heraus, da das Gesamtvorkommen von MSI, MSI-L oder MSI-H in Rektumkarzinomen wesentlich seltener ist. Trotzdem kann angenommen werden, dass bei einem größeren Panel mehr als ein MSI-L-Fall aufgetreten wäre.

In der Studie von Laiho et al. (2002) zeigten sich die Instabilitäten ausschließlich in dinukleotiden Markern. Auch der MSI-L-Fall meiner Ergebnisse war in einem dinukleotiden Marker (D17S250) sichtbar geworden.

Der Patient, bei dem ich MSI-L fand, liegt in der Gruppe der 70-79jährigen zum Zeitpunkt der Diagnosestellung. Dies ist konsistent mit der Beobachtung von Laiho et al. (2002), dass die Rate an MSI-L mit steigendem Alter zunimmt.

Promotor-Hypermethylierung, z. B. der CIMP, ist typischerweise im Entstehungsweg sporadisch entstandener MSI-Tumore zu finden (Toyota et al. 1999). Da beim MSI-LStatus eher von einer sporadischen Genese ausgegangen werden kann, als von einer erblichen Komponente, kann die Promotor-Hypermethylierung als Ursache für den MSI-L Fall in Frage kommen. In Rektumkarzinomen als eigene Entität ist eine Promotor-Hypermethylierung jedoch seltener als in der Gesamtheit aller kolorektaler Karzinome (Kalady et al. 2009; O'Brien et al. 2006). Laiho et al. (2002) konnten keinen Unterschied in der Rate der Promotor-Hypermethylierung zwischen MSI-L-Tumoren und MSS-Tumoren feststellen. Dies spricht mehr dafür, dass die PromotorHypermethylierung nicht die häufigste Ursache für die Entstehung von MSI-L-Tumoren ist. Es wäre sonst eine höhere Rate von Promotor-Hypermethylierung in MSI-LTumoren zu erwarten gewesen.

KRAS-Mutationen sind häufig in Kombination mit MMR-Mutationen bei HNPCCPatienten zu finden und sind untypisch für sporadisch entstandene, instabile Tumore (Gryfe et al. 1997; Ogino et al. 2009). Laiho et al. (2002) fanden keine Unterschiede in 
der KRAS-Mutationsrate zwischen MSS- und MSI-L-Tumoren. Die Assoziation von KRAS-Mutationen mit HNPCC und die nicht erhöhte Mutationsrate in MSI-L-Tumoren gegenüber MSS-Tumoren machen eine KRAS-Mutation als Ursache für den MSI-LFall unwahrscheinlich. Es gibt sehr unterschiedliche Beobachtungen bezüglich der Häufigkeit von KRAS-Mutationen in MSI-L-Tumoren. Daher kann trotz der zwei dagegen sprechenden Beobachtungen eine KRAS-Mutation als Ursache für den MSIL-Phänotyp nicht ausgeschlossen werden.

Laiho et al. (2002) hatten keine Unterschiede in der Häufigkeit von LOH bei MSS- und MSI-L-Tumoren gesehen. In einer weiteren Studie zum Thema LOH von Chang et al. (2005) wurde über LOH als unabhängigen prognostischen Faktor für das Überleben von Patienten mit kolorektalen Karzinomen geforscht. Es wurde gezeigt, dass MSI-HTumore eine niedrigere Frequenz von LOH aufweisen, als MSI-L-/ MSS-Tumore. Die Schlussfolgerung hieraus lautete, dass dinukleotide Primer, die sensitiver für MSI-L sind, ein hohes Potential haben, Informationen über LOH in einer Zelle bereitzustellen. In den von mir prätherapeutisch untersuchten kolorektalen Karzinomen fand sich in 9,3\% LOH. Alle 6 Fälle waren in dinukleotiden Primern aufgetreten (D5S346, D2S123, D17S250). Diese Beobachtungen finden folglich Übereinstimmung und lassen den Wert der MSI-L- und LOH-Untersuchungen in Rektumkarzinomen höher steigen, da MSI-H hier keine große Bedeutung hat.

$\mathrm{LOH}$ als Prognosefaktor und seine Rolle in der Karzinogenese ist in mehreren Studien untersucht worden (Jernvall et al. 1999; Zhou et al. 2004). Chang et al. (2005) untersuchten 14 Mikrosatellitenmarker, welche nahebei oder innerhalb von Genregionen lagen, die in den Prozess der kolorektalen Karzinogenese involviert sind. $79 \%$ der Karzinome zeigten LOH, 45\% davon in >3 Markern. In Stadium-I-Tumoren (klassifiziert nach UICC, Tab.I-2, S.9 unter 1.1.2) fand sich in $23 \%$ der Fälle LOH, In Stadium-IV-Tumoren fand sich in $48 \%$ der Fälle LOH. Das krankheitsfreie Überleben wurde über drei Jahre beobachtet. Ein hoher Grad an LOH wirkte sich negativ aus. Patienten mit einer großen Anzahl an $\mathrm{LOH}$ in den untersuchten Markern zeigten ein krankheitsfreies Überleben in 50\%. Patienten mit einer geringen Anzahl LOH-positiver Marker zeigten ein krankheitsfreies Überleben in 84\%. LOH geht somit mit einer verschlechterten Prognose einher. Die Ursache könnte in einer erhöhten Fernmetastasierungsrate zu finden sein, wie Chang et al. (2005) bei Stadium-I- und II-Patienten mit hohen LOH-Raten entdeckten (32\% vs. $9 \%$ bei Patienten mit niedriger 
LOH-Rate). Daraus wurde geschlossen, dass hochgradige LOH-Tumore sich klinisch ähnlich verhalten wie Tumore im Stadium IV.

In einer weiteren Studie über die genetische Klassifikation kolorektaler Karzinome anhand von $\mathrm{LOH}$ wurde dargelegt, dass bei Patienten mit hochgradigen $\mathrm{LOH}$ Tumoren die Tumorlokalisation häufig im Rektum und der Krankheitsbeginn früh ist (Choi et al. 2002). Auch in anderen Studienergebnissen wurde $\mathrm{LOH}$ in Rektumkarzinomen häufiger gefunden als in Kolonkarzinomen, und ein unterschiedlicher genetischer Hintergrund wurde dafür verantwortlich gemacht (Vogelstein et al. 1989; Kern et al. 1989). Choi et al. (2002) beobachteten ebenfalls, dass LOH zur Tumorinvasion und Metastasierung beiträgt, das Erkrankungsalter herabsetzt und vor allem auf Tumore in einem frühen Stadium Einfluss nimmt.

LOH ist in Rektumkarzinomen häufiger zu erwarten als MSI. In der Gesamtheit der kolorektalen Karzinome wiesen in der Studie von Chang et al. (2005) 79\% LOH auf. Choi et al. (2002) beobachteten eine LOH-Häufung in Rektumkarzinomen vs. Kolonkarzinomen. Da sich in meinen Untersuchungen mit einem wenig sensitiven Primerpanel für MSI-L und LOH bereits in 9,3\% LOH zeigte, ist anzunehmen, dass sich mit mehr Markern noch wesentlich mehr Fälle demaskieren ließen.

In den beschriebenen Studien über $\mathrm{LOH}$ zeigen sich große Diskrepanzen im krankheitsfreien Überleben zwischen Patienten mit und ohne LOH. MSI hat sich in Rektumkarzinomen als einen nur unter Vorsicht anzuwendenden Biomarker für das Überleben herausgestellt, da sich eine Beeinflussbarkeit durch die Therapie gezeigt hat. Da MSI in Rektumkarzinomen ohnehin selten ist, bietet sich mit der Untersuchung auf $\mathrm{LOH}$ ein weiteres Feld an, das sich als ergiebig herausstellen könnte. Die Untersuchungsmethode entspricht der MSI-Analyse. Das Primerpanel müsste aber mehr zugunsten von dinukleotiden Primern gewählt werden, da diese sensitiver sind für LOH. Untersucht wurde bisher jedoch noch nicht, ob $\mathrm{LOH}$ ebenfalls durch therapeutische Interventionen entstehen kann, wie MSI. Dies gilt es zu ergründen, bevor LOH als Biomarker für das Überleben herangezogen werden kann. LOH ist häufiger in Tumoren zu finden, die in früherem Lebensalter entstanden sind und zu einer veränderten Fernmetastasierungsrate führen. Patienten, die solche Tumore aufweisen, wären evtl. mit einer aggressiveren Therapie zu behandeln, etwa wie einer zusätzlichen Gabe von Oxaliplatin, welches die Fernmetastasierungsrate senken soll. In den Ergebnissen der MSI-Analyse fanden sich zwei LOH-Fälle in der Gruppe der 50-59jährigen, 3 LOH-Fälle in der Gruppe der 70-79jährigen und ein Fall in der Gruppe der 80-89jährigen. In den verwendeten Proben zeigte sich somit eine stärkere 
Häufung in höherem Lebensalter, was durch das vergleichsweise kleine, von mir untersuchte, Kollektiv bedingt sein könnte.

\subsection{MSI-Status als Diagnosekriterium für HNPCC}

Die Analyse der Mikrosatelliten ist neben klinischen Kriterien ein zentraler Bestandteil in der Diagnostik des HNPCC-Syndroms (Umar et al. 2004). Es hat sich aber gezeigt, dass Tumor-DNA durch eine Chemoradiotherapie mikrosatelliteninstabil werden kann. Aus meinen Untersuchungen lässt sich ableiten, dass bei einer niedrigen Prävalenz von MSI in Rektumkarzinomen es von großer Bedeutung ist, zu welchem Zeitpunkt in der Therapie des Patienten die DNA-Analyse vorgenommen wird. Diesem Aspekt wurde bisher in der HNPCC-Diagnostik keine Bedeutung beigemessen. Es existiert kein Standard, der den Zeitpunkt der MSI-Analyse festlegt. Die Ergebnisse der prä-

und posttherapeutischen MSI-Analysen legen nahe, dass jede Mikrosatelliteninstabilität als fragwürdig bezüglich ihrer Genese angesehen werden muss, die nicht ausdrücklich prätherapeutisch erhoben wurde.

Die Beobachtung, dass MSI, bzw. die Herunterregulation der MMR-Gene erst durch eine Therapie entstehen kann, stellt die Indikatorfunktion der MSI für das HNPCCSyndrom infrage. Im Falle einer DNA-Untersuchung, die erst an Resektat-Material im Anschluss an neoadjuvante Chemoradiotherapie durchgeführt wird, kann das Ergebnis anders ausfallen, als bei einer prätherapeutischen Untersuchung. So kann es zu falsch-positiven Diagnosestellungen eines HNPCC-Syndroms kommen, die für den Patienten eine andere Behandlung bahnen, als er tatsächlich bräuchte. Die Folgen wären „Übertherapieren“, hohe psychische und körperliche Belastungen für den Patienten und hohe Therapiekosten. Auch könnte ein Arzt möglicherweise falsche Rückschlüsse aus dem MSI-Status eines Tumors ziehen und somit dem Patienten eine Prognose vermitteln, die unwahrscheinlich ist.

In Zukunft wird ein besonderes Augenmerk darauf gerichtet werden müssen, ob eine mögliche Herunterregulation bzw. ein Ausfall des MMR-Systems nicht auf die Therapie selbst zurückzuführen ist und nicht auf vererbte genetische Defekte. Posttherapeutisch untersuchte Proben können nicht nur falsch-positiv durch neue Veränderungen, verursacht durch die Therapie, auffallen. Sie können auch falschnegativ sein, wenn nicht größte Sorgfalt in der Gewinnung der DNA angewandt wird, was eine histologische und immunhistochemische Prüfung erfordert. 


\subsection{HNPCC und MSI-L/ MSH6-Defizienz}

An Mammakarzinomen wurde ebenso, wie durch Mitarbeiter des Teilprojektes 5 der KFO 179 an Rektumkarzinomen, beobachtet, dass MSH6 durch Chemoradiotherapie defizient werden kann. Chintamani et al. (2007) untersuchten Mammakarzinome vor und nach neoadjuvanter Chemotherapie (5-FU, Cyclophosphamid, Adriamycin) immunhistochemisch. MSH6 war das MMR-Gen, welches am häufigsten in der Immunhistochemie verändert war. Die Expressionsänderungen aller vier untersuchten MMR-Gene (MLH1, MSH2, MSH6 und PMS2) waren aber insgesamt nicht statistisch signifikant.

Seit über 10 Jahren ist bekannt, dass Mutationen im MSH6-Gen mit MSI-L-Tumoren assoziiert sind und häufig in Familien beobachtet werden, die Verdacht auf ein HNPCC-Syndrom haben, bei denen die Diagnose jedoch klinisch nicht eindeutig ist (Wu Y et al. 1999). Ebenfalls wurde bei Patienten mit einer MSH6-Mutation, welche nicht die klassischen HNPCC-Kriterien erfüllten, eine spätere Manifestation kolorektaler Karzinome (late-onset-type) beobachtet (mittleres Erkankungsalter 64 Jahre) (Kolodner et al. 1999).

Sicher diagnostizierte HNPCC-Patienten, bei denen eine Mutation im MSH6-Gen identifiziert wurde, weisen häufiger einen MSI-L-Phänotyp (13\%) auf, als einen MSI-HPhänotyp (11\%) (Zhao et al. 2009).

Patienten mit MSH6-Mutation weisen besondere Merkmale auf und sind besonderen Risiken ausgesetzt. Aus den Ergebnissen der KFO 179 ergeben sich daher Konsequenzen für die Tumor-Vor- und Nachsorge, wenn eine MSH6-Mutation gefunden wurde. Berends et al.(2002) untersuchten Patienten und ihre Verwandten mit MSH6-Mutationen. Das Risiko an einem Endometriumkarzinom zu erkranken zeigte sich für MSH6-Mutationsträger als erhöht gegenüber MLH1- oder MSH2Mutationsträgern. Das Risiko an einem kolorektalen Karzinom zu erkranken erwies sich als niedriger gegenüber dem Risiko eines MLH1- oder MSH2-Mutationsträgers. Außerdem zeigten MSH6-Mutationsträger die Tendenz, eher Tumore im distalen Kolorektum zu entwickeln (70\% der Tumore lagen linksseitig).

Dass eine MSH6-Mutation zu einem MSI-L-Phänotyp führen kann, ist übereinstimmend mit den vorliegenden Untersuchungsergebnissen. Es wäre weit hergeholt eine Korrelation herzustellen zwischen der Feststellung, dass MSH6Mutationsträger häufig nicht sicher HNPCC-diagnostiziert werden können und der Beobachtung der Chemoradiotherapie-induzierten MSH6-Mutation. Zugelassen 
werden kann aber die Schlussfolgerung, dass Auswirkungen und Ursachen einer MSH6-Mutation noch viel weniger verstanden und erforscht sind, als beispielsweise bei MLH1 oder MSH2. Bisher ist jedoch das Wissen, um welche Mutation es sich handelt, für den Patienten letztlich weniger wichtig, da die Therapie bei allen Mutationen gleich ist. Vor dem Hintergrund der hier aufgezeigten Ergebnisse erscheint ein Umdenken auf diesem Gebiet sinnvoll, da es, wie oben beschrieben, einige Unterschiede gibt.

Einige Arbeitsgruppen, die zum Thema MSH6 forschen, empfehlen, alle HNPCCverdächtigen Patienten auf MSH6-Mutationen zu untersuchen (Wu Y et al. 1999; Berends et al. 2002). Dazu ist hinzuzufügen, dass zukünftig in der Diagnostik sichergestellt werden muss, dass es sich tatsächlich um eine Keimbahnmutation und nicht um eine Therapie-induzierte Mutation handelt.

Der Mechanismus, der dazu führt, dass MSH6, durch äußere Faktoren induziert, instabil wird, ist noch nicht bekannt. Möglicherweise wäre zukünftig für Patientinnen, die eine ebensolche Neumutation in MSH6 entwickeln, eine verstärkte Überwachung und Tumornachsorge nötig. Es ist noch nicht untersucht, ob sich diese Mutationen nur im Tumorgewebe entwickeln, oder ob sie zum Beispiel auch im Endometrium entstehen können. Da bei MSH6- Mutationsträgerinnen das Risiko, an einem Endometriumkarzinom zu erkranken sehr hoch ist, wäre hier eine regelmäßige und sorgfältige Kontrolle des Endometriums sinnvoll.

Die Beobachtung, dass durch MSH6 verursachte Tumore eher im distalen Kolorektum entstehen, deckt sich mit den vorliegenden Untersuchungsergebnissen an Rektumkarzinomen, kann aber auch zufällig sein. Um dies abschließend beurteilen zu können, wären sehr viel größere Fallzahlen nötig.

\subsection{Ursachen eines variierenden Grades an MSI im Tumorgewebe}

Der Expressionsausfall der MMR-Gene und somit der Grad an Instabilität der Mikrosatelliten, variierte bemerkenswerterweise innerhalb des Tumors. Die Mikrosatellitenanalyse zeigte in zwei Karzinomen DNA-Veränderungen mit neuen Peaks. Die Stärke der DNA-Veränderungen nahm mit der Tiefe der Tumorinvasion zu. Aus DNA auf Höhe der Muscularis propria, oder tiefer gelegener DNA, wenn die Muscularis propria bereits durchbrochen war (= yp T2/3 Level), ließen sich die stärksten DNA-Veränderungen in den Mikrosatelliten darstellen. 
Veränderte Genexpressionsmuster innerhalb eines Tumors (superfizial vs. tiefe Invasionsfront) wurden bereits für andere Gene in unterschiedlichen Tumoren beschrieben, vgl. Mammakarzinom (Zhu et al. 2003), malignes Melanom (Roesch et al. 2003) und kolorektales Karzinom (Oku et al. 2008).

Der Mechanismus, der zu einem Chemoradiotherapie-induzierten MMR-Ausfall führt, der sich innerhalb des Tumors in unterschiedlich ausgeprägter Mikrosatelliteninstabilität darstellt, ist unbekannt. Ein möglicher Grund wäre, dass ein durch Hypoxie ausgelöster Stress in der Mikroumgebung des Tumors genetische Instabilitäten in den Karzinomzellen, insbesondere im MMR-System, hervorruft. Vor allem eine chronische Hypoxie, weniger eine kurze Hypoxiezeit, scheint als Auslöser dafür in Frage zu kommen. Chronische Hypoxie führt sowohl zu einer verminderten Expression, als auch zu einer verminderten Repair-Aktivität des MMR-Systems (Review Bindra et al. 2007).

In Studien konnte gezeigt werden, dass die Expression von MLH1 und MSH2 durch Hypoxie herunterreguliert wird. Ein mildes Hypoxie-Level von 1,0\% Sauerstoff führte zu verminderter MSH2-Expression. Ein starkes Hypoxie-Level von 0,01\% Sauerstoff führte zu verminderter MLH1-Expression. (Mihaylova et al. 2003; Shahrzad et al. 2005; Bindra \& Glazer 2007)

Als Ursache einer verminderten Gen-Expression unter Hypoxie könnte eine veränderte Histon-Deacetylierung des Genabschnittes für das entsprechende Gen in Frage kommen, wie es für MLH1 beschrieben wurde (Review Bindra et al. 2007).

Koshiji et al. (2005) beschreiben einen weiteren Mechanismus der MMRHerunterregulation unter Hypoxie durch den Hypoxie-induzierten Faktor 1alpha (HIF1alpha). Untersucht wurde die Expression von MSH2 und MSH6 unter hypoxischen Bedingungen. Koshiji et al. (2005) fanden, dass HIF-1alpha, ein Transkriptionsfaktor, der die Versorgung einer Zelle mit Sauerstoff reguliert, in die Unterdrückung der Transkription von MSH2 und MSH6 unter Hypoxie involviert ist. HIF-1alpha bewirkt dies, indem er das Protein C-Myc von seinen Bindungsstellen an MSH2 und MSH6 verdrängt. C-Myc ist für die Regulierung der DNA-Expression verantwortlich. Kann CMyc nicht mehr binden, werden die MMR-Gene vermindert exprimiert.

Die Beobachtungen, die man über die Auswirkungen einer Hypoxie auf das MMRSystem gemacht hat, lassen die Hypoxie als Verursacher der Therapie-induzierten Downregulation von MMR-Genen als möglich erscheinen. Es wäre interessant an 
dieser Stelle weiter zu erforschen, ob einer der bereits bekannten Mechanismen auch für den Therapie-induzierten MSI-L-Phänotyp verantwortlich ist.

\subsection{Chemoresistenz durch neoadjuvante Behandlung}

In ersten Langzeitergebnissen der CAO/ARO/AIO-04-Studie konnte gezeigt werden: das rezidivfreie Überleben bei Patienen mit verminderter MSH6-Expression ist kürzer als bei Patienten mit unveränderter MSH6-Expression (46\% vs. 63\%). Auch ein Tumorregressionsgrad III durch neoadjuvante Chemoradiotherapie konnte in geringerem Prozentanteil erreicht werden (30\% vs. $46 \%$ ).

In einer Studie von Chintamani et al. (2007) über Mammakarzinome wurden MLH1, MSH2, MSH6 und PMS2 vor und nach neoadjuvanter Chemotherapie mit 5-FU, Cyclophosphamid und Adriamycin immunhistochemisch untersucht. MSH6 zeigte nach der Therapie am häufigsten Expressionsänderungen. Patienten mit hohen MSH6-Expressionen fielen durch schlechtes Ansprechen auf die neoadjuvante Therapie auf.

Insgesamt wurde für MMR-defiziente Patienten ein schlechteres Ansprechen auf 5-FU beschrieben (Sargent et al. 2010). Sargent et al. (2010) verglichen die Therapie kolorektaler Karzinome bestehend aus OP und Chemotherapie (5-FU + Levamisole/ Leucovorin) mit der alleinigen operativen Behandlung. Patienten mit MMR-Defizienz, die OP plus Chemotherapie erhielten, hatten kein verlängertes krankheitsfreies Überleben, verglichen mit MMR-defizienten Patienten, welche nur eine Operation erhielten. Patienten mit funktionierendem MMR-System, welche OP plus Chemotherapie erhielten, zeigten ein verlängertes krankheitsfreies Überleben gegenüber Patienten mit funktionierendem MMR-System, die nur eine Operation erhielten.

Die Beobachtungen Chintamanis et al. (2007) stimmen mit den Ergebnissen der CAO/ARO/AIO-04-Studie überein. Patienten mit MSH6-Mutationen scheinen weniger gute Überlebenschancen zu haben, als Patienten mit anderen Mutationen in MMRGenen. Ursächlich kann ein schlechtes Ansprechen auf bestimmte Chemotherapeutika, insbesondere auf den Antimetabolit 5-FU, angenommen werden. Die Vergleichbarkeit ist eingeschränkt, da alle Defekte in MMR-Genen zu einem verminderten Ansprechen auf 5-FU und andere Chemotherapeutika führen: auch für 
alkylierende Substanzen, methylierende Substanzen und Topoisomerase-II-Inhibitoren wurde eine Resistenz MMR-defizienter Zellen beobachtet (Fink et al. 1998). Da in der Studie von Sargent et al. (2010) über kolorektale Karzinome nicht zwischen Mutationen der einzelnen MMR-Gene unterschieden wurde, ist der Vergleich schwierig Eine generelle Chemoresistenz MMR-defizienter Patienten kann aber angenommen werden.

Bei HNPCC-Patienten finden sich in 90\% Defekte in MLH1 und MSH2 und in 7-10\% der Fälle Defekte in MSH6 (Review Kohlmann \& Gruber 2006). Der Anteil MMRdefizienter, sporadisch entstandener Tumore an der Gesamtzahl der Tumore ist jedoch größer (12-17\% sporadische, 3\% HNPCC-assoziierte) (Popat et al. 2005; Ward et al. 2001; Hampel et al. 2008). Welche Gene bei sporadischer MMR-Defizienz betroffen sind ist noch relativ wenig erforscht. Im Falle einer MMR-Defizienz sporadischer Genese scheint nahezu ausschließlich eine epigenetische Inaktivierung von MLH1 die Ursache zu sein (Dietmaier 2010).

Untersucht man wie Sargent et al. (2010) ein Patientenkollektiv lediglich auf einen MMR-Ausfall hin, z. B. über Mikrosatelliten-Analyse, hätten insgesamt nur maximal $10 \%$ eine Mutation in MSH6 (Review Kohlmann \& Gruber 2006), wenn ausschließlich HNPCC-Fälle angenommen würden. Je höher der Anteil sporadisch entstandener MMR-Mutationen ist, die v.a. MLH1 betreffen, desto weniger Prozent MSH6Mutationen werden es sein. Desto geringer ist demzufolge auch die Wahrscheinlichkeit, dass der beobachtete Effekt eines verminderten Ansprechens allein auf MSH6 zurück zu führen ist.

Trotzdem lassen die vorliegenden Ergebnisse und die Beobachtungen Chintamanis et al. (2007) an Mammakarzinomzellen vermuten, dass MSH6 als Subgruppe anders auf die Therapie reagiert, als die übrigen MMR-Gene. Da bei beiden erwähnten Studien sowie auch bei der CAO/ARO/AIO-04-Studie die Basis der Therapie 5-FU ist, darf angenommen werden, dass Patienten mit MSH6-Mutation auf dieses Therapeutikum schlechter ansprechen.

Zukünftige Bemühungen, für jeden Patienten eine individuelle und optimale Therapie zu finden, sollten bei MMR-defizienten Patienten die genaue Analyse mit einbeziehen, welches Gen mutiert ist. Bei MSH6-defizienten Patienten sollte ein anderes Therapiekonzept gefunden werden, das nicht auf 5-FU basiert.

Doch eine individualisierte Therapie sollte nicht nur für MSH6-defiziente Patienten gefunden werden. $\mathrm{Da}$ alle MMR-Mutationen $\mathrm{zu}$ einem verminderten 
Therapieansprechen führen, sollte für die Gesamtheit der betroffenen Patienten eine andere Therapie entwickelt werden.

Es wurde bereits gezeigt, dass die Sensitivität MMR-defizienter Zellen für Oxaliplatin gleich gut ist, wie in Zellen mit intaktem MMR-System. Die Sensitivität für Irinotecan (Topoisomerase-I-Inhibitor) wurde sogar als möglicherweise besser beschrieben, als in MMR-funktionsfähigen Zellen. (Review Damia \& D'Incalci 2010)

Anhand dieses Ansatzes könnte durch weitere Forschung ein neues, angepasstes Therapiekonzept entwickelt werden.

\subsection{Einschränkungen und Gewinn dieser Arbeit}

Für die Ergebnisse meiner Arbeit ist einschränkend zu sagen, dass das Patientenkollektiv mit 65 Patienten für die posttherapeutische Nachuntersuchung sehr klein gewählt war. Nach neoadjuvanter Chemoradiotherapie sind zumeist kaum noch Tumorzellen im Resektatmaterial vorhanden. Auch sind nicht alle Proben immunhistochemisch auffällig, sodass hier auch wiederum eine Auswahl getroffen werden musste. Letztlich haben zwei Fälle einen Chemoradiotherapie-induzierten MSI-L-Phänotyp gezeigt. Nichtsdestotrotz ist dieses Ergebnis eine Neuerkenntnis, die viel Umdenken und Umstrukturierung erforderlich macht. Das gilt sowohl in der Therapie von Rektumkarzinomen als auch in der Nutzung von MSI als Biomarker und Prädiktor für die Prognose und eine mögliche Chemoresistenz. Ein neuer Schritt ist getan, weitere Studien zu dieser Fragestellung müssen an größeren Kollektiven vorgenommen werden und die Bedeutung dieser neuen Erkenntnisse erforscht werden. Ein neuer Baustein zur Verbesserung von Therapie und Überlebenschance für Patienten mit rektalen Karzinomen ist gelegt. 


\section{ZUSAMMENFASSUNG}

Kolorektale Karzinome stellen die zweithäufigste Krebserkrankung dar. Während Prävalenz und Inzidenz der Erkrankung in den letzten Jahren angestiegen sind, konnte die Mortalität deutlich gesenkt werden. Ursachen für eine gesenkte Mortalität sind in neu eingeführten Früherkennungsprogrammen, verbesserten Therapieverfahren und der Entwicklung spezieller Untersuchungsmethoden, wie z.B. der Untersuchung auf Mikrosatelliteninstabilität (MSI), zu suchen. Sowohl spontan aufgetretene als auch ererbte genomische Veränderungen können die Entstehung eines kolorektalen Karzinoms begünstigen. Genomische Analysen auf MSI gelten heute als Standard in der Diagnostik kolorektaler Karzinome. Zunächst etablierte sich für Rektumkarzinome ein adjuvantes Therapiekonzept aus einer Kombination von Chemo- und Radiotherapie. Neoadjuvante Behandlung ist eine neuere Entwicklung, die ein Downstaging, eine verbesserte Operabilität und eine Reduktion der Anzahl positiver Lymphknoten möglich machte. Das Überleben soll in der CAO/ARO/AIO-04-Studie durch eine Senkung der Fernmetastasierungsrate mittels Oxaliplatin als zusätzliche Gabe zu 5-FU verbessert werden. Das Patientenkollektiv dieser Arbeit rekrutiert sich aus der CAO/ARO/AIO-04-Studie, sowie aus ihrer Vorläuferstudie CAO/ARO/AIO-94. Untersucht wurde das Patientenkollektiv auf MSI. MSI entsteht durch Fehler im Mismatch-Repair-System (MMR) einer Zelle. Veränderungen in den MMR-Genen, wie Mutationen oder epigenetische Hemmung, können zu einer verminderten Funktion oder einem Funktionsausfall des MMR-Systems führen. Eine hereditäre Form dieser Erkrankung ist das HNPCC-Syndrom (Hereditary Nonpolyposis Colorectal Cancer). Bei dieser Erkrankung sind häufig die MMR-Gene MLH1, MSH2, MSH6 und PMS2 betroffen. MSI-Analysen werden als Biomarker und Prädiktor für das Überleben eines Patienten und das Ansprechen auf die Therapie herangezogen. MSI (insbesondere MSI-High) gilt heute als günstiger Prognosefaktor für das kolorektale Karzinom. Die Funktion der $\mathrm{MSI}$ als Prädiktor für eine Chemoresistenz gegen 5-FU wird derzeit diskutiert.

Untersucht wurde die DNA von 65 Patienten mit Rektumkarzinomen vor und nach neoadjuvanter Chemoradiotherapie auf MSI. Parallel dazu wurden die Gewebeproben immunhistochemisch ausgewertet durch Mitarbeiter des Teilprojektes 5 der KFO 179. Als MSI-Marker wurde ein Panel von 5 Primern ausgewählt, welche in einer internationalen Konferenz als Referenz-Primer für die Diagnosestellung eines HNPCCSyndroms festgelegt wurden. Als Methoden wurden Mikrodissektion, PCR und 
Fragmentlängenanalyse mittels eines Genetic Analyzers gewählt. Die Ergebnisse wurden bezüglich zweier Fragestellungen ausgewertet: Hat die neoadjuvante Chemoradiotherapie einen Effekt auf den MSI-Status? Und: Ist der MSI-Status als Biomarker und Prädiktor für das Überleben und das Ansprechen auf die Therapie geeignet? Von 65 prätherapeutisch untersuchten Proben zeigte sich in einem Fall MSILow. Von 7 immunhistochemisch auffälligen posttherapeutischen Proben zeigten 2 einen neu aufgetretenen MSI-Low-Phänotyp. In der Immunhistochemie wurde parallel eine Veränderung des Ausfalls der MMR-Expression zwischen Tumoroberfläche und der Invasionstiefe sichtbar. An der tiefen Invasionsfront des Tumors nahm die Expression ab. Folgende Thesen lassen sich aus den vorliegenden Ergebnissen ableiten: 1. MSI-High ist in Rektumkarzinomen selten zu beobachten. 2. Rektumkarzinome zeigen eine erhöhte MSI-Low-Frequenz nach neoadjuvanter Chemoradiotherapie.

Die Ergebnisse der Untersuchung haben gezeigt, dass der MSI-Status durch äußere Faktoren wie die neoadjuvante Chemoradiotherapie beeinflussbar ist. Ein Rückschluss auf die Prognose sollte mit Vorsicht gezogen werden, da noch zu viele Fragen bezüglich des induzierten MSI-Low-Phänotyps offen sind. Eine Eignung von MSI als Prädiktor für eine mögliche Chemoresistenz gegen 5-FU zeichnet sich aus den vorliegenden Ergebnissen der CAO/ARO/AIO-04-Studie ab: Das Follow-up über 54 Monate von 31 Patienten hat ergeben, dass Patienten mit MSH6-Redukion ein verkürztes rezidivfreies Überleben aufweisen. Es ergibt sich somit eine neue Hinweisquelle für Prognose und Verlauf der Erkrankung. Diese neuen Erkenntnisse sind der Grundbaustein für verbesserte und individualisierte Therapieverfahren, die das Überleben von Patienten mit Rektumkarzinomen verlängern können. 


\section{LITERATUR}

Aaltonen LA, Peltomäki P, Leach FS, Sistonen P, Pylkkänen L, Mecklin JP, Järvinen H, Powell SM, Jen J, Hamilton SR (1993): Clues to the pathogenesis of familial colorectal cancer. Science 260, 812-6.

Aaltonen LA, Salovaara R, Kristo P, Canzian F, Hemminki A, Peltomäki P, Chadwick RB, Kääriäinen H, Eskelinen M, Järvinen $H$ et al. (1998): Incidence of hereditary nonpolyposis colorectal cancer and the feasibility of molecular screening for the disease. N Engl J Med 338, 1481-7.

Aarnio M, Mecklin JP, Aaltonen LA, Nyström-Lahti M, Järvinen HJ (1995): Life-time risk of different cancers in hereditary non-polyposis colorectal cancer (HNPCC) syndrome. Int J Cancer 64, 430-3.

Acharya S, Wilson T, Gradia S, Kane MF, Guerrette S, Marsischky GT, Kolodner R, Fishel R (1996): hMSH2 forms specific mispair-binding complexes with hMSH3 and hMSH6. Proc Natl Acad Sci USA 93, 13629-34.

Aebi S, Fink D, Gordon R, Kim HK, Zheng H, Fink JL, Howell SB (1997): Resistance to cytotoxic drugs in DNA mismatch repair-deficient cells. Clin Cancer Res 3, 1763-7.

André T, Boni C, Navarro M, Tabernero J, Hickish T, Topham C, Bonetti A, Clingan P, Bridgewater J, Rivera F et al. (2009): Improved overall survival with oxaliplatin, fluorouracil, and leucovorin as adjuvant treatment in stage II or III colon cancer in the MOSAIC trial. J Clin Oncol 27, 3109-16.

Aschele C, Pinto C, Cordio S, Rosati G, Tagliagambe A, Artale S, Rosetti P, Lonardi S, Boni L, Cioni L (2009): Preoperative fuorouracil (FU)-based chemoradiation with and without weekly oxaliplatin in locally advanced rectal cancer: Pathologic response analysis of the Studio Terepia Adiuvante Retto (STAR)-01 randomized phase III trial. $J$ Clin Oncol 27, Suppl 18s, Abstr CRA4008. 
Auclair J, Vaissière T, Desseigne F, Lasset C, Bonadona V, Giraud S, Saurin J, Joly M, Leroux D, Faivre L et al. (2011): Intensity-dependent constitutional MLH1 promoter methylation leads to early onset of colorectal cancer by affecting both alleles. Genes Chromosomes Cancer 50, 178-85.

Ballonoff A, Kavanagh B, McCarter M, Kane M, Pearlman N, Nash R, Shah RJ, Raben D, Schefter TE (2008): Preoperative capecitabine and accelerated intensity-modulated radiotherapy in locally advanced rectal cancer: a phase II trial. Am J Clin Oncol 31, 264-70.

Berends MJ, Wu Y, Sijmons RH, Mensink RG, van der Sluis T, Hordijk-Hos JM, Vries EG de, Hollema H, Karrenbeld A, Buys $\mathrm{CH}$ et al. (2002): Molecular and clinical characteristics of MSH6 variants: an analysis of 25 index carriers of a germline variant. Am J Hum Genet 70, 26-37.

Beresford M, Glynne-Jones R, Richman P, Makris A, Mawdsley S, Stott D, Harrison M, Osborne M, Ashford R, Grainger J et al. (2005): The reliability of lymph-node staging in rectal cancer after preoperative chemoradiotherapy. Clin Oncol 17, 448-55.

Bertz J, Dahm F, Haberland J, Kraywinkel K, Kurth B, Wolf U (2010): Verbreitung von Krebserkrankungen in Deutschland: Entwicklung der Prävalenzen zwischen 1990 und 2010. Beiträge zur Gesundheitsberichterstattung des Bundes; hrsg: Robert-KochInstitut; Westkreuz-Druckerei, Berlin 2010, 37-44

Bindra RS, Glazer PM (2007): Co-repression of mismatch repair gene expression by hypoxia in cancer cells: role of the Myc/Max network. Cancer Lett 252, 93-103.

Bindra RS, Crosby ME, Glazer PM (2007): Regulation of DNA repair in hypoxic cancer cells. Cancer Metastasis Rev 26, 249-60.

Bocker T, Barusevicius A, Snowden T, Rasio D, Guerrette S, Robbins D, Schmidt C, Burczak J, Croce CM, Copeland T et al. (1999): hMSH5: a human MutS homologue that forms a novel heterodimer with $\mathrm{hMSH} 4$ and is expressed during spermatogenesis. Cancer Res 59, 816-22. 
Boland CR, Thibodeau SN, Hamilton SR, Sidransky D, Eshleman JR, Burt RW, Meltzer SJ, Rodriguez-Bigas MA, Fodde R, Ranzani GN et al. (1998): A National Cancer Institute Workshop on Microsatellite Instability for cancer detection and familial predisposition: development of international criteria for the determination of microsatellite instability in colorectal cancer. Cancer Res 58, 5248-57.

Bosset JF, Calais G, Daban A, Berger C, Radosevic-Jelic L, Maingon P, Bardet E, Pierart M, Briffaux A (2004): Preoperative chemoradiotherapy versus preoperative radiotherapy in rectal cancer patients: assessment of acute toxicity and treatment compliance. Report of the 22921 randomised trial conducted by the EORTC Radiotherapy Group. Eur J Cancer 40, 219-24.

Bosset J, Collette L, Calais G, Mineur L, Maingon P, Radosevic-Jelic L, Daban A, Bardet E, Beny A, Ollier J (2006): Chemotherapy with preoperative radiotherapy in rectal cancer. N Engl J Med 355, 1114-23.

Brenner H, Stegmaier C, Ziegler H (2005): Long-term survival of cancer patients in Germany achieved by the beginning of the third millenium. Ann Oncol 16, 981-6.

Bronner CE, Baker SM, Morrison PT, Warren G, Smith LG, Lescoe MK, Kane M, Earabino C, Lipford J, Lindblom A (1994): Mutation in the DNA mismatch repair gene homologue hMLH1 is associated with hereditary non-polyposis colon cancer. Nature 368, 258-61.

Carethers JM, Chauhan DP, Fink D, Nebel S, Bresalier RS, Howell SB, Boland CR (1999): Mismatch repair proficiency and in vitro response to 5-fluorouracil. Gastroenterology 117, 123-31.

Cawkwell L, Li D, Lewis FA, Martin I, Dixon MF, Quirke P (1995): Microsatellite instability in colorectal cancer: improved assessment using fluorescent polymerase chain reaction. Gastroenterology 109, 465-71.

Chang S, Lin J, Lin T, Liang W (2005): Loss of heterozygosity: an independent prognostic factor of colorectal cancer. World J Gastroenterol 11, 778-84. 
Charara M, Edmonston TB, Burkholder S, Walters R, Anne P, Mitchell E, Fry R, Boman B, Rose D, Fishel R et al. (2004): Microsatellite status and cell cycle associated markers in rectal cancer patients undergoing a combined regimen of 5-FU and CPT-11 chemotherapy and radiotherapy. Anticancer Res 24, 3161-7.

Chintamani, Jha BP, Bhandari V, Bansal A, Saxena S, Bhatnagar D (2007): The expression of mismatched repair genes and their correlation with clinicopathological parameters and response to neo-adjuvant chemotherapy in breast cancer. Int Semin Surg Oncol 14, 5.

Choi S, Lee KJ, Bae Y, Min K, Kwon M, Kim K, Rhyu M (2002): Genetic classification of colorectal cancer based on chromosomal loss and microsatellite instability predicts survival. Clin Cancer Res 8, 2311-22.

Church J (2009): Familial adenomatous polyposis. Surg Oncol Clin N Am 18, 585-98.

Colombino M, Cossu A, Manca A, Dedola MF, Giordano M, Scintu F, Curci A, Avallone A, Comella G, Amoruso M et al. (2002): Prevalence and prognostic role of microsatellite instability in patients with rectal carcinoma. Ann Oncol 13, 1447-53.

Corvò R, Pastrone I, Scolaro T, Marcenaro M, Berretta L, Chiara S (2003): Radiotherapy and oral capecitabine in the preoperative treatment of patients with rectal cancer: rationale, preliminary results and perspectives. Tumori $\mathbf{8 9}, \mathbf{3 6 1 - 7 .}$

Cunningham JM, Christensen ER, Tester DJ, Kim CY, Roche PC, Burgart LJ, Thibodeau SN (1998): Hypermethylation of the hMLH1 promoter in colon cancer with microsatellite instability. Cancer Res 58, 3455-60.

Damia G, D'Incalci M (2010): Genetic instability influences drug response in cancer cells. Curr Drug Targets 11, 1317-24.

Deschoolmeester V, van Damme N, Baay M, Claes K, van Marck E, Baert FJ, Wuyts W, Cabooter M, Weyler J, Vermeulen P et al. (2008): Microsatellite instability in sporadic colon carcinomas has no independent prognostic value in a Belgian study population. Eur J Cancer 44, 2288-95. 
Dietmaier W (2010): Microsatellite instability. Der Pathologe 31, Suppl 2, 268-73.

Dietmaier W, Wallinger S, Bocker T, Kullmann F, Fishel R, Rüschoff J (1997): Diagnostic microsatellite instability: definition and correlation with mismatch repair protein expression. Cancer Res 57, 4749-56.

Duffy MJ, van Dalen A, Haglund C, Hansson L, Holinski-Feder E, Klapdor R, Lamerz R, Peltomaki P, Sturgeon C, Topolcan O (2007): Tumour markers in colorectal cancer: European Group on Tumour Markers (EGTM) guidelines for clinical use. Eur $J$ Cancer 43, 1348-60.

Ellegren $\mathrm{H}$ (2000): Microsatellite mutations in the germline: implications for evolutionary inference. Trends Genet 16, 551-8.

Elsaleh H, Joseph D, Grieu F, Zeps N, Spry N, lacopetta B (2000): Association of tumour site and sex with survival benefit from adjuvant chemotherapy in colorectal cancer. Lancet $355,1745-50$.

Emterling A, Wallin A, Arbman G, Sun X (2004): Clinicopathological significance of microsatellite instability and mutated RIZ in colorectal cancer. Ann Oncol 15, 242-6.

Fernebro E, Halvarsson B, Baldetorp B, Nilbert M (2002): Predominance of CIN versus MSI in the development of rectal cancer at young age. BMC Cancer 14, 25.

Fink D, Aebi S, Howell SB (1998): The role of DNA mismatch repair in drug resistance. Clin Cancer Res 4, 1-6.

Fishel R, Wilson T (1997): MutS homologs in mammalian cells. Curr Opin Genet Dev 7, 105-13.

Frykholm GJ, Glimelius B, Påhlman L (1993): Preoperative or postoperative irradiation in adenocarcinoma of the rectum: final treatment results of a randomized trial and an evaluation of late secondary effects. Dis Colon Rectum 36, 564-72. 
Gebert J, Sun M, Ridder R, Hinz U, Lehnert T, Möller P, Schackert HK, Herfarth C, Knebel Doeberitz M v. (2000): Molecular profiling of sporadic colorectal tumors by microsatellite analysis. Int J Oncol 16, 169-79.

Gerard J, Azria D, Gourgou-Bourgade S, Martel-Laffay I, Hennequin C, Etienne P, Vendrely V, Conroy T, Francois E, Montoto-Grillot C (2009): Randomized multicenter phase III trial comparing two neoadjuvant chemoradiotherapy (CT-RT) regimes (RT45Cap versus RT50-Capox) in patients (pts) with locally advanced rectal cancer (LARC): Results of the ACCORD 12/0405 PRODIGE 2. J Clin Oncol 27, Suppl 18s, Abstr LBA4007.

Gérard J, Conroy T, Bonnetain F, Bouché O, Chapet O, Closon-Dejardin M, Untereiner M, Leduc B, Francois E, Maurel J et al. (2006): Preoperative radiotherapy with or without concurrent fluorouracil and leucovorin in T3-4 rectal cancers: results of FFCD 9203. J Clin Oncol 24, 4620-5.

Giuffrè G, Müller A, Brodegger T, Bocker-Edmonston T, Gebert J, Kloor M, Dietmaier W, Kullmann F, Büttner R, Tuccari G et al. (2005): Microsatellite analysis of hereditary nonpolyposis colorectal cancer-associated colorectal adenomas by laser-assisted microdissection: correlation with mismatch repair protein expression provides new insights in early steps of tumorigenesis. J Mol Diagn 7, 160-70.

Gondos A, Holleczek B, Arndt V, Stegmaier C, Ziegler H, Brenner H (2007): Trends in population-based cancer survival in Germany: to what extent does progress reach older patients? Ann Oncol 18, 1253-9.

Grilley M, Holmes J, Yashar B, Modrich P (1990): Mechanisms of DNA-mismatch correction. Mutat Res 236, 253-67.

Gryfe R, Swallow C, Bapat B, Redston M, Gallinger S, Couture J (1997): Molecular biology of colorectal cancer. Curr Probl Cancer 21, 233-300. 
Habr-Gama A, Perez RO, Proscurshim I, Rawet V, Pereira DD, Sousa AH, Kiss D, Cecconello I (2008): Absence of lymph nodes in the resected specimen after radical surgery for distal rectal cancer and neoadjuvant chemoradiation therapy: what does it mean? Dis Colon Rectum 51, 277-83.

Halford SE, Sawyer EJ, Lambros MB, Gorman P, Macdonald ND, Talbot IC, Foulkes WD, Gillett CE, Barnes DM, Akslen LA et al. (2003): MSI-low, a real phenomenon which varies in frequency among cancer types. J Pathol 21, 389-94.

Hampel H, Frankel WL, Martin E, Arnold M, Khanduja K, Kuebler P, Nakagawa H, Sotamaa K, Prior TW, Westman J et al. (2005): Screening for the Lynch syndrome (hereditary nonpolyposis colorectal cancer). N Engl J Med 352, 1851-60.

Hampel H, Frankel WL, Martin E, Arnold M, Khanduja K, Kuebler P, Clendenning M, Sotamaa K, Prior T, Westman JA et al. (2008): Feasibility of screening for Lynch syndrome among patients with colorectal cancer. J Clin Oncol 26, 5783-8.

Hawn MT, Umar A, Carethers JM, Marra G, Kunkel TA, Boland CR, Koi M (1995): Evidence for a connection between the mismatch repair system and the G2 cell cycle checkpoint. Cancer Res 55, 3721-5.

Heald RJ, Ryall RD (1986): Recurrence and survival after total mesorectal excision for rectal cancer. Lancet 1, 1479-82.

Heald RJ, Moran BJ, Ryall RD, Sexton R, MacFarlane JK (1998): Rectal cancer: the Basingstoke experience of total mesorectal excision, 1978-1997. Arch Surg 133, 8949.

Hemminki A, Mecklin JP, Järvinen H, Aaltonen LA, Joensuu H (2000): Microsatellite instability is a favorable prognostic indicator in patients with colorectal cancer receiving chemotherapy. Gastroenterology 119, 921-8. 
Herman JG, Umar A, Polyak K, Graff JR, Ahuja N, Issa JP, Markowitz S, Willson JK, Hamilton SR, Kinzler KW et al. (1998): Incidence and functional consequences of hMLH1 promoter hypermethylation in colorectal carcinoma. Proc Natl Acad Sci USA 95, 6870-5.

Hoang JM, Cottu PH, Thuille B, Salmon RJ, Thomas G, Hamelin R (1997): BAT-26, an indicator of the replication error phenotype in colorectal cancers and cell lines. Cancer Res 57, 300-3.

Holmqvist A, Gao J, Adell G, Carstensen J, Sun X (2010): The location of lymphangiogenesis is an independent prognostic factor in rectal cancers with or without preoperative radiotherapy. Ann Oncol 21, 512-7.

Hoogerbrugge N, Willems R, van Krieken HJ, Kiemeney LA, Weijmans M, Nagengast FM, Arts N, Brunner HG, Ligtenberg MJ (2003): Very low incidence of microsatellite instability in rectal cancers from families at risk for HNPCC. Clin Genet 63, 64-70.

Hyams DM, Mamounas EP, Petrelli N, Rockette H, Jones J, Wieand HS, Deutsch M, Wickerham L, Fisher B, Wolmark N (1997): A clinical trial to evaluate the worth of preoperative multimodality therapy in patients with operable carcinoma of the rectum: a progress report of National Surgical Breast and Bowel Project Protocol R-03. Dis Colon Rectum 40, 131-9.

Iglesias AR, Kindlund E, Tammi M, Wadelius C (2004): Some microsatellites may act as novel polymorphic cis-regulatory elements through transcription factor binding. Gene 27, 149-65.

Institut für Medizininformatik, Biometrie und Epidemiologie

Direktor Prof. D. O. Gefeller

CAO/ARO/AIO-04-Studie - Homepage - Info für Ärzte Studienschema http://www.rektumkarzinom.med.uni-erlangen.de/outline/arztinformation.htm 1.9.2010

Järvinen HJ (2003): Genetic testing for polyposis: practical and ethical aspects. Gut $\mathbf{5 2}$, Suppl 2, ii19-22. 
Jass JR (2006): Colorectal cancer: a multipathway disease. Crit Rev Oncog 12, 273 87.

Javle M, Hsueh C (2010): Recent advances in gastrointestinal oncology--updates and insights from the 2009 annual meeting of the American society of clinical oncology. $J$ Hematol Oncol 23, 11.

Jernvall P, Mäkinen MJ, Karttunen TJ, Mäkelä J, Vihko P (1999): Loss of heterozygosity at $18 q 21$ is indicative of recurrence and therefore poor prognosis in a subset of colorectal cancers. Br J Cancer 79, 903-8.

Jover R, Zapater P, Castells A, Llor X, Andreu M, Cubiella J, Balaguer F, Sempere L, Xicola RM, Bujanda L et al. (2009): The efficacy of adjuvant chemotherapy with 5fluorouracil in colorectal cancer depends on the mismatch repair status. Eur $J$ Cancer 45, 365-73.

Kalady MF, Sanchez JA, Manilich E, Hammel J, Casey G, Church JM (2009): Divergent oncogenic changes influence survival differences between colon and rectal adenocarcinomas. Dis Colon Rectum 52, 1039-45.

Kapiteijn E, Marijnen CA, Nagtegaal ID, Putter H, Steup WH, Wiggers T, Rutten HJ, Pahlman L, Glimelius B, van Krieken JH et al. (2001): Preoperative radiotherapy combined with total mesorectal excision for resectable rectal cancer. $N$ Engl J Med 345, 638-46.

Kapiteijn E, Putter H, van de Velde CJ (2002): Impact of the introduction and training of total mesorectal excision on recurrence and survival in rectal cancer in The Netherlands. Br J Surg 89, 1142-9.

Kern SE, Fearon ER, Tersmette KW, Enterline JP, Leppert M, Nakamura Y, White R, Vogelstein B, Hamilton SR (1989): Clinical and pathological associations with allelic loss in colorectal carcinoma [corrected]. JAMA 261, 3099-103.

Kim J, Kim J, Cho M, Song K, Yoon W (2002): Preoperative chemoradiation using oral capecitabine in locally advanced rectal cancer. Int J Radiat Oncol Biol Phys 54, 403-8. 
Kohlmann W, Gruber SB (2006): Hereditary Non-Polyposis Colon Cancer 1993-2004. Gene Review [Internet] Feb 05 [updated 2006 Nov 29]

Kolodner RD, Tytell JD, Schmeits JL, Kane MF, Gupta RD, Weger J, Wahlberg S, Fox EA, Peel D, Ziogas A et al. (1999): Germ-line msh6 mutations in colorectal cancer families. Cancer Res 59, 5068-74.

Konishi M, Kikuchi-Yanoshita R, Tanaka K, Muraoka M, Onda A, Okumura Y, Kishi N, Iwama T, Mori T, Koike M et al. (1996): Molecular nature of colon tumors in hereditary nonpolyposis colon cancer, familial polyposis, and sporadic colon cancer. Gastroenterology 111, 307-17.

Koshiji M, To KK, Hammer S, Kumamoto K, Harris AL, Modrich P, Huang LE (2005): HIF-1alpha induces genetic instability by transcriptionally downregulating MutSalpha expression. Mol Cell 17, 793-803.

Krebs in Deutschland, Häufigkeiten und Trends; o.Verf.; hrsg: Gesellschaft der epidemiologischen Krebsregister in Deutschland e.V. in Zusammenarbeit mit dem Robert Koch Institut; 7. überarbeitete, aktualisierte Ausgabe; o.Verl., Saarbrücken 2008, 19-36

Laiho P, Launonen V, Lahermo P, Esteller M, Guo M, Herman JG, Mecklin J, Järvinen $\mathrm{H}$, Sistonen P, Kim K et al. (2002): Low-level microsatellite instability in most colorectal carcinomas. Cancer Res 62, 1166-70.

Lay GC, Caraul B, Dessì M, Orrù S, Murtas R, Deidda MA, Farigu R, Farci D, Maxia L, Casula G et al. (2007): Phase II study of preoperative irradiation and chemotherapy with capecitabine in patients with locally advanced rectal carcinoma. J Exp Clin Cancer Res 17, 61-70.

Leach FS, Nicolaides NC, Papadopoulos N, Liu B, Jen J, Parsons R, Peltomäki P, Sistonen P, Aaltonen LA, Nyström-Lahti M (1993): Mutations of a mutS homolog in hereditary nonpolyposis colorectal cancer. Cell 75, 1215-25. 
Leong V, Lorenowicz J, Kozij N, Guarné A (2009): Nuclear import of human MLH1, PMS2, and MutLalpha: redundancy is the key. Mol Carcinog 48, 742-50.

Li Y, Korol AB, Fahima T, Nevo E (2004): Microsatellites within genes: structure, function, and evolution. Mol Biol Evol 21, 991-1007.

Lichtenstein P, Holm NV, Verkasalo PK, Iliadou A, Kaprio J, Koskenvuo M, Pukkala E, Skytthe A, Hemminke A (2000): Environmental and heritable factors in the causation of cancer: analyses of cohorts of twins from Sweden, Denmark, and Finland. $N$ Engl $J$ Med 343, 78-85.

Lièvre A, Samalin E, Mitry E, Assenat E, Boyer-Gestin C, Lepère C, Bachet J, Portales F, Vaillant J, Ychou M et al. (2009): Bevacizumab plus FOLFIRI or FOLFOX in chemotherapy-refractory patients with metastatic colorectal cancer: a retrospective study. BMC Cancer 28, 347.

Lim YK, Law WL, Liu R, Poon JT, Fan JF, Lo OS (2010): Impact of neoadjuvant treatment on total mesorectal excision for ultra-low rectal cancers. World J Surg Oncol 26, 23.

Liska D, Weiser MR (2010): Optimal surgical treatment of locally advanced low rectal cancer. Minerva Chir 65, 181-96.

Lynch HT, La Chapelle A de (2003): Hereditary colorectal cancer. N Engl J Med 348, 919-32.

Marijnen CA, Kapiteijn E, van de Velde CJ, Martijn $H$, Steup WH, Wiggers $T$, Kranenbarg EK, Leer JW (2002): Acute side effects and complications after short-term preoperative radiotherapy combined with total mesorectal excision in primary rectal cancer: report of a multicenter randomized trial. J Clin Oncol 20, 817-25.

Marsh RW de, George TJ, Siddiqui T, Mendenhall WM, Zlotecki RA, Grobmyer S, Hochwald S, Chang M, Larson B, King J (2010): A phase II trial of neoadjuvant capecitabine combined with hyperfractionated accelerated radiation therapy in locally advanced rectal cancer. Am J Clin Oncol 33, 251-6. 
Martling AL, Holm T, Rutqvist LE, Moran BJ, Heald RJ, Cedemark B (2000): Effect of a surgical training programme on outcome of rectal cancer in the County of Stockholm. Stockholm Colorectal Cancer Study Group, Basingstoke Bowel Cancer Research Project. Lancet 356, 93-6.

Meng W, Sun X, Tian C, Wang L, Yu Y, Zhou B, Gu J, Xia Q, Li Y, Wang R et al. (2007): Microsatellite instability did not predict individual survival in sporadic stage II and III rectal cancer patients. Oncology 72, 82-8.

Mihaylova VT, Bindra RS, Yuan J, Campisi D, Narayanan L, Jensen R, Giordano F, Johnson RS, Rockwell S, Glazer PM (2003): Decreased expression of the DNA mismatch repair gene Mlh1 under hypoxic stress in mammalian cells. Mol Cell Biol 23, 3265-73.

Mueller J, Gazzoli I, Bandipalliam P, Garber JE, Syngal S, Kolodner RD (2009): Comprehensive molecular analysis of mismatch repair gene defects in suspected Lynch syndrome (hereditary nonpolyposis colorectal cancer) cases. Cancer Res 69, 7053-61.

Müller A, Fishel R (2002): Mismatch repair and the hereditary non-polyposis colorectal cancer syndrome (HNPCC). Cancer Invest 20, 102-9.

Müller A, Edmonston TB, Dietmaier W, Büttner R, Fishel R, Rüschoff J (2004a): MSItesting in hereditary non-polyposis colorectal carcinoma (HNPCC). Dis Markers 20, 225-36.

Müller A, Giuffre G, Edmonston TB, Mathiak M, Roggendorf B, Heinmöller E, Brodegger T, Tuccari G, Mangold E, Buettner R et al. (2004b): Challenges and pitfalls in HNPCC screening by microsatellite analysis and immunohistochemistry. $J$ Mol Diagn 6, 308-15.

Musio D, Raffetto N, Dionisi F, lannacone E, Dipalma B, Caparrotti F, Meaglia I, Caiazzo R, Bangrazi C, Banelli E (2010): Comparison between intensified neoadjuvant treatment and standard preoperative chemoradiation for rectal cancer. Tumori 96, $11-$ 6. 
Nicolaides NC, Papadopoulos N, Liu B, Wei YF, Carter KC, Ruben SM, Rosen CA, Haseltine WA, Fleischmann RD, Fraser CM (1994): Mutations of two PMS homologues in hereditary nonpolyposis colon cancer. Nature $371,75-80$.

Nilbert M, Planck M, Fernebro E, Borg A, Johnson A (1999): Microsatellite instability is rare in rectal carcinomas and signifies hereditary cancer. Eur J Cancer 35, 942-5.

O'Brien MJ, Yang S, Mack C, Xu H, Huang CS, Mulcahy E, Amorosino M, Farraye FA (2006): Comparison of microsatellite instability, CpG island methylation phenotype, BRAF and KRAS status in serrated polyps and traditional adenomas indicates separate pathways to distinct colorectal carcinoma end points. Am J Surg Pathol 30, 1491-501.

O'Connell MJ, Martenson JA, Wieand HS, Krook JE, Macdonald JS, Haller DG, Mayer RJ, Gunderson LL, Rich TA (1994): Improving adjuvant therapy for rectal cancer by combining protracted-infusion fluorouracil with radiation therapy after curative surgery. N Engl J Med 331, 502-7.

Ogino S, Nosho K, Kirkner GJ, Kawasaki T, Meyerhardt JA, Loda M, Giovannucci EL, Fuchs CS (2009): CpG island methylator phenotype, microsatellite instability, BRAF mutation and clinical outcome in colon cancer. Gut 58, 90-6.

Oku Y, Shimoji T, Takifuji K, Hotta T, Yokoyama S, Matsuda K, Higashiguchi T, Tominaga T, Nasu T, Tamura $\mathrm{K}$ et al. (2008): Identification of the molecular mechanisms for dedifferentiation at the invasion front of colorectal cancer by a gene expression analysis. Clin Cancer Res 14, 7215-22.

Papadopoulos N, Nicolaides NC, Liu B, Parsons R, Lengauer C, Palombo F, D'Arrigo A, Markowitz S, Willson JK, Kinzler KW (1995): Mutations of GTBP in genetically unstable cells. Science 268, 1915-7.

Pearson CE, Nichol Edamura K, Cleary JD (2005): Repeat instability: mechanisms of dynamic mutations. Nat Rev Genet 6, 729-42. 
Peeters KC, Marijnen CA, Nagtegaal ID, Kranenbarg EK, Putter H, Wiggers T, Rutten H, Pahlman L, Glimelius B, Leer JW et al. (2007): The TME trial after a median followup of 6 years: increased local control but no survival benefit in irradiated patients with resectable rectal carcinoma. Ann Surg 246, 693-701.

Peltomäki P, Vasen HF (1997): Mutations predisposing to hereditary nonpolyposis colorectal cancer: database and results of a collaborative study. The International Collaborative Group on Hereditary Nonpolyposis Colorectal Cancer. Gastroenterology $113,1146-58$.

Peltomäki P, Lothe RA, Aaltonen LA, Pylkkänen L, Nyström-Lahti M, Seruca R, David L, Holm R, Ryberg D, Haugen A (1993): Microsatellite instability is associated with tumors that characterize the hereditary non-polyposis colorectal carcinoma syndrome. Cancer Res 53, 5853-5.

Popat S, Hubner R, Houlston RS (2005): Systematic review of microsatellite instability and colorectal cancer prognosis. J Clin Oncol 23, 609-18.

Rhyu MG, Park WS, Meltzer SJ (1994): Microsatellite instability occurs frequently in human gastric carcinoma. Oncogene 9, 29-32.

Rigau V, Sebbagh N, Olschwang S, Paraf F, Mourra N, Parc Y, Flejou J (2003): Microsatellite instability in colorectal carcinoma. The comparison of immunohistochemistry and molecular biology suggests a role for hMSH6 [correction of hMLH6] immunostaining. Arch Pathol Lab Med 127, 694-700.

Risinger JI, Berchuck A, Kohler MF, Watson P, Lynch HT, Boyd J (1993): Genetic instability of microsatellites in endometrial carcinoma. Cancer Res 53, 5100-3.

Rödel C, Sauer R (2007): Integration of novel agents into combined-modality treatment for rectal cancer patients. Strahlenther Onkol 183, 227-35.

Rödel C, Grabenbauer GG, Schick C, Papadopoulos T, Hohenberger W, Sauer R (2000): Preoperative radiation with concurrent 5-fluorouracil for locally advanced T4primary rectal cancer. Strahlenther Onkol 176, 161-7. 
Rödel C, Liersch T, Hermann RM, Arnold D, Reese T, Hipp M, Fürst A, Schwella N, Bieker M, Hellmich G et al. (2007): Multicenter phase II trial of chemoradiation with oxaliplatin for rectal cancer. J Clin Oncol 25, 110-7.

Rodriguez-Bigas MA, Boland CR, Hamilton SR, Henson DE, Jass JR, Khan PM, Lynch H, Perucho M, Smyrk T, Sobin L et al. (1997): A National Cancer Institute Workshop on Hereditary Nonpolyposis Colorectal Cancer Syndrome: meeting highlights and Bethesda guidelines. J Natl Cancer Inst 89, 1758-62.

Roesch A, Vogt T, Stolz W, Dugas M, Landthaler M, Becker B (2003): Discrimination between gene expression patterns in the invasive margin and the tumour core of malignant melanomas. Melanoma Res 13, 503-9.

Roth AD, Tejpar S, Yan P, Fiocco R, Dietrich D, Delorenzi M, Labianca R, Cunningham D, van Cutsem E, Bosman F (2009): Stage-specific prognostic value of molecular markers in colon cancer: Results of the translational study on the PETACC 3-EORTC 40993-SAKK 60-00 trial. J Clin Oncol 27, Suppl 15s, Abstr 4002.

Rüschoff J, Roggendorf B, Brasch F, Mathiak M, Aust DE, Plaschke J, Mueller W, Poremba C, Kloor M, Keller G et al. (2004): Molecular pathology in hereditary colorectal cancer. Recommendations of the Collaborative German Study Group on hereditary colorectal cancer funded by the German Cancer Aid (Deutsche Krebshilfe). Pathologe 25, 178-92.

Salovaara R, Loukola $A$, Kristo $P$, Kääriäinen $H$, Ahtola $H$, Eskelinen $M$, Härkönen $N$, Julkunen R, Kangas E, Ojala S et al. (2000): Population-based molecular detection of hereditary nonpolyposis colorectal cancer. J Clin Oncol 18, 2193-200.

Samowitz WS, Curtin K, Wolff RK, Tripp SR, Caan BJ, Slattery ML (2009): Microsatellite instability and survival in rectal cancer. Cancer Causes Control 20, 17638. 
Sargent DJ, Marsoni S, Monges G, Thibodeau SN, Labianca R, Hamilton SR, French AJ, Kabat B, Foster NR, Torri V et al. (2010a): Defective mismatch repair as a predictive marker for lack of efficacy of fluorouracil-based adjuvant therapy in colon cancer. J Clin Oncol 28, 3219-26.

Sauer R, Fietkau R, Wittekind C, Martus P, Rödel C, Hohenberger W, Jatzko G, Sabitzer H, Karstens JH, Becker H et al. (2001): Adjuvant versus neoadjuvant radiochemotherapy for locally advanced rectal cancer. A progress report of a phase-III randomized trial (protocol CAO/ARO/AIO-94). Strahlenther Onkol 177, 173-81.

Sauer R, Becker H, Hohenberger W, Rödel C, Wittekind C, Fietkau R, Martus P, Tschmelitsch J, Hager E, Hess CF et al. (2004): Preoperative versus postoperative chemoradiotherapy for rectal cancer. N Engl J Med 351, 1731-40.

Shahrzad S, Quayle L, Stone C, Plumb C, Shirasawa S, Rak JW, Coomber BL (2005): Ischemia-induced K-ras mutations in human colorectal cancer cells: role of microenvironmental regulation of MSH2 expression. Cancer Res 65, 8134-41.

Silberfein EJ, Kattepogu KM, Hu C, Skibber JM, Rodriguez-Bigas MA, Feig B, Das P, Krishnan S, Crane C, Kopetz S et al. (2010): Long-Term Survival and Recurrence Outcomes Following Surgery for Distal Rectal Cancer. Annals of surgical oncology 17, 2863-9.

Sinicrope FA, Rego RL, Halling KC, Foster N, Sargent DJ, La Plant B, French AJ, Laurie JA, Goldberg RM, Thibodeau SN et al. (2006): Prognostic impact of microsatellite instability and DNA ploidy in human colon carcinoma patients. Gastroenterology 131, 729-37.

Spirio L, Joslyn G, Nelson L, Leppert M, White R (1991): A CA repeat 30-70 KB downstream from the adenomatous polyposis coli (APC) gene. Nucleic Acids Res 19, 6348. 
Steele GD, Augenlicht LH, Begg CB, Gelber RD, Green MR, Niederhuber JE, Phillips TL, Williams B, Winawar SJ, Winchester DP et al. (1991): Adjuvant therapy for patients with colon and rectal cancer: summary of $\mathrm{NIH}$ consensus statement. National Cancer Institute and the Office of Medical Applications of Research of the National Institutes of Health. Aust N Z J Surg 61, 23.

Tesniere A, Schlemmer F, Boige V, Kepp O, Martins I, Ghiringhelli F, Aymeric L, Michaud M, Apetoh L, Barault L et al. (2010): Immunogenic death of colon cancer cells treated with oxaliplatin. Oncogene 29, 482-91.

Thibodeau SN, Bren G, Schaid D (1993): Microsatellite instability in cancer of the proximal colon. Science 260, 816-9.

Thibodeau SN, French AJ, Roche PC, Cunningham JM, Tester DJ, Lindor NM, Moslein G, Baker SM, Liskay RM, Burgart LJ et al. (1996): Altered expression of hMSH2 and hMLH1 in tumors with microsatellite instability and genetic alterations in mismatch repair genes. Cancer Res 56, 4836-40.

Toyota M, Ahuja N, Ohe-Toyota M, Herman JG, Baylin SB, Issa JP (1999): CpG island methylator phenotype in colorectal cancer. Proc Natl Acad Sci USA 96, 8681-6.

Umar A, Boland CR, Terdiman JP, Syngal S, La Chapelle A de, Rüschoff J, Fishel R, Lindor NM, Burgart LJ, Hamelin R et al. (2004): Revised Bethesda Guidelines for hereditary nonpolyposis colorectal cancer (Lynch syndrome) and microsatellite instability. J Natl Cancer Inst 96, 261-8.

Vasen HF, Mecklin JP, Khan PM, Lynch HT (1991): The International Collaborative Group on Hereditary Non-Polyposis Colorectal Cancer (ICG-HNPCC). Dis Colon Rectum 34, 424-5.

Velenik V, Ocvirk J, Oblak I, Anderluh F (2010): A phase II study of cetuximab, capecitabine and radiotherapy in neoadjuvant treatment of patients with locally advanced resectable rectal cancer. Eur J Surg Oncol 36, 244-50. 
Vogelstein B, Fearon ER, Hamilton SR, Kern SE, Preisinger AC, Leppert M, Nakamura Y, White R, Smits AM, Bos JL (1988): Genetic alterations during colorectal-tumor development. N Engl J Med 319, 525-32.

Vogelstein B, Fearon ER, Kern SE, Hamilton SR, Preisinger AC, Nakamura Y, White R (1989): Allelotype of colorectal carcinomas. Science 244, 207-11.

Wadlow RC, Ryan DP (2010): The role of targeted agents in preoperative chemoradiation for rectal cancer. Cancer 116, 3537-48.

Waldmann A, Eberle A, Hentschel S, Holleczek B, Katalinic A (2010): Populationbased incidence rates of colorectal neoplasms (2000 - 2006) - has systematic colonoscopy screening an impact on incidence? A combined analysis of cancer registry data of the Federal States of Bremen, Hamburg, Saarland and Schleswig-Holstein. $Z$ Gastroenterol 48, 1358-66.

Ward R, Meagher A, Tomlinson I, O'Connor T, Norrie M, Wu R, Hawkins N (2001): Microsatellite instability and the clinicopathological features of sporadic colorectal cancer. Gut 48, 821-9.

Warusavitarne J, Schnitzler M (2007): The role of chemotherapy in microsatellite unstable (MSI-H) colorectal cancer. Int J Colorectal Dis 22, 739-48.

Weber JL, May PE (1989): Abundant class of human DNA polymorphisms which can be typed using the polymerase chain reaction. Am J Hum Genet 44, 388-96.

Weber JL, Kwitek AE, May PE, Wallace MR, Collins FS, Ledbetter DH (1990): Dinucleotide repeat polymorphisms at the D17S250 and D17S261 loci. Nucleic Acids Res 18, 4640.

Weisenberger DJ, Siegmund KD, Campan M, Young J, Long TI, Faasse MA, Kang GH, Widschwendter M, Weener D, Buchanan D et al. (2006): CpG island methylator phenotype underlies sporadic microsatellite instability and is tightly associated with BRAF mutation in colorectal cancer. Nat Genet 38, 787-93. 
Weissenbach J, Gyapay G, Dib C, Vignal A, Morissette J, Millasseau P, Vaysseix G, Lathrop M (1992): A second-generation linkage map of the human genome. Nature 359, 794-801.

Wichmann MW, Müller C, Meyer G, Strauss T, Hornung HM, Lau-Werner U, Angele MK, Schildberg FW (2002): Effect of preoperative radiochemotherapy on lymph node retrieval after resection of rectal cancer. Arch Surg 137, 206-10.

Wittekind C, Meyer HJ hrgs. (2010): UICC - International Union Against Cancer: Darmtumore; in: TNM - Klassifikation maligner Tumore; 7. Auflage; Wiley-VCH Verlag GmBH \& Co. KGaA 2010, 98-99

Wolmark N, Wieand S, Kuebler PJ, Colangelo L, O'Connell M.J., Yothers G (2008): A phase III trial comparing FULV to FULV + oxaliplatin in stage II or III carcinoma of the colon: Survival results of NSABP Protocol C-07. J Clin Oncol 26, Suppl 18s, Abstr LBA4005.

Wu X, Platt JL, Cascalho M (2003): Dimerization of MLH1 and PMS2 limits nuclear localization of MutLalpha. Mol Cell Biol 23, 3320-8.

Wu Y, Berends MJ, Mensink RG, Kempinga C, Sijmons RH, van der Zee AG, Hollema $\mathrm{H}$, Kleibeuker JH, Buys CH, Hofstra RM (1999): Association of hereditary nonpolyposis colorectal cancer-related tumors displaying low microsatellite instability with MSH6 germline mutations. Am J Hum Genet 65, 1291-8.

Zhao Y, Hu F, Wang F, Han B, Li D, Li X, Zhu S (2009): Meta-analysis of MSH6 gene mutation frequency in colorectal and endometrial cancers. J Toxicol Environ Health Part A 72, 690-7.

Zhou C, Qiu G, Zhang F, He L, Peng Z (2004): Loss of heterozygosity on chromosome 1 in sporadic colorectal carcinoma. World J Gastroenterol 10, 1431-5. 
Zhu G, Reynolds L, Crnogorac-Jurcevic T, Gillett CE, Dublin EA, Marshall JF, Barnes D, D'Arrigo C, van Trappen PO, Lemoine NR et al. (2003): Combination of microdissection and microarray analysis to identify gene expression changes between differentially located tumour cells in breast cancer. Oncogene 22, 3742-8. 


\section{DANKSAGUNG}

Ich danke Herrn Prof. Dr. med. Josef Rüschoff, der diese interessante Arbeit in seiner Abteilung ermöglicht hat.

Herrn Prof. Dr. med. Josef Rüschoff und Frau Prof. Dr. med. Annegret MüllerDornieden danke ich für die intensive Betreuung und kompetente Beratung in allen Belangen dieser Arbeit. Ihr Engagement und ihre Zuverlässigkeit haben mir die Arbeit sehr erleichtert.

Ich danke ebenso Herrn Prof. Dr. med. Michael Klintschar, Frau Lange und Frau Rinke. Sie haben mich geduldig in die Arbeit mit DNA eingeführt, für eine schöne Arbeitsatmosphäre gesorgt und mir bei Problemen immer hilfreich und zuverlässig zur Seite gestanden. 